\title{
INTRUSÃO RADICULAR E EFEITO DE VÁCUO EM GOTEJAMENTO ENTERRADO NA IRRIGAÇÃO DE CANA-DE-AÇÚCAR
}

\author{
RONALDO SOUZA RESENDE
}

Tese apresentada à Escola Superior de Agricultura

"Luiz de Queiroz", Universidade de São Paulo, para obtenção do título de Doutor em Agronomia, Área de Concentração: Irrigação e Drenagem.

P I R A C I C A B A

Estado de São Paulo- Brasil

Novembro - 2003 


\title{
INTRUSÃO RADICULAR E EFEITO DE VÁCUO EM GOTEJAMENTO ENTERRADO NA IRRIGAÇÃO DE CANA-DE-AÇÚCAR
}

\author{
RONALDO SOUZA RESENDE
}

Engenheiro Agrônomo

ORIENTADOR: Prof. Dr. RUBENS DUARTE COELHO

\footnotetext{
Tese apresentada à Escola Superior de Agricultura

"Luiz de Queiroz", Universidade de São Paulo, para obtenção do título de Doutor em Agronomia, Área de Concentração: Irrigação e Drenagem.
}

P I R A C I C A B A

Estado de São Paulo- Brasil

Novembro - 2003 
Dados Internacionais de Catalogação na Publicação (CIP) DIVISÃO DE BIBLIOTECA E DOCUMENTAÇÃO - ESALQ/ USP

Resende, Ronaldo Souza

Intrusão radicular e efeito de vácuo em gotejamento enterrado na

irrigação de cana-de-açúcar / Ronaldo Souza Resende. - - Piracicaba, 2003. 124 p. : il.

Tese (doutorado) - Escola Superior de Agricultura Luiz de Queiroz, 2003. Bibliografia.

1. Cana-de-açúcar 2. Irrigação localizada 3. Irrigação por gotejamento 4. Raiz I. Título

CDD 631.7

"Permitida a cópia total ou parcial deste documento, desde que citada a fonte - $O$ autor" 
À minha esposa, Alda, e filhas, Isadora e Lara, pelo muito que abdicaram da minha convivência e de tudo que as cercavam, em solidariedade ao meu objetivo.

Dedico

Aos meus pais e irmãos, pelo eterno incentivo, mesmo no silêncio.

Ofereço 


\section{AGRADECIMENTOS}

Ao Prof. Dr. Rubens Duarte Coelho, pela orientação e confiança no meu trabalho,

Aos Professores Drs. Carlos Alberto Vetorazzi, José Antônio Frizzone, Rubens Angulo, Rubens Duarte Coelho, Sérgio Nascimento Duarte, Tarley Ariel Botrel, pelo prazer demonstrado na transmissão dos conhecimentos;

À Companhia de Desenvolvimento de Recursos Hídricos e Irrigação de Sergipe COHIDRO, pela oportunidade de realização do curso de Doutorado;

À Fundação de Apoio à Pesquisa do Estado de São Paulo - FAPESP, pelo apoio financeiro através do Projeto de Pesquisa n ${ }^{\circ}$ 10267-4/2000, o qual viabilizou a realização do presente trabalho;

Ao Conselho Nacional de Desenvolvimento e Pesquisa - CNPq, pela concessão da bolsa de estudo;

Às Empresas de irrigação Carborundum, Éden, Irrigaplan, Irrimon, Isratec, Netafim e Rain Bird, que gentilmente cederam os modelos de gotejadores utilizados no experimento.

Aos funcionários do Departamento de Engenharia Rural, Antônio A. Gozzo, Antônio César de S. Rocha, Davilmar Collevatti, Gilmar Grigolon e Hélio Toledo Gomes;

Aos colegas do curso e amigos, Edivaldo Casarini, René Porfírio C. do Brasil e Tamara M. Gomes pelo, pelo belo convívio;

Ao colega e amigo, Luis Fernando Faria, parceiro firme na condução do experimento;

À Força que sempre me conduziu, como quer que a queiram chamar. 


\section{SUMÁRIO}

Página

LISTA DE FIGURAS.................................................................................. vii

LISTA DE TABELAS................................................................................

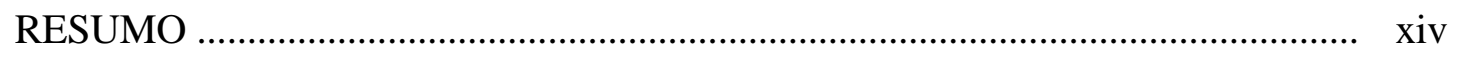

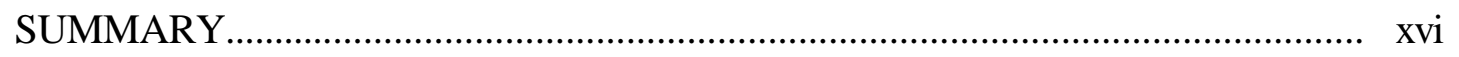

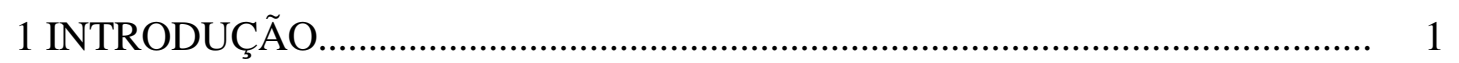

2 REVISÃO DE LITERATURA................................................................... 4

2.1 Irrigação localizada subsuperficial ................................................................ 4

2.2 Intrusão de raízes em gotejadores .................................................................. 8

2.3 Sistema radicular da cana-de-açúcar e do feijão .................................................. 10

2.4 Características da trifluralina nos sistemas de irrigação por gotejamento

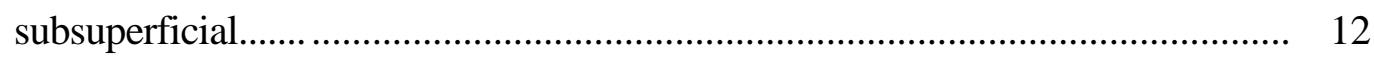

2.5 Vácuo na malha hidráulica de sistemas de irrigação localizados.......................... 15

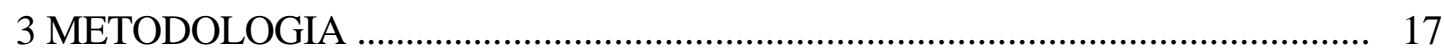

3.1 Experimentos sobre intrusão radicular em gotejadores ................................... 17

3.1.1 Localização dos experimentos.................................................................... 17

3.1.2 Tratamentos e delineamento estatístico.......................................................... 17

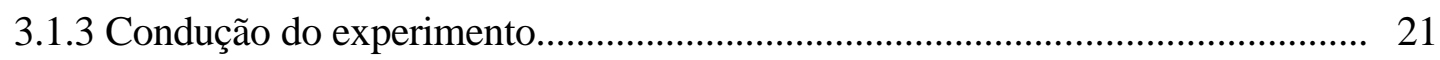

3.1.4 Tratamento preventivo do entupimento de emissores de causa

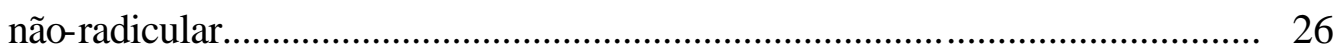

3.2 Experimento sobre o efeito do vácuo no desempenho hidráulico de gotejadores na irrigação subsuperficial 


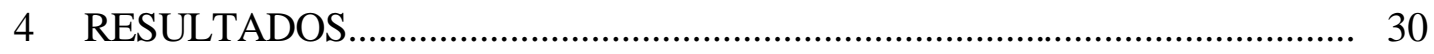

4.1 Experimento com a cultura da cana-de-açúcar............................................... 31

4.1.1 Gotejadores não-compensantes de pressão ...................................................... 31

4.1.2 Gotejadores autocompensantes de pressão ..................................................... 38

4.2 Experimento com a cultura do feijão ………................................................. 50

4.2.1 Gotejadores não-compensantes de pressão................................................................. 50

4.2.2 Gotejadores autocompensantes de pressão ................................................... 53

4.2 Experimento com a ocorrência de vácuo sobre o desempenho

hidráulico de gotejadores em irrigação subsuperficial......................................... 63

4.2.1 Gotejadores não-compensantes de pressão .................................................. 63

4.2.2 Gotejadores autocompensantes de pressão ...................................................... 66

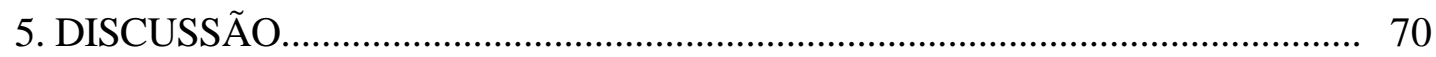

5.1 Interação sistema radicular x umidade do solo x profundidade de instalação....... 70

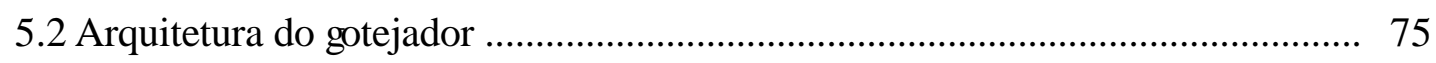

5.2.1 Gotejadores não-compensantes de pressão ................................................. 77

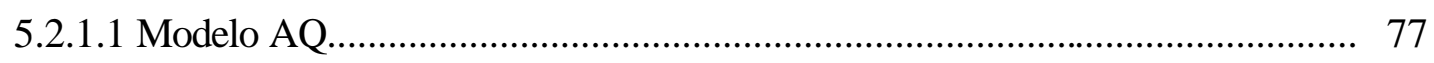

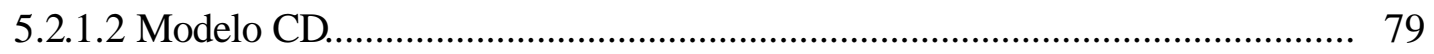

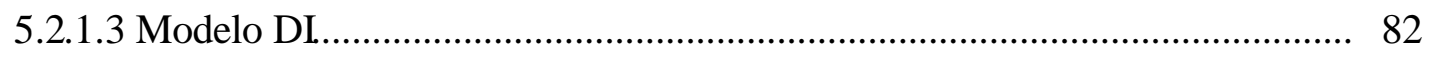

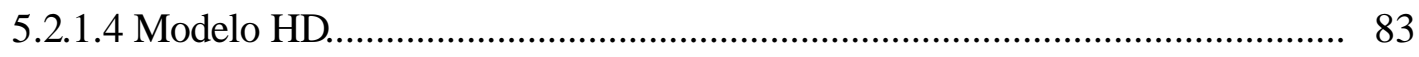

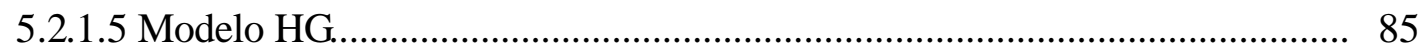

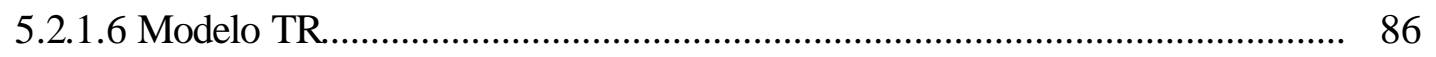

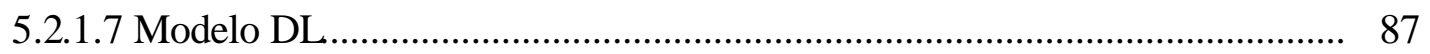

5.2.2 Gotejadores autocompensantes de pressão .................................................... 88

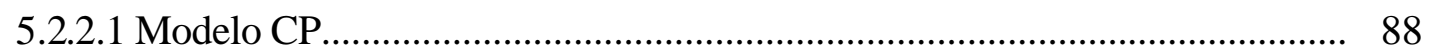

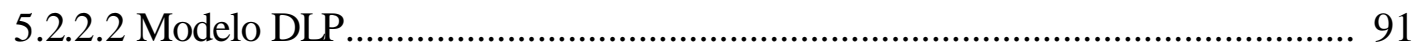

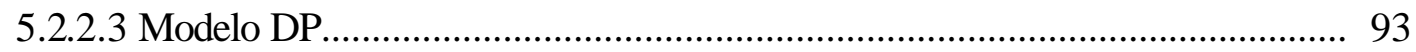

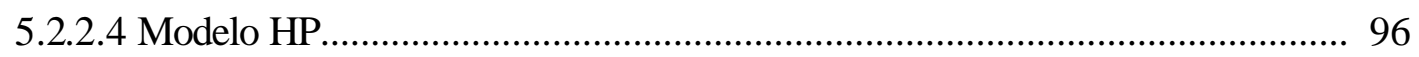

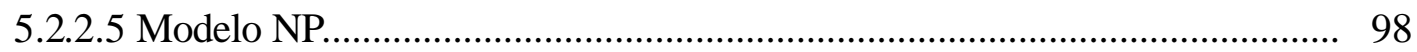

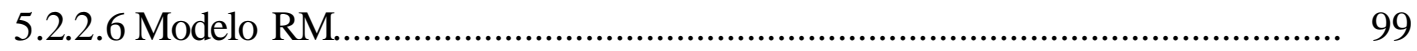

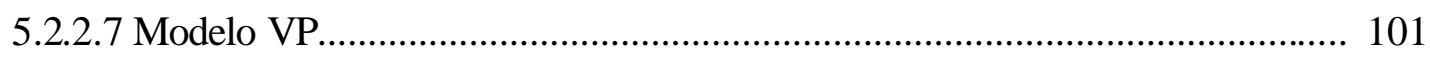


5.3 Arquitetura do gotejador x intrusão de raiz e ocorrência de vácuo................... 105

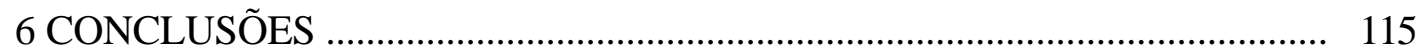

REFERÊNCIAS BIBLIOGRÁFICAS......................................................... 118 


\section{LISTA DE FIGURAS}

Página

1 Esquema geral dos experimentos no interior da estufa

2 Curva de retenção de umidade do solo utilizado no experimento

3 Vista lateral e longitudinal dos vasos e instalação dos tubos gotejadores.

4 Medidor de vazão, do tipo eletromagnético, utilizado no experimento

5 Potencial da água no solo nos tratamentos Cana-Úmido (a), Cana-Seco (b),

Feijão-Úmido (c), Feijão-Seco (d), para as profundidades P15 e P30

6 Vazão relativa, Qr, ao longo do período do experimento, para gotejadores não compensantes de pressão no experimento com cana-de-açúcar 36

7 Vazão relativa, Qr, ao longo do período do experimento, para gotejadores autocompensantes de pressão no experimento com cana-de-açúcar 40

8 Vazão relativa, Qr, ao longo do período do experimento, para gotejadores não-compensantes de pressão no experimento com a cultura do feijão 51

9 Vazão relativa, Qr, ao longo do período do experimento, para gotejadores autocompensantes de pressão no experimento com a cultura do feijão 
10 Vazão relativa dos gotejadores não-compensantes em função dos níveis de vácuo avaliados

11 Vazão relativa dos gotejadores autocompensantes em função dos níveis de vácuo avaliados 67

12 Sistema radicular da cana-de-açúcar, no tratamento com solo úmido 72

13 Enovelamento de raízes no interior do tubo gotejador. 75

14 Desenho esquemático do modelo AQ 78

15 Desenho esquemático do modelo CD 80

16 Desenvolvimento de raízes, no modelo $\mathrm{CD}$, na câmara de saída de água (a), na saída do labirinto (b) e evolução da vazão em função do tempo (c).... 81

17 Desenvolvimento de raízes, no modelo $\mathrm{CD}$, na câmara de saída de água, com presença de solo (a) e evolução da vazão em função do tempo (b). 82

18 Desenho esquemático do modelo DI 83

19 Desenho esquemático do modelo HD 84

20 Desenvolvimento de raízes, no modelo HD, na câmara de saída de água (a), na saída do labirinto (b) e evolução da vazão em função do tempo (c). 85

21 Desenho esquemático do modelo HG 86

22 Desenho esquemático do modelo TR. 87 
23 Desenho esquemático do modelo DL

24 Desenho esquemático do modelo $\mathrm{CP}$

25 Penetração da raiz mo interior do tubo, no modelo $\mathrm{CP}$, através da área de encaixe da tampa da câmara (a) e evolução da vazão em função do tempo (b).

26 Desenho esquemático do modelo DLP

27 Raiz intrusiva, no modelo DLP se desenvolvendo em direção à câmara morta (a) e evolução da vazão em função do tempo (b). Observar, presença de solo (em vermelho) no interior do labirinto......

28 Desenvolvimento da raiz que alcança a câmara morta através do canalículo de acesso à câmara de compensação.

29 Desenho esquemático do modelo DP

30 Penetração de raiz no interior do tubo, no modelo DP, através da câmara de compensação e área de filtragem(a), seu desenvolvimento no interior do tubo (b) e evolução da vazão emfunção do tempo (c) 95

31 Desenho esquemático do modelo HP. 97

32 Penetração da raiz na câmara de compensação do modelo HP através do cana lículo de passagem de água (a), no interior da câmara, junto à membrana de silicone, de cor verde (b) e evolução da vazão em função do tempo (c). 
34 Desenho esquemático do modelo RAM, em vistas inferior (a), lateral (b) e superior $(\mathrm{c})$ 99

35 Penetração de raiz para o interior do tubo através da borda da membrana de silicone (a) e evolução de vazão do modelo RM em função do tempo (b)...... 101

36 Desenho esquemático do modelo VP; vistas anterior (a), posterior (b) e superior $(c)$

37 Vista superior (a) e posterior (b) do gotejador VP com raiz intrusa evolução da vazão em função do tempo (c).

38 Intrusão de raiz em gotejadores do tipo plano, sem penetração no interior do tubo (a) e com raiz no interior do tubo gotejador (b) e (c) 106

39 Gotejador plano com raiz em crescimento ao longo do labirinto; sem atingir a área de filtragem (a) e evolução da vazão em função do tempo (b).

40 Desenvolvimento de raiz causando obstrução do ponto crítico de um gotejador plano (a) e conseqüente redução d a vazão em função do tempo (b).... 109

41 Depósito de partículas de solo em gotejador, por efeito provável da ocorrência de vácuo 


\section{LISTA DE TABELAS}

Página

1 Características operacionais dos gotejadores avaliados 19

2 Esquema de análise de variância (ANOVA) dos experimentos com cana-de-açúcar e do feijão

3 Características físico-químicas do solo utilizado no experimento

4 Caracterização química da água utilizada no experimento

5 Vazão relativa (Qr), em L.h ${ }^{-1}$, e coeficiente de variação de vazão $(\mathrm{CV})$, em \%,dos gotejadores na cultura da cana-de-açúcar, na profundidade P15 e no tratamento Úmido

6 Vazão relativa (Qr), em L.h ${ }^{-1}$, e coeficiente de variação de vazão $(\mathrm{CV})$, em \%, dos gotejadores na cultura da cana-de-açúcar, na profundidade $\mathrm{P} 30$ e no tratamento Úmido 45

7 Vazão relativa (Qr), em L.h ${ }^{-1}$, e coeficiente de variação de vazão $(\mathrm{CV})$, em \%, dos gotejadores na cultura da cana-de-açúcar, na profundidade $\mathrm{P} 15$ e tratamento Seco 46

8 Vazão relativa (Qr), em L.h ${ }^{-1}$, e coeficiente de variação de vazão $(\mathrm{CV})$, em \%, dos gotejadores na cultura da cana-de-açúcar, na profundidade $\mathrm{P} 30$ e tratamento Seco 
9 Resultados da análise de variância e teste de comparação de médias para os dados de vazão relativa (Qr), em L.h ${ }^{-1}$, dos gotejadores não-compensantes, aos 270 dias do início do experimento, na cultura da cana-de-açúcar. 48

10 Resultados da análise de variância e teste de comparação de médias para os dados de vazão relativa $(\mathrm{Qr})$, em L.h ${ }^{-1}$, dos gotejadores autocompensantes, aos 270 dias do início do experimento, na cultura da cana-de-açúcar.

11 Vazão relativa (Qr), em L.h ${ }^{-1}$, e coefic iente de variação de vazão (CV), em \%, dos gotejadores na cultura do feijão, na profundidade P15 e condição de enraizamento Ú mido.

12 Vazão relativa (Qr), em L.h ${ }^{-1}$, e coeficiente de variação de vazão (CV), em \%, dos gotejadores na cultura do feijão, na profundidade P30 e condição de enraizamento Úmido.

13 Vazão relativa (Qr), em L.h ${ }^{-1}$, e coeficiente de variação de vazão (CV), em \%, dos gotejadores na cultura do feijão, na profundidade P15 e condição de enraizamento Seco-S. 58

14 Vazão relativa, Qr, e coeficiente de variação de vazão (CV), em \%, dos gotejadores na cultura do feijão, na profundidade P30 e condição de enraizamento Seco-S

15 Vazão relativa (Qr), em L.h ${ }^{-1}$, e coeficiente de variação de vazão (CV), em \%, dos gotejadores para condição de enraizamento sem cultivo (SC), na profundidade P15 59

16 Vazão relativa (Qr), em L.h ${ }^{-1}$, e coeficiente de variação de vazão, 
(CV), em \%, dos gotejadores para a condição de enraizamento sem cultivo( SC), na profundidade P30. 60

17 Resultados da análise de variância e teste de comparação de médias para os dados de vazão relativa (Qr), em L.h ${ }^{-1}$, dos gotejadores não-compensantes, aos 90 dias do início do experimento, na cultura do feijão 61

18 Resultados da análise de variância e teste de comparação de médias para os dados de vazão relativa (Qr), em L.h ${ }^{-1}$, dos gotejadores autocompensantes, aos 90 dias do início do experimento, na cultura do feijão

19 Vazão relativa (Qr), em L.h ${ }^{-1}$, e coeficiente de variação de vazão (CV), em \%, dos gotejadores não-compensantes, para os níveis de vácuo avaliados 66

20 Vazão relativa (Qr), em L.h ${ }^{-1}$, e coeficiente de variação de vazão (CV), em \%, dos gotejadores autocompensantes, para os níveis de vácuo avaliados 68

21 Medidas da arquitetura dos gotejadores não-compensantes 104

22 Medidas da arquitetura dos gotejadores autocompensantes 104 


\title{
INTRUSÃO RADICULAR E EFEITO DE VÁCUO EM GOTEJAMENTO ENTERRADO NA IRRIGAÇÃO DE CANA-DE-AÇÚCAR
}

\author{
Autor: RONALDO SOUZA RESENDE \\ Orientador: Prof. Dr. RUBENS DUARTE COELHO
}

\section{RESUMO}

Com o propósito de avaliar o potencial de intrusão radicular e os efeitos da ocorrência de vácuo nas linhas de irrigação em diversos modelos de gotejadores, quando utilizados em irrigação subsuperficial, foram conduzidos três experimentos em condição de ambiente protegido. Dois experimentos foram conduzidos em vasos: um com a cultura da cana-de-açúcar; e o outro com o objetivo específico de avaliar a possibilidade de estabelecimento da cultura do feijão como padrão de ensaio para experimentos de suscetibilidade de gotejadores à intrusão radicular. Para esses dois experimentos, os tratamentos consistiram de 14 modelos de gotejadores de diferentes marcas comerciais, dos quais 7 do tipo não-compensante e 7 do tipo autocompensante de pressão; os modelos foram instalados em duas profundidades, $0,15 \mathrm{~m} \mathrm{e} 0,30 \mathrm{~m}$ do nível da superfície (P15 e P30, respectivamente), e conduzidos em solo sob três condições de enraizamento: $a$ )Úmido, no qual a irrigação era iniciada quando o potencial de água no solo atingia $-30 \mathrm{kPa}$, medido através de tensiômetro, $b$ ) Seco, quando o potencial matricial da água no solo atingia $-80 \mathrm{kPa}$ e $c$ ) Sem cultivo (SC), no qual os vasos foram 
mantidos sem plantas, sendo utilizados para comparação das vazões determinadas nos vasos com culturas, tanto do experimento com cana-de-açúcar como com feijão, possibilitando, assim, isolar o efeito de outros fatores causadores de variação de vazão dos gotejadores que não a intrusão de raízes. O terceiro, conduzido nos mesmos vasos do feijão após finalizado o experimento inicial, simulou o efeito de 5 níveis de vácuo na vazão dos gotejadores, em função do sucção de partículas do solo. Os níveis de sucção avaliados foram $-13,-20, \quad-26,-53$ e $-80 \mathrm{kPa}$. Com o propósito de avaliar a capacidade de recuperação da vazão de gotejadores afetados pela sucção de partículas, foi efetuada uma leitura de vazão após 3 irrigações, de 1 hora cada. As leituras de vazão foram realizadas com freqüência mensal, por um período de 90 dias para o feijão, e de 270 dias para a cana-de-açúcar. No experimento com a cana-de-açúcar, os resultados obtidos mostraram diferenças marcantes no comportamento do gotejadores do tipo nãocompensante de pressão daqueles do tipo autocompensante e, dentro de cada tipo, diferenças estatisticamente significativas quanto à suscetibilidade à intrusão de raízes. Quanto ao efeito d intrusão e enterrio, os modelos autocompensantes apresentaram maior magnitude de variação da vazão em relação aos gotejadores não-compensantes, em todos os experimentos conduzidos. Nos modelos mais susceptíveis, observoutse maior nível de intrusão na condição de enraizamento úmido, embora esse comportamento não tenha sido estatisticamente significante na análise efetuada para a leitura de vazão efetuada no final do experimento, aos 270dias. Tanto para a cana como para o fe ijão, não foi observada diferença significativa no nível de intrusão de raízes em relação à profundidade de instalação dos gotejadores. Os resultados obtidos com a cultura do feijão indicam sua inadequabilidade para testes rápidos de suscetibilidade de gotejadores à intrusão de raízes. Evidenciourse que as estratégias de barreira física devem ser definidas visando não apenas à prevenção da ocorrência da intrusão mas também, depois de efetivada a intrusão, a minimização da possibilidade de a raiz intrusa penetrar no interior da linha lateral de gotejadores, o que ampliaria o efeito da intrusão na malha hidráulica da parcela de irrigação; pequenas adequações em parâmetros da arquitetura ou no processo de montagem dos tubos gotejadores poderiam reduzir essa possibilidade. 


\title{
ROOT INTRUSION AND VACUMM EFFECTS IN SUBSURFACE DRIP IRRIGATION OF SUGAR CANE
}

\author{
Author: RONALDO SOUZA RESENDE \\ Adviser: Prof. Dr. RUBENS DUARTE COELHO
}

\section{SUMMARY}

In order to evaluate the potential of root intrusion and vacuum damage (flow disturbance) in subsurface drip irrigation (SDI), fourteen emitters were tested on three experiments under controlled environment (greenhouse and vase conditions). The first one was based on sugar-cane crop and the second one based on bean crop, aiming to establish this temporary crop (bean) as a reference plant in a future root intrusion standard test applied to SDI. Among the selected emitters from different manufactures, seven of them were no compensating drippers and the others pressure compensating drippers. The drippers were installed in two different depths: $0.15 \mathrm{~m}$ and $0.30 \mathrm{~m}$ from soil surface (P15 and P30) and conducted under three watering conditions: 1. Moist : irrigation started when the water potential in soil reached $-30 \mathrm{kPa}$ (tensiometer) 2. Dry, irrigation started when the water potential in soil reached $-80 \mathrm{kPa}$, and 3. No crop / Moist (NOC) where the vases were kept without any crop (Control) with the same irrigation level of condition 1 , being possible to isolate other factors than root intrusion, which could disturbed emitters flow rate. The third experiment was conducted after finalizing the experiment with the bean crop (same vases), simulating 5 levels of vacuum in the hydraulic network (condition reached just after closing parcel valves in the field), trying to measure the flow rate variation of emitters, related to particles 
suctioned from soil. The suction levels evaluated were $-13,-20,-26,-53$ and $-80 \mathrm{kPa}$ for a short time and flow rate was measured just after 3 hours of irrigation, in order to stimulate the self-cleaning processes of emitters before measuring the vacuum-disturbed flow rate. An electromagnetic flow meter was used during all experiment, in order to measure the individual flow rate of buried emitters in vases; flow rate readings were taken every month in the bean crop (90 days cycle) and in the sugar cane crop (270 days cycle). For the sugar-cane experiment, the root intrusion results showed remarkable differences between no compensating and pressure compensating drippers (statistically significant). The self-compensating models showed a larger flow rate variation, compared to the no compensating emitters. It was visually observed for some susceptible emitters a greater level of root intrusion under high soil moisture content, although this behavior has not been statistically significant at the end of the sugar cane experiment $\left(270^{\text {th }}\right.$ day). There were no significantly differences in root intrusion (either for sugar-cane or bean crops) related to the installation depth of emitters (15 and $30 \mathrm{~cm}$ ). The obtained results do not recommend the use of a temporary crop (bean) as a reference plant for a standard test related to root intrusion, because it takes at least 6 month to detected significant root intrusion in SDI.

The strategy of developing emitters physical barriers against root intrusion, should focus not only in the prevention of entering but also in the minimization of damage related to the intruded root inside the emitter, because in some circumstances it is possible to keep flow rate close to nominal rate even with roots inside the drippers. 


\section{INTRODUÇÃO}

A irrigação localizada subsuperficial, que se constitui na aplicação localizada de água diretamente na zona radicular da cultura, apresenta elevado potencial de utilização no futuro, em função da perspectiva de eficiência de uso da água, além de ter a vantagem de possibilitar a minimização dos riscos à saúde humana quando da utilização de águas residuais.

Para o sistema de gotejamento enterrado, a intrusão radicular constitui um dos principais aspectos de manejo a ser considerado visando assegurar a vida útil prevista em projeto (Camp et al., 2000). Na cultura da cana-de-açúcar o problema é ampliado por causa do sistema radicular do tipo fasciculado, aliado às características de plantio em linha contínua. Outro fator a ser considerado com maior evidência no gotejamento subsuperficial é a ocorrência de vácuo no interior das linhas terciária e de gotejadores, após o desligamento de determinado setor de irrigação, o que pode resultar em succionamento de partículas sólidas do solo para o interior dos gotejadores, constituindo-se em uma caus a adicional de entupimento, essa de natureza física.

As principais medidas adotadas pela indústria de equipamentos para contenção da intrusão radicular baseiam-se em princípios químicos, através da incorporação de herbicidas no material plástico do gotejador (Camp et al., 2000) ou da aplicação de um herbicida ministrado diretamente na da água de irrigação (Zoldoske, 1999), e de princípios físicos, ligados à arquitetura interna ou configuração do orifício de saída do gotejador (Barth, 1999).

A barreira química à intrusão de raízes em gotejamento subsuperficial se constitui em importante ferramenta no sentido de minimizar o problema. Entretanto, além dos aspectos ligados às questões ambientais (resíduo, persistência no solo, contaminação de lençol freático, inexistência de produtos registrados), é mínima a 
quantidade de estudos envolvendo o manejo da aplicação desses produtos. Questões como dosagens em diferentes tipos de solo, variabilidade do volume de solo tratado dentro da parcela de irrigação e suas implicações no desenvolvimento do sistema radicular da cultura, custos do tratamento, etc, carecem de estudos científicos.

A imposição de barreira física ao intrusionamento se constitui em uma estratégia de solução do problema que está isenta dos questionamentos acima referidos. Se não no sentido da completa eliminação da necessidade de tratamento químico, pode contribuir para reduzir, significativamente, a freqüência destes.

A comprovação da ocorrência de intrusão radicular em campo é dificultada justamente pelo fato de as mangueiras estarem enterradas, uma vez que outros fatores podem, também, ocasionar redução de vazão dos emissores, como: entupimento por causas química, física ou biológica (Nakayama \& Bulks, 1991), redução da secção transversal do tubo gotejador por ação da compactação da camada de solo acima do tubo (Steele et al., 1996) e redução do diferencial de pressão entre o interior do tubo e o ambiente externo ao gotejador, em função da saturação do solo ao redor deste (Shani et al., 1996). Dessa forma, a realização de ensaios em condições controladas faz-se necessária para a determinação do comportamento de diferentes modelos de gotejadores frente às condições favoráveis ao intrusionamento de raízes, sendo importante o estabelecimento de um padrão de ensaio da suscetibilidade de emissores, até agora inexistente.

Visando minorar o efeito do vácuo, são fabricados emissores com característica anti-drenante ou com mecanismo anti-sucção. Com relação a modelos de gotejadores com incorporação de barreira química no processo de extrusão do polietilieno, há somente um produto disponível no mercado, embora ainda não comercializado no País. Emissores com anunciada proteção baseada em princípios físicos carecem de comprovação científica de sua eficiência, devido à escassez de trabalho científicos na área.

O potencial de aplicação da irrigação localizada enterrada na cultura da canade-açúcar cresce à medida que além dos aspectos de eficiência acima citados soma-se a não-interferência nas operações de cultivo na área irrigada, inclusive na colheita 
mecânica. Além disso, resta ainda a minimização de danos mecânicos às mangueiras, uma vez que as atividades de preparo do solo se realizam em espaços de tempo bem mais amplos.

Trabalhos conduzidos em São Paulo por Tuler et al. (1981) e Guazzelli \& Paez (1997) resultaram em incrementos de produtividade da cana-de-açúcar da ordem de 30 a 35 t/ha, como resultado do uso da irrigação por gotejamento. A viabilidade econômica do seu uso, para a cana colhida nos meses de maio a julho, demonstrada por Mattiole (1998) para as condições da região norte do Estado.

O objetivo deste trabalho foi o de avaliar o potencial de intrusão radicular em diversos modelos de gotejadores instalados em diferentes profundidades no solo e sob diferentes condições de enraizamento, quando utilizados em irrigação subsuperficial na cultura da cana-de-açúcar. Paralelamente, avalioutse o efeito da ocorrência de vácuo no interior da malha hidráulica da parcela de irrigação sobre o desempenho hidráulico dos emissores estudados. Adicionalmente, o trabalho visa adequar uma metodologia de ensaios de curta duração para avaliar a suscetibilidade de emissores à intrusão radicular.

Em vista dos objetivos propostos, as seguintes hipóteses foram estabelecidas:

a) $\mathrm{O}$ efeito da entrada de raízes no orifício dos emissores deve estar relacionado à redução de vazão para o grupo de emissores não-compensantes e ao aumento de vazão, no grupo dos autocompensantes.

b) Sob regime de maior alternância de umidade do solo, no caso os tratamentos com solo seco (CNS e FJS), a probabilidade de intrusão de raízes no orifício dos emissores pode aumentar, verificando os reflexos discutidos no item " $a$ "

c) Os emissores dos vasos sem cultivo (SC) devem apresentar maior vazão que os dos vasos com cultivo ( $\mathrm{CN}$ e FJ) no grupo dos emissores não-compensantes e menor vazão que nos autocompensantes, com base no pressuposto no item " $a$ " 


\section{REVISÃO DE LITERATURA}

\subsection{Irrigação localizada subsuperficial}

A irrigação por gotejamento subsuperficial é um método de suprir baixos volumes de água à zona radicular das culturas (Caldwell et al., 1994) utilizando-se linhas de gotejadores enterradas no solo, em profundidade variável, segundo parâmetros baseados em fatores diversos como tipo de solo, cultura irrigada, sistema de cultivo, etc.

As principais vantagens gerais do sistema foram apresentadas por Oron et al. (1991) e Bar-Yosef et al. (1989) como sendo: redução de perdas por evaporação; reduzida geração de escorrimento superficial; flexibilidade do uso de maquinário agrícola; maior dificuldade na germinação de sementes de ervas daninhas, uma vez que o solo se mantém seco na superfície; maior disponibilidade de nutrientes, uma vez que o ponto de emissão se encontra mais próximo da raiz. Outra vantagem oferecida por esse método se refere ao menor nível de redução da produção quando do uso de água salina (Oron et al., 1999). Algumas desvantagens do sistema foram apontadas por Oron et al. (1991) como sendo, entre outras: possíveis problemas de germinação de sementes da cultura principal; dificuldade na detecção de problemas de entupimento de emissores; nas instalações enterradas a pequenas profundidades, pode haver dificuldade no cultivo do solo, resultando em dano mecânico, principalmente quando as linhas de gotejadores são posicionadas fora da linha de plantio (Ayars et al., 1995); dano mecânico causado por roedores tem sido reportado, principalmente nas fitas gotejadoras, as quais possuem pequena espessura de parede (Sorensen et al., 2001; Ayars et al., 1999).

O fato de o suprimento de água se dar diretamente na zona radicular torna esse sistema bastante eficiente na minimização de perdas evaporativas, além de reduzir tanto 
o risco de lixiviação do íon nitrato como o de transmissão de doenças causadas por bactérias e fungos, possibilitando o uso de águas residuais (Suarez-Rey et al., 1999; Phene \& Ruskin, 1995). Além de reduzir o potencial de contágio humano, outra vantagem apresentada pela irrigação subsuperficial se refere à menor probabilidade de aparecimento de doenças vegetais. Resultados obtidos por Bell et al. (1998) indicaram que o efeito supressivo da irrigação por subsuperfície, comparado com a irrigação por sulco, na incidência de podridão-das-raízes causada pelo fungo Sclerotinia minor, foi resultado direto do diferencial de distribuição de umidade nos dois sistemas de irrigação. Na cultura do pimentão (Capsicum annuum), a incidência de podridão-das-raízes, causada por Phytophthora capsici, foi mais alta no gotejamento superficial que no sistema com emissores enterrados a 0,15m (Café Filho \& Duniway, 1996).

A irrigação localizada caracteriza-se por um reduzido volume de solo molhado, resultando na necessidade de maior frequiência de irrigação. Dada essa elevada freqüência, a superfície do solo se mantém, no gotejo superficial, por um período maior de tempo com alto nível de umidade, fazendo com que o primeiro estágio da evaporação persista por maior tempo (Meshkat et al., 2000). Esse primeiro estágio da evaporação a que se refere este último autor é caracterizado por Lemon (1956), citado por Reichardt (1996), por uma alta velocidade de evaporação, a qual é constante e independente da umidade do solo, estando principalmente relacionado às condições reinantes na atmosfera junto ao solo, tais como energia radiante, velocidade do vento, temperatura e umidade do ar.

A esse respeito, Matthias et al. (1986) estimaram que a evaporação respondeu por uma perda de $33 \%$ a $40 \%$ da água aplicada em um solo nu, irrigado por gotejamento em um período de 7 dias. Da mesma forma, Lamm et al. (1995), utilizando gotejamento subsuperficial em milho e analisando os componentes do balanço de água calculados, indicaram que um cuidadoso manejo de sistemas subsuperficiais pode reduzir necessidades de irrigação líquidas em quase 25\%. Já Evett et al. (1995), também com a cultura do milho, apontaram uma economia de água de $10 \%$ quando usaram gotejadores enterrados a profundidade de 0,3 m. A maio parte dessa economia de água ocorreu, 
segundo os autores, devido à minimização dos componentes não-benéficos do balanço, como evaporação e drenagem de longo período.

Um aspecto de manejo no gotejamento subsuperficial, apontado por Phene et al. (1987) como vantajoso em relação ao gotejamento superficial, é a eliminação da variabilidade da infiltração na uniformidade da irrigação. No entanto, Amali et al. (1997) não observaram essa vantagem ao compararem a variabilidade da água no solo nos sistemas de irrigação subsuperficial, no de sulcos com fluxo contínuo e no de sulco com fluxo intermitente: os autores observaram uma variação espacial mais alta no gotejamento enterrado na camada de solo acima do emissor e equivalente aos demais métodos na camada abaixo do emissor. Uma ressalva para esses resultados, admitida pelos autores, se refere a uma possível inadequação dos pontos de medição da umidade, em relação à localização dos emissores.

Para propósito de projeto hidráulico, sistemas de irrigação localizada subsuperficial somente diferem do gotejamento superficial pelo fato de exigirem a instalação de válvulas antivácuo em maior quantidade nas parcelas de irrigação. Do ponto de vista do manejo da irrigação, dependendo da qualidade de água, os sistemas subsuperficiais podem requerer aplicações preventivas mais freqüentes de ácido e/ou cloro (Phene, 1995). A maior necessidade de utilização de válvulas antivácuo está relacionada ao objetivo de minimizar o succionamento e a conseqüente entrada de partículas de solo no interior dos emissores, que provoca variação de vazão nos emissores.

A ocorrência de vazões superiores à nominal do emissor, ou seja, um efeito inverso ao normalmente esperado para as fontes causadoras de entupimento, foi observado por Vilela et al. (2001), num estudo de simulação de entrada de particulados sólidos na malha hidráulica; nesse trabalho, foi constatado aumento de vazão de até 33\% para emissor autocompensante, quando utilizado solo arenoso na simulação. A deposição de material na região de assentamento da membrana responsável pela característica da compensação de vazão foi a hipótese utilizada para explicar o fato observado. 
Para ser viável, a linha lateral dos sistemas de irrigação subsuperficial deve ser resistente o bastante para suportar instalação e remoção periódica como também resistente ao entupimento, à intrusão de raízes e ao colapso mecânico (Camp et al., 1989); este último se constitui na possibilidade de deformação da seção circular das mangueiras de polietileno como conseqüência da pressão exercida pela camada de solo, podendo esta pressão ser ampliada em função do grau de compactação do solo nas diferentes práticas de cultivo. Uma elevada redução de vazão foi constatada por Steele et al. (1996) ao longo de laterais instaladas à profundidade de $0,28 \mathrm{~m}$, tendo se atribuído o fato às deformações da seção circular sofridas pelas laterais. Ainda com respeito ao fenômeno do colapso de laterais de polietileno, Hills et al. (1989) conduziram ensaios em laboratório simulando três níveis de compressão de mangueiras de gotejadores. Estes autores observaram que o efeito da compressão foi diretamente relacionado com a pressão de serviço na rede hidráulica: as reduções de vazão foram da ordem de $25 \%$ com $50 \%$ de compressão, para as mais altas pressões ensaiadas (100 kPa). Sob pressões mais baixas $(50 \mathrm{kPa})$, a redução da vazão foi da ordem de $10 \%$, para a mesma taxa de compressão.

A tendência atual é utilizar tubos gotejadores com espessura de parede mais fina (0,20 a 0,45 mm), sob a ótica de que o material enterrado está sujeito a menor risco de dano físico, o que, potencialmente, aumentaria a possibilidade de ocorrência de colapso das mangueiras, conforme observado por Steele et al. (1996), com suas implicações na hidráulica do projeto. Outro aspecto apontado pela indústria, que vai de encontro ao critério de viabilidade acima apontado por Camp et al. (1989), seria a não-reutilização do material finda sua vida útil; na prática, para as maiores profundidades de enterrio (acima de 0,40 m) torna-se difícil a remoção das laterais já instaladas, resultando em um problema adicional do sistema, uma vez que origina resíduos plásticos no campo, com impacto visual e ecológico.

$\mathrm{Na}$ irrigação subsuperficial a vazão de um emissor é função, também, do diferencial de pressão entre a entrada e a saída do orifício do emissor. Sadler et al. (1995) observaram que a vazão dos emissores aumentava em 2,8\% a 4\% quando eram desenterrados para avaliação da uniformidade de aplicação de água; os autores 
afirmaram que esses valores eram duas vezes maiores que a variação da vazão teórica em função da variação da carga hidráulica, indicando algum efeito da resistência ao fluxo pelo solo em volta do gotejador. A esse respeito, Shani et al. (1996) e Warrick \& Shani, (1996) evidenciaram que na irrigação subsuperficial o solo age como um elemento indutor de perda de energia: quando a descarga de um emissor é maior que a capacidade de infiltração do solo, ocorre uma contrapressão na saída do gotejador, podendo essa reduzir o diferencial de pressão ao longo do gotejador e, em conseqüência, diminuir a vazão do emissor. Em estudos preliminares, esses autores observaram reduções de vazão de $10 \%$ a 50\% em gotejadores, sem sinais aparentes de ent upimento.

A tendência de o entupimento de gotejadores de causa biológica ocorrer no final da linha lateral foi relatada por Ravina et al. (1992) e por Lau (1978), citado por Bralts (1982). Essa tendência não é esperada m entupimento por intrusionamento radicular; hipoteticamente, este deve apresentar um comportamento aleatório, como o observado por Boman (1995) para o entupimento causado por partícula física, ou uniformemente distribuído ao longo da lateral de irrigação. No entanto, tal tendência de localização poderia ocorrer em uma situação de desuniformidade extrema na aplicação de água ao longo da linha lateral ou da linha terciária, causada por problemas de projeto hidráulico ou mesmo pela topografia do terreno, resultando em maior probabilidade de intrusão de raízes nos pontos com maior déficit hídrico no solo.

\subsection{Intrusão de raízes em gotejadores}

Os principais desafios na utilização de sistemas de irrigação subsuperficial, em longo prazo, são o potencial succionamento de partículas do solo e a intrusão de raízes através do orifício dos gotejadores. Suarez-Rey et al. (2000) afirmam que, uma vez que a raiz tenha penetrado no labirinto dos gotejadores, torna-se muito difícil sua remoção e, dessa forma, a intrusão de raízes deve ser encarada como um sério obstáculo no sucesso da irrigação localizada subsuperficial, em longo prazo. Duas formas de prevenir a intrusão de raízes são utilizadas: a primeira refere-se a emissores projetados para oferecer uma barreira física à intrusão (Barth, 1999) e a segunda, ao uso de emissores 
que apresentam o herbicida trifluralina incorporado ao polietileno durante o processo de extrusão do gotejador. Entretanto, evidências recentes relatadas de intrusão de raízes através da barreira física têm mostrado necessidade de novos estudos e avaliações (Gushiken, 1995).

Embora adicionando ao elenco de vantagens apresentadas pelo gotejamento subsuperficial a eliminação do efeito da variabilidade de infiltração na uniformidade da irrigação, Phene et al. (1987) apontam a intrusão de raízes nos orifícios dos emissores como uma das desvantagens do método.

Uma limitação relacionada à constatação da ocorrência da intrusão de raízes na entrada do orifício de emissores enterrados reside na dificuldade de efetuar a observação em condições naturais, sem que ocorra modificação da condição original do sistema radicular em relação ao emissor. A retirada da mangueira do solo para análise pode remover as raízes intrusivas, mascarando as vazões medidas posteriormente. Dessa forma, diversos trabalhos de pesquisa não constatam o problema: Camp et al. (1998) e Howell et al. (1997), não observaram evidências de entupimento ou intrusão na cultura do milho irrigada por subsuperfície, embora não tenham utilizado técnica destrutiva para a confirmação do fato. Do mesmo modo, também não foi observada intrusão nas culturas de melão, cebola, cenoura (Bucks et al., 1981) e milho-doce (Bar-Yosef et al., 1989) irrigadas subsuperficialmente, embora também não tenham deixado claro em sua metodologia de que forma foi obtida a observação.

Num trabalho conduzido por SuarezRey et al. (2000), com análise destrutiva de emissores utilizados em gotejamento subsuperficial de grama bermuda, foi constatado uma redução significativa no coeficiente de uniformidade estatístico, em relação a emissores novos; os autores constataram que alguns emissores tinham problemas com intrusão de raízes, resultando em moderada redução de vazão. Mitchell (1981) irrigando milho com cintas de exsudação afirmou que o sistema apresentou significativa redução de vazão. Posteriormente, Mitchell (1982) observou que as raízes do milho chegaram a “envelopar" a cinta de exsudação.

O manejo da irrigação pode influenciar a probabilidade de ocorrer intrusão de raízes, dado que interfere no ambiente imediatamente adjacente ao emissor; irrigação de 
alta frequiência, que mantém o solo em volta do emissor sempre próximo à saturação, pode inibir crescimento radicular na área para algumas plantas, mas não para outras. De modo contrário, déficits de umidade do solo, algumas vezes imposto com o objetivo de controle da frutificação ou da qualidade na maturação ou no crescimento vegetativo, pode aumentar a intrusão como conseqüência da alta concentração de raízes na área do emissor (Camp et. al., 2000). De modo análogo, parâmetros como espaçamento entre emissores, características do solo e práticas de fertilização, que interferem no formato do bulbo úmido do solo, podem determinar o potencial de intrusão radicular em um sistema de irrigação subsuperficial.

\subsection{Sistema radicular da cana-de-açúcar e do feijão}

A cana-de-açúcar, sendo uma gramínea, apresenta sistema radicular fasciculado. Durante os primeiros 30 dias de brotação das gemas a cana-de-açúcar utiliza as reservas de nutrientes contidas no tolete e, parcialmente, do suprimento de água e nutrientes proporcionados pelas primeiras raízes de fixação. Após esse período, inicia-se o desenvolvimento das raízes a partir dos perfilhos primários e, posteriormente, dos secundários. À medida que as raízes dos perfilhos se desenvolvem, as raízes de fixação perdem sua função e a cana passa a depender exclusivamente das raízes dos perfilhos. Dependendo das condições climáticas e do solo, após, aproximadamente, 90 dias todo o sistema radicular encontra-se distribuído nos primeiros Q3 $\mathrm{m}$ de profundidade do solo (Casagrande, 1991).

Para a cana-de-açúcar irrigada por gotejamento, Hunsigi (1993) afirma que o sistema radicular se espalha na camada superficial do solo, resultando em maior propensão da planta ao acamamento; o autor apresenta um padrão de extração de umidade do solo pela cultura nas porcentagens de 40, 30, 20 e 10 para as profundidades de 20, 40, 60 e $80 \mathrm{~cm}$, respectivamente. Esse padrão concorda com os valores determinados por Souza (1976) para cana irrigada por sulcos, o qual observou que $82 \%$ das raízes encontravam-se nos primeiros $0,6 \mathrm{~m}$ de profundidade, comparado a $75 \% \mathrm{em}$ cana não-irrigada. Os dados obtidos por Korndöfer et al. (1989) demonstraram um perfil 
de crescimento ainda mais superficial; esses autores observaram, em cana-planta, uma concentração de $89 \%$ a $92 \%$ das raízes nos primeiros $0,3 \mathrm{~m}$ de profundidade, enquanto em cana soca $85 \%$ a $92 \%$ das raízes encontravam-se nos primeiros $0,4 \mathrm{~m}$ de profundidade.

Em trabalho conduzido por Pitts et al. (1993) com o plantio de cana ma presença de lençol freático a diferentes profundidades, foi observado que a quantidade de raízes produzidas no primeiro ano foi idêntica para todas as profundidades de lençol avaliadas $(0,45,0,60$ e $0,75 \mathrm{~m}) ; 95 \%$ e $86 \%$ das raízes se concentraram nos primeiros $0,3 \mathrm{~m}$ do solo, nos tratamentos de profundidade do lençol de 0,45 e $0,75 \mathrm{~m}$, respectivamente.

Avaliando o regime de umidade, o espaçamento da linha lateral e o efeito do posicionamento da linha lateral em relação à linha de plantio da cana-de-açúcar, Batchelor et al. (1990) observaram ser esse último fator o que mais afetou a distribuição das raízes, sendo que o desenvolvimento radicular ocorreu, predominantemente e para todos os tratamentos, até a profundidade de 0,6 m, embora tenha havido uma leve tendência de o tratamento sem irrigação apresentar maior porcentagem de raízes nas camadas mais profundas do perfil do solo. Quanto ao fator regime de umidade do solo, o autor afirma que não houve indicação de que o crescimento radicular tenha sido prejudicado no tratamento com condições de prolongada umidade em volta do gotejador (tratamento com âmina equivalente a 1,5 vezes o valor da evapotranspiração de cultivo).

Na cultura do feijão, a morfologia do desenvolvimento inicial das raízes foi descrita por Avilan Rovira \& Neptune, (1976b) como composta de três fases: a primeira, caracterizada pelo aparecimento e desenvolvimento da radícula; a segunda, pela emissão das primeiras ramificações secundárias, em número de quatro, orientadas na direção dos quatro pontos cardeais e originadas ao redor de apenas uma região da radícula; a terceira, caracterizada pelo aparecimento de novas ramificações secundárias e terciárias. O desenvolvimento das raízes secundárias e terciárias ocorre u aos quatro e nove dias, respectivamente, após a emergência da radícula.

A configuração radicular do feijoeiro se assemelha ao sistema fasciculado, uma vez que a raiz primária não é uma raiz pivotante típica (Vieira, 1967), característica das 
dicotiledôneas. Esse autor observou um sistema radicular superficial, com a maior parte das raízes se concentrando nos primeiros $0,2 \mathrm{~m}$ do perfil do solo, sendo de $62 \%$ a $87 \%$ nos primeiros $0,1 \mathrm{~m}$. Perfil de distribuição idêntico foi observado por Avilan Rovira \& Neptune (1976a), que constataram que a maior atividade das raízes estava restrita aos primeiros $0,10 \mathrm{~m}$ de profundidade do solo e a $0,1 \mathrm{~m}$ do colo da planta, lateralmente. A máxima profundidade de enraizamento encontrada por esses autores foi de $0,5 \mathrm{~m}$ e a máxima distância lateral foi de $0,25 \mathrm{~m}$, atingindo a profundidade de 0,1 a 0,2 m

Makasheva (1984) relata que, sob irrigação, o maior volume de raízes do feijoeiro no fim do período vegetativo concentrourse nos primeiros $0,6 \mathrm{~m}$ do solo. Essa mesma profundidade foi observada por Calheiros (1992) no cultivo sem irrigação, sendo que $56 \%$ e $24 \%$ nas duas camadas superficiais ( 0 a 0,1 me 0,1 a $0,2 \mathrm{~m}$ ), decrescendo para a média de $5 \%$ nas demais $(0,2$ a 0,$3 ; 0,3$ a 0,$4 ; 0,4$ a 0,5 e 0,5 a $0,6 \mathrm{~m})$; já em cultivo irrigado, o sistema radicular mostroutse mais superficial, com $70 \%$ das raízes localizadas na camada mais superficial ( 0 a 0,1 m) e não se aprofundando além dos 0,5 m. O padrão de distribuição de raízes encontrado por Oliveira \& Silva, (1990), também com a cultura sob irrigação, mostrou-se mais equilibrado que o observado por Calheiros, (1992), com porcentuais de 28, 17, 23, 15, 11 e 6, para as mesmas camadas avaliadas por esse autor.

Em feijão cultivado em rotação com milho e mucuna-preta, Wutke et al. (2000) encontraram uma profundidade do sistema radicular de 0,35 a $0,4 \mathrm{~m}$, onde se concentraram aproximadamente $80 \%$ das raízes finas.

\subsection{Caractenísticas da trifluralina nos sistemas de irrigação subsuperficial}

Uma das principais estratégias apontadas no tratamento preventivo da intrusão radicular em gotejadores instalados em subsuperfície se refere à criação de uma barreira química no solo através do uso de herbicida aplicado na água de irrigação. Dentre os produtos comumente referidos para a criação dessa barreira, o herbicida trifluralina se apresenta como o de maior referência pela indústria de equipamentos de irrigação voltada especificamente para a irrigação subsuperficial. 
A trifluralina faz parte do grupo químico das dinitroanilinas, convencionalmente utilizado no tratamento de pré-emergência de ervas daninhas de folha estreita e larga (Hertwig, 1983). Apresenta-se como um sólido cris talino de cor amarelo alaranjada, ponto de fusão de $48,5^{\circ} \mathrm{C}$ a $49^{\circ} \mathrm{C}$, ponto de ebulição de $96^{\circ} \mathrm{C}$ a $97^{\circ} \mathrm{C}$, solubilidade em água de 0,1 a 0,3 partes por milhão, a $27^{\circ} \mathrm{C}$, e pressão de vapor de $1,99 \times 10^{-4} \mathrm{~mm} \mathrm{de} \mathrm{Hg}$ a $29,5^{\circ} \mathrm{C}$ ( Probst et al, 1975).

Uma das principais preocupações da aplicação do herbicida trifluralina na irrigação subsuperficial refere-se ao risco de poluição do lençol freático, através $\mathbf{b}$ processo de lavagem. A intensidade com que esse processo pode ocorrer é função tanto de parâmetros ligados ao manejo da irrigação como às propriedades físico-químicas do herbicida. As principais características físico-químicas que determinam a eficiência e o potencial de lavagem dos herbicidas são o nível de adsorção do herbicida no solo, solubilidade em água, pressão de vapor e fotólise.

A adsorção física de herbicidas é um fenômeno reversível, no sentido de que, se a concentração externa se r eduzir após a adsorção parecer completa, uma parte do soluto adsorvido volta à solução (Crosby, 1976). A adsorção reduz a lavagem do herbicida, diminuindo, desta forma, o potencial de contaminação de águas subterrâneas, mas ao mesmo tempo aumenta o potencial de perdas por fotodecomposição ou volatilização se o herbicida é aplicado na superfície do solo (Koskinen \& Harper, 1987). A quantidade de herbicida adsorvido pode ser caracterizada pelo coeficiente de distribuição, $\mathrm{Kd}=$ $(\mathrm{x} / \mathrm{m}) / \mathrm{C}$, onde $(\mathrm{x} / \mathrm{m})$ é a quantidade adsorvida e $\mathrm{C}$ a quantidade do herbicida em solução. A importância desse parâmetro repousa na sua habilidade em predizer a capacidade de adsorção de um herbicida sobre a superfície das partículas de um solo em relação a outros herbicidas e tipos de solos (Koskinen \& Harper, 1987).

A pressão de vapor de um herbicida afetará a dissipação do herbicida em termos de perdas por volatilização. À medida que a pressão de vapor aumenta, a volatilidade ou a tendência para um herbicida emitir vapor também aumenta. $\mathrm{O}$ maior potencial para perdas por volatilização está em herbicidas que têm pressão de vapor maior que $1 \times 10^{-2} \mathrm{~Pa}$, aí se inclui o herbicida trifluralina. A incorporação ao solo tem mostrado 
redução drástica de tais perdas. Para o herbicida trifluralina, a recomendação é a incorporação no máximo 24 horas após a aplicação (Koskinen \& Harper, 1987).

A volatilização de herbicida é maior em condição de solo úmido. Nessa condição, maior quantidade de sítios de adsorção nos colóides do solo são ocupados por moléculas de água. Isso resulta em mais moléculas do herbicida estando na solução do solo e disponíveis para perdas por volatilização. Perda cumulativa de herbicidas em solo úmido, condição predominante em irrigação localizada, pode ser tão alta como 90\%, embora a incorporação reduza isso significativamente (Devine et al., 1993). Adicionalmente, solubilidade em água muito baixa pode promover volatilização de compostos com baixa pressão de vapor.

Fotólise, ou foto-decomposição, é a decomposição de um químico induzida por radiação eletromagnética, ou luz. Para herbicidas aplicados no solo e sensíveis à radiação ultravioleta, como a trifluralina, torna-se imprescindível a incorporação ao solo imediatamente após a aplicação (Devine et al., 1993).

O movimento de um herbicida é o resultado final de outros processos que afetam sua persistência. O mecanismo desse movimento depende dos processos de troca dominantes no local de aplicação e das propriedades químicas, físicas, da pressão de vapor e da solubilidade do herbicida. (Koskinen \& Harper, 1987). Análises químicas indicam que a trifluralina não é prontamente lavada nos solos (Probst et al. 1975). Estudos conduzidos por Miller et al. (1975) confirmaram que esse herbicida não sofre lavagem ou acumulação nos solos depois de repetidas aplicações.

Os conteúdos de matéria orgânica e argila do solo são os fatores mais importantes, os quais, indiretamente, influenciam todos os processos, afetando os herbicidas. Como regra, quanto maior o conteúdo de argila e matéria orgânica, maior a adsorção do herbicida às partículas do solo (Koskinen \& Harper, 1987).

Estudando a liberação ao solo de trifluralina impregnada em emissores, Von Voris et al. (1988) observaram que a taxa de liberação, era direta e altamente influenciada pela temperatura.

Estudos de absorção e translocação indicam que a trifluralina é pouco transportada das raízes para a parte aérea das plantas. Efeitos na divisão das células nas 
raízes e na germinação de plântulas de espécies susceptíveis indicam que a inibição da mitose pode ser o principal mecanismo de ação. Existem também indicações da interferência coma fotossíntese e a respiração (Probst et al., 1975).

Em resumo, dada a peculiaridade da aplicação via irrigação subsuperficial, o herbicida trifluralina constitui-se num dos mais adequados para a prevenção da intrusão radicular em emissores, prevalência configurada por: a) baixo nível de toxidade ao homem e animais, com valor DL50 cutânea de $10 \mathrm{~g} / \mathrm{kg}$ de peso vivo (Probst et al. 1975); b) dado que a aplicação é efetuada diretamente na subsuperfície do solo, o potencial de perdas por volatilização e fotólise torna-se drasticamente reduzida (Devine et al., 1993); c) reduzido deslocamento e acumulação nos tecidos das plantas, resultando em efeito localizado apenas nas raízes da planta, o que reduz o risco de fitotoxidade e transporte na cadeia alimentar (Probst et al., 1975; Van Voris et al., 1988); d) baixa solubilidade em água, reduzindo o potencial de lavagem do produto; e) meia-vida no solo de aproximadamente 60 dias, o que diminui a acumulação no meio ambiente (Von Voris et al., 1988), mesmo com repetidas aplicações (Miller et al., 1975).

\subsection{Vácuo na malha hidráulica de sistemas de irrigação localizados}

A irrigação localizada subsuperficial apresenta um risco inerente de partículas do solo serem succionadas através do orifício de saída de água dos gotejadores em virtude da ocorrência de vácuo, podendo resultar no entupimento dos gotejadores (Ruskin, 1992). O problema de succionamento de partículas afeta tanto a irrigação por gotejamento superficial como subsuperficial, sendo mais crítico neste último: diversos modelos apresentam um segundo ou terceiro orifício de saída de água, o qual(is) funcionam como orifícios de admissão de ar, quando da ocorrência do vácuo; na condição de enterrio, esses orifícios tornamse não efetivos, agravando o problema. Embora seja citado por diversos autores, poucos trabalhos foram realizados no sentido de quantificar e melhor qualificar o problema.

A ocorrência de vácuo na parcela de irrigação está relacionada, principalmente, à parada do sistema de irrigação: em linhas laterais não niveladas, à medida que a água 
no interior do tubo é drenada através dos gotejadores localizados na parte mais baixa, origina uma pressão negativa que provoca o succionamento do solo da zona saturada em volta do gotejadores localizados nas partes mais altas do perfil (Weatherhead, 2002). No nível de parcela de irrigação, o esvaziamento das linhas de gotejadores pode resultar em valores de pressões negativas suficientes para colapsar as linhas secundárias, de PVC.

Camp et al. (2000) observaram que a entrada de partículas de solo em um sistema de irrigação por gotejamento subsuperficial com oito anos de operação, durante a implantação ou reparos, provavelmente causou entupimento nos gotejadores, e enfatizam a necessidade de se dedicar maiores cuidados na instalação e manutenção desses sistemas se uma maior vida útil é esperada (10 a 15 anos). A mesma explicação foi dada por Sadler et al. (1995) para emissores enterrados apresentando vazão nula. Em uma linha de trabalho idêntica, Vilela et al., (2001) simularam a entrada de particulados sólidos na linha de gotejadores, utilizando um solo de caráter franco-arenoso e outro de caráter franco-argiloso, e avaliaram o impacto resultante na vazão de cinco modelos de gotejadores, sob duas posições de instalação (gotejadores voltados para cima e para baixo); os autores observaram que o fator posição de instalação do emissor foi de maior preponderância em relação ao fator textura do solo e que as diferenças observadas entre modelos relacionava-se co a altura do corpo do gotejado em relação à parede do tubo de polietileno.

A instalação de válvulas anti-vácuo em maior número que na irrigação localizada superficial se mostra como requisito básico dado ser a formação de vácuo no interior das linha secundária e lateral(Phene, 1995). 


\section{METODOLOGIA}

\subsection{Experimento sobre intrusão radicular em gotejadores}

\subsubsection{Localização dos experimentos}

Foram conduzidos dois experimentos no Departamento de Engenharia Rural da Escola Superior de Agricultura "Luiz de Queiroz" - USP/ESALQ, no município de Piracicaba - SP: o primeiro estudou o potencial de intrusão radicular em gotejadores na irrigação subsuperficial da cultura da cana-de-açúcar (Sacharum sp.) - CN; o segundo, seguindo metodologia similar ao primeiro, utilizou a cultura do feijão Phaseolus vulgaris) - FJ, visando estudar a viabilidade de utilização dessa cultura como padrão para ensaios de suscetibilidade de gotejadores ao entupimento por intrusão radicular. A metodologia experimental utilizada nesses ensaios foi idealizada por Coelho, R.D. ${ }^{2}$, sendo de caráter original na literatura; ela se baseia no enterrio de gotejadores individualizados em vasos e em condição de ambiente protegido (estufa), de maneira a ser possível a mensuração da vazão de cada gotejador ao longo do experimento, com emissores justapostos em alta densidade, para otimizar o espaço requerido na condução do experimento.

\subsubsection{Tratamentos e delineamento estatístico}

Para cada uma das culturas citadas foram avaliados, quanto à ocorrência do processo de intrusão de raízes sob condição de irrigação subsuperficial, 14 modelos de gotejadores, de diferentes marcas comerciais, submetidos a duas profundidades de

\footnotetext{
${ }^{2}$ Comunicação Pessoal, Prof. Dr. Rubens Duarte Coelho, Departamento de Engenharia Rural ESALQ / USP. Projeto FAPESP Número 10267-4/2000.
} 
instalação no solo, P15 (0,15m) e P30 (0,3m), e a três condições de enraizamento: $a)$ Úmido (U), no qual a umidade do solo foi mantida próxima à capacidade de campo, com manejo diário da irrigação; $b$ ) Seco (S), no qual foi imposta uma condição de déficit hídrico severo, sem irigação até que quando o potencial matricial da água no solo atingia $-80 \mathrm{kPa}$ (esse procedimento visou avaliar a possibilidade de o déficit hídrico induz a raíz a "direcionar-se" ao orifício de saída de água do emissor, favorecendo, assim, o processo de intrusão); e c) Sem Cultivo (SC), no qual os vasos foram mantidos sem cultivo, sendo utilizados para comparação das vazões determinadas nos vasos com culturas, tanto do experimento com cana-de-açúcar como com o de feijão, possibilitando, assim, isolar o efeito de outros fatores (químico, físico, biológico, etc.) causadores de variação de vazão dos gotejadores que não a intrusão de raízes. Nos vasos sem cultivo, a irrigação foi efetuada todas as vezes que se procedia a irrigação no tratamento úmido.

Os modelos avaliados, a vazão, dimensões e a pressão utilizada para cada produto encontram-se na Tabela 1. Inicialmente, não estava prevista a divulgação nominal dos gotejadores utilizados nesse trabalho para evitar qualquer tipo de especulação comercial que possa ser efetuada contra qualquer um dos gotejadores aqui analisados; porém, não seria possível apresentar a discussão da arquitetura dos mesmos, para avanço do conhecimento científico sobre design, sem que fossem identificados ao menos visualmente. Dado o caráter original desse experimento, não existe nenhuma norma técnica ou trabalho científico em literatura que ofereça suporte ao trabalho aqui apresentado, principalmente pelo fato das vazões dos gotejadores não serem padronizadas e pelo fato da amostragem dos gotejadores não ter seguido nenhum critério de identificação de lotes de fabricação.

As amostras dos gotejadores aqui avaliados foram solicitadas diretamente aos fabricantes ou representantes comerciais, sem que os detalhes desse experimento fossem previamente discutidos em profundidade com a equipe de engenharia de cada fabricante, podendo ter sido entregue material de lotes com algum tipo mínimo de problema técnico, que tenha sido descartado para venda, porém disponibilizados para doação, ou até mesmo lotes de gotejadores que já estejam reformulados tecnicamente no mercado 
(obsoletos), porém mantendo as mesmas especificações comerciais. Face ao exposto, espera-se que os dados aqui apresentados sejam analisados com a devida cautela da ética profissional.

Tabela 1. Características operacionais dos gotejadores avaliados

\begin{tabular}{lcccccc}
\hline \multicolumn{1}{c}{ Modelo } & Cód. & Tipo & $\begin{array}{c}\text { Vazão } \\
\left(\mathbf{L . h}^{-\mathbf{1}}\right)\end{array}$ & $\begin{array}{c}\text { Pressão } \\
(\mathbf{k P a})\end{array}$ & $\begin{array}{c}\text { Espessura de } \\
\text { parede(mm) }\end{array}$ & $\begin{array}{c}\varnothing \text { interno do } \\
\text { tubo (mm) }\end{array}$ \\
\hline Carbodrip & CD & Cilíndrico & 2,30 & 100 & 0,85 & 13,8 \\
Carbodrip PC & CP & Cilíndrico & 2,50 & 100 & 0,90 & 14,2 \\
Drip In PC & DP & Cilíndrico & 4,00 & 100 & 1,00 & 14,0 \\
Drip In & DI & Cilíndrico & 1,60 & 100 & 0,80 & - \\
Naan-Tif PC & NP & Cilíndrico & 1,60 & 100 & 1,00 & 15,6 \\
VIP & VP & Botão & 3,60 & 100 & & - \\
Tiran & TR & Plano & 2,00 & 100 & 0,90 & 14,4 \\
Ram & RM & Plano & 2,30 & 100 & 0,60 & 15,5 \\
Dripline & DL & Plano & 2,00 & 100 & 0,90 & 15,2 \\
HydroDrip II & HD & Plano & 2,30 & 100 & 0,45 & - \\
Hydrodrip PC & HP & Cilíndrico & 2,20 & 100 & 0,90 & 16,0 \\
Hydrogol & HG & Cilíndrico & 2,00 & 100 & 0,90 & 14,4 \\
Dripline PC & DLP & Cilíndrico & 3,40 & 100 & 1,15 & 13,7 \\
Acqua-Traxx & AQ & Fita & 1,44 & 70 & 0,15 & 15,6 \\
\hline
\end{tabular}

O período de coleta de dados foi de 90 dias, para o experimento de feijão e de 270 dias para o de cana; ambos corresponderam ao ciclo produtivo completo das respectivas culturas. Embora pós a finalização do experimento, com a realização do corte da cana planta, tenha sido interrompida a leitura mensal de vazão dos gotejadores, optou-se por permitir o crescimento da primeira soca, visando a trabalhos posteriores Dessa forma, foi possível proceder a dissecação de gotejadores aos 450 dias desde o início do experimento e avaliar o resultado intrusivo das raízes

A análise estatística foi efetuada somente para a última leitura de vazão, aos 270 dias do início do experimento para a cana-de-açúcar e 90 dias para o feijão. O 
delineamento estatístico adotado seguiu um esquema inteiramente casualizado, com parcelas sub-subdivididas, constituindo parcela (em número de 3) a condição de enraizamento (úmido, seco e sem cultivo), subparcela (em número de 2) a profundidade de instalação dos gotejadores (P15 e P30) e sub-subparcela os modelos de gotejadores; Para cada cultura e condição de enraizamento, foram montados 10 vasos, sendo esse, portanto, o número de repetições. $\mathrm{O}$ teste $\mathrm{F}$ foi utilizado para a análise de variância e o teste de Tuckey, no nível de 5\% de probabilidade, para comparação de médias.

No experimento com a cultura da cana-de-açúcar, dado que um dos vasos foi desmontado aos 240 dias para observação do sistema radicular, portanto antes do final do período de coleta de dados, o número de repetições para a análise de variância foi reduzido para nove. O esquema de análise de variância para cada experimento é apresentado na Tabela 2.

Para possibilitar a avaliação do efeito dos tratamentos e a comparação entre os gotejadores estudados, os quais apresentam vazões nominais diversas (Tabela 1), os dados de vazão foram proporcionalizados em relação à vazão nominal do respectivo modelo, conforme eq. 1 .

$$
\mathrm{Qr}=\left(\frac{\mathrm{qa}}{\mathrm{qn}}\right) \times 100
$$

onde:

Qr - vazão relativa, \%

qa - vazão atual, L.h ${ }^{-1}$

Qr - vazão nominal do modelo, $L \cdot \mathrm{h}^{-1}$ 
Tabela 2. Esquema de análise de variância (ANOVA) dos experimentos com cana-deaçúcar e feijão

\begin{tabular}{lc}
\hline Causa de variação & G.L \\
\hline Condição de enraizamento (CE) & 2 \\
Resíduo (a) & 24 \\
Total de Parcelas & $\mathbf{2 6}$ \\
Profundidade (PROF) & 1 \\
CE x PROF & 2 \\
Resíduo (b) & 24 \\
Total de subparcelas & $\mathbf{5 3}$ \\
Modelo (MOD) & 13 \\
MOD x CE & 26 \\
MOD x PROF & 13 \\
MOD x CE x PROF & 26 \\
Resíduo & 624 \\
Total & $\mathbf{7 5 5}$ \\
\hline
\end{tabular}

\subsubsection{Condução do experimento}

Os experimentos foram conduzidos em estufa, com dimensões de $6,35 \mathrm{~m}$ de largura por 17,4 m de comprimento e altura de $3 \mathrm{~m}$. O esquema geral dos experimentos é apresentado na Figura 1.

A variedade de cana plantada foi a SP-801842, que apresenta um desenvolvimento radicular mais agressivo, além de ser uma das mais plantadas no Estado de São Paulo. Foi plantada no dia 08/05/2001, sendo utilizados dois toletes com 3 gemas em cada vaso, no sentido longitudinal à maior dimensão do vaso e espaçados de 0,15 m entre si, resultando, após replantio para cobrir eventuais falhas de germinação, na manutenção de seis plantas por vaso. Anteriormente ao plantio, foi efetuada uma adubação utilizando um produto de liberação lenta, com relação NPK de 15-9-12 e tempo médio de liberação de 8 a 9 meses. O produto contém na sua formulação, adicionalmente, $2,3 \%$ de enxofre, $0,02 \%$ de boro, $0,05 \%$ de cobre, $0,45 \%$ de ferro, $0,06 \%$ de manganês, $0,02 \%$ de molibdênio e $0,05 \%$ de zinco. Devido ao baixo valor de $\mathrm{pH}(4,3)$ detectado na análise química do solo, foi adicionado calcáreo correspondente à 


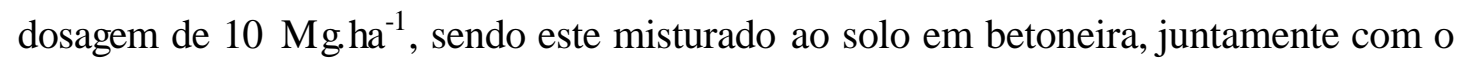
adubo.

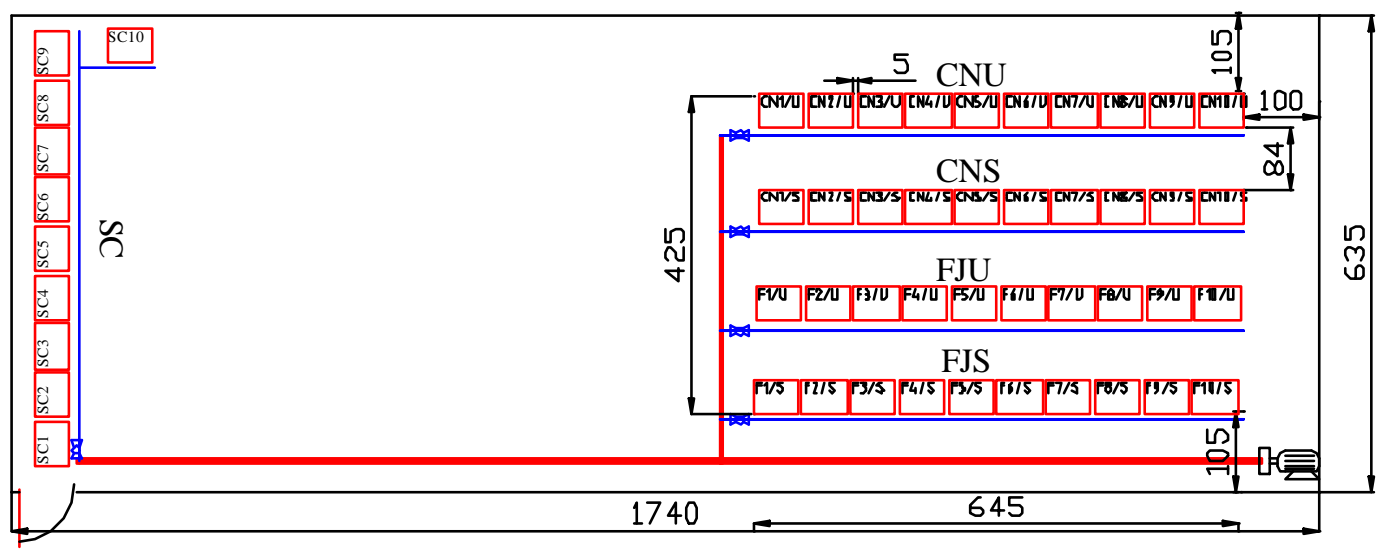

Figura 1 - Esquema geral dos experimentos no interior da estufa

Para o experimento com feijão foi utilizada a cultivar Carioquinha, sendo abertas 6 covas e mantidas 3 plantas por cova, totalizando 18 plantas em cada vaso. O plantio foi efetuado em 26/06/2001, tendo sido colhido em 26/09/2001. Após o estabelecimento da cultura, iniciourse o monitoramento, para aplicação dos tratamentos de umidade do solo.

A adubação inicial para a cultura do feijão foi idêntica à utilizada na cultura da cana-de-açúcar, diferindo apenas quanto ao tempo de liberação do adubo, que nesse caso foi de 6 meses. A dose de calcáreo e a forma de mistura do substrato para os vasos também foram idênticas à da cana.

O acompanhamento das culturas definiu a necessidade de aplicação de defensivos agrícolas, para o controle de pragas e doenças; no entanto a necessidade se resumiu apenas a pulverizações na cultura da cana-de-açúcar para o controle de pulgão.

O solo utilizado nos ensaios foi um Latossolo-Vermelho-Amarelo, textura franco-arenosa, coma caracterização físico-química indicada na Tabela 3. Utilizando a 
metodologia de saturar uma massa de solo com água e após o escorrimento do excesso determinar a relação entre o peso da amostra e o potencial de água, medido através de tensiometria para diversos níveis de umidade, Silva (2001) obteve a Figura 2, que representa a curva de retenção de umidade do solo empregada nesta pesquisa

Tabela 3. Característic as físico-químicas do solo utilizado no experimento

\begin{tabular}{|c|c|c|}
\hline Parâmetro & Unidade & Resultado \\
\hline \multicolumn{3}{|l|}{ 1. Caracterização física } \\
\hline Argila & $\%$ & 28 \\
\hline Silte & $\%$ & 5 \\
\hline Areia & $\%$ & 67 \\
\hline Areia grossa & $\%$ & 3 \\
\hline Areia média & $\%$ & 24 \\
\hline Areia fina & $\%$ & 40 \\
\hline Densidade aparente & g. $\mathrm{dm}^{-3}$ & 1,2 \\
\hline Densidade real & g. $\mathrm{dm}^{-3}$ & 2,9 \\
\hline \multicolumn{3}{|l|}{ 2. Caracterização química } \\
\hline Fósforo & mg.dm ${ }^{-3}$ & 1 \\
\hline Matéria orgânica & g. $\mathrm{dm}^{-3}$ & 7 \\
\hline $\mathrm{pH}$ & - & 4,2 \\
\hline Potássio & mmolc. $\mathrm{dm}^{-3}$ & 0,2 \\
\hline Cálcio & mmolc. $\mathrm{dm}^{-3}$ & 3 \\
\hline Magnésio & mmolc. $\mathrm{dm}^{-3}$ & 2 \\
\hline Hidrogênio+Alumínio & mmolc. $\mathrm{dm}^{-3}$ & 33 \\
\hline Alumínio & mmolc. $\mathrm{dm}^{-3}$ & 5 \\
\hline $\mathrm{S}-\mathrm{SO}_{4}^{-2}$ & mg.dm ${ }^{-3}$ & 25 \\
\hline Boro & mg.dm ${ }^{-3}$ & 0,07 \\
\hline Cobre & mg.dm ${ }^{-3}$ & 0,3 \\
\hline Ferro & mg.dm ${ }^{-3}$ & 14 \\
\hline Manganês & mg.dm ${ }^{-3}$ & 1,1 \\
\hline Zinco & mg.dm ${ }^{-3}$ & 0,2 \\
\hline
\end{tabular}

Para cada cultura e regime de umidade avaliado, foram instalados dois tensiômetros, um para cada profundidade de instalação do emissor. A determinação do 
potencial de água no solo dos vasos foi efetuada diariamente, às 8 horas, por meio de tensímetro digital.

Em cada vaso, com dimensões de 0,58 x 0,45 x 0,43 m e capacidade de 100L, foram montados todos os modelos. Para isto os vasos foram perfurados na direção transversal à maior dimensão, de forma que o tubo gotejador, constando de um emissor, o transpassasse. Os tubos gotejadores foram colocados lado a lado, para cada profundidade estudada, sendo suas posições aleatorizadas em cada repetição e profundidade (Figura 3).

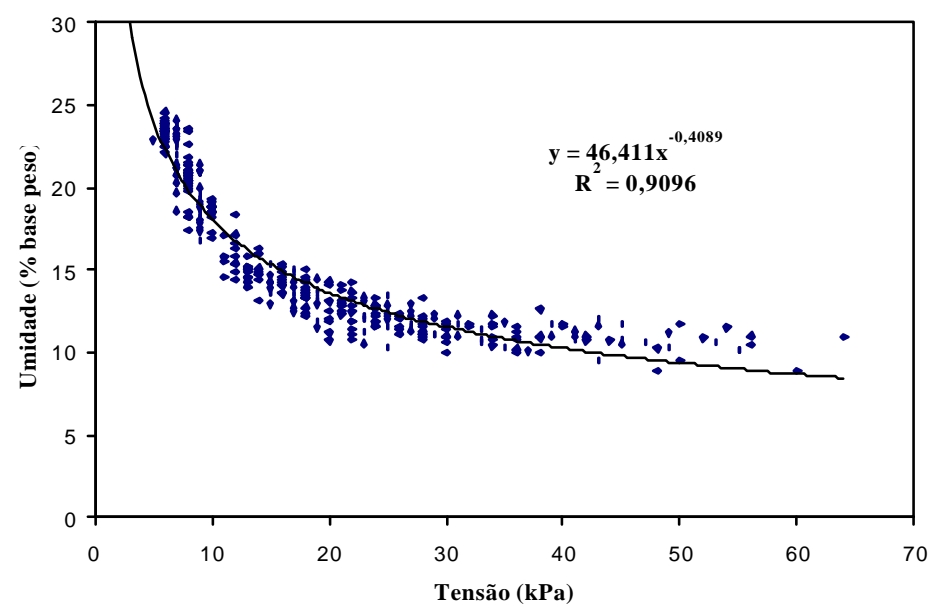

Figura 2 - Curva de retenção de umidade do solo utilizado no experimento (Silva, 2000)

Cada gotejador foi conectado à linha lateral por meio de microtubo: uma das extremidades do tubo gotejador instalado no vaso foi vedada e a outra cone ctada a uma linha de abastecimento de polietileno por meio de adaptador para mangueira, cap de PVC e adaptador para microtubo. 

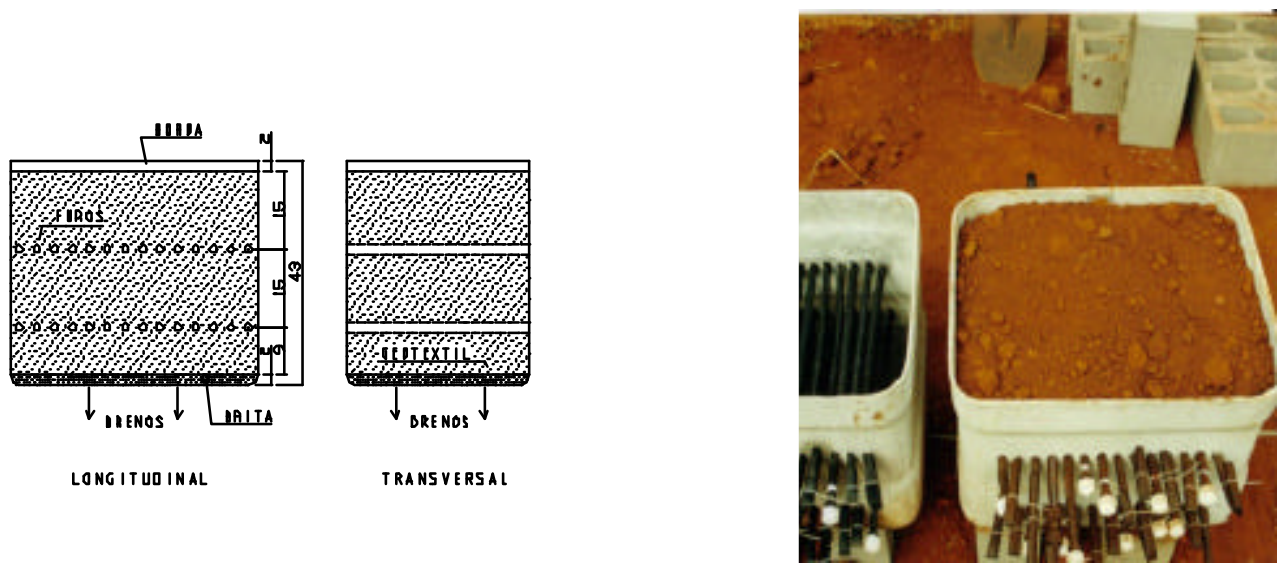

Figura 3 - Vista lateral e longitudinal dos vasos e instalação dos tubos gotejadores

Os vasos foram nantidos sobre blocos de cimento nivelados. Com objetivo de propiciar condição de livre drenagem da água, foram efetuados orifícios no fundo dos vasos e colocado um envelope constituído de uma camada de pedra britada $\mathrm{n}^{\circ} 1 \mathrm{e}$, sobre esta, uma camada de manta de poliéster $\left(\operatorname{Bidim}^{\circledR}\right)$.

Até a formação do sistema radicular das culturas, o solo dos vasos foi mantido próximo à capacidade de campo; a partir daí, a irrigação foi efetuada conforme os tratamentos preestabelecidos.

A determinação da vazão dos emissores foi efetuada com frequiência mensal, utilizando-se um medidor do tipo eletromagnético com faixa de medição de 0,01 a 10 L. $h^{-1}$ e desvio médio na calibração de $\pm 0,11 \%$ (Figura 4).

Cada gotejador era conectado à linha supridora de água por meio de um microtubo, o qual permitiu que a água fosse canalizada individualmente para cada um deles. No momento da leitura, o medidor era conectado entre a linha lateral supridora de água e o gotejador, permitindo a leitura individual da vazão dos mesmos. Antes da medição da vazão, o solo era saturado com água, no intuito de garantir uniformidade de ambiente em todos os gotejadores do vaso. Junto ao medidor de vazão foi instalado um 
manômetro digital, previamente aferido, para checagem constante da pressão de serviço, não se permitindo variações maiores que $5 \mathrm{kPa}$.

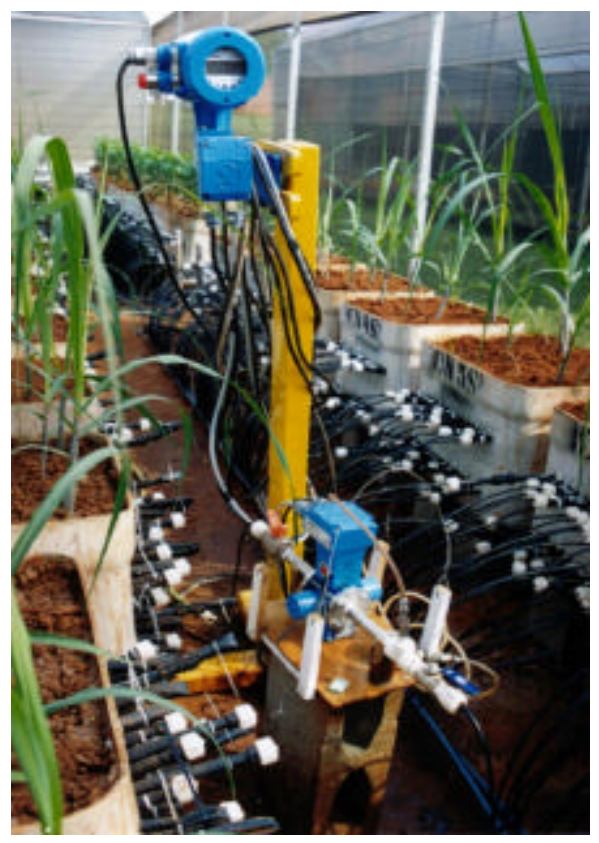

Figura 4 - Medidor de vazão, do tipo eletromagnético, utilizado no experimento

\subsubsection{Tratamento preventivo do entupimento de emissores de causa não-radicular}

Com o propósito de evitar a ocorrência de entupimento de emissores por causas outras que não a intrusão de raízes, a água utilizada nos experimentos foi oriunda do sistema de abastecimento urbano, o que reduziu a probabilidade de ocorrência de entupimento de causa biológica ou física; a análise de caracterização da água utilizada é apresentada na Tabela 4. 
Tabela 4. Caracterização química da água utilizada no experimento

\begin{tabular}{lcc}
\hline \multicolumn{1}{c}{ Parâmetro } & Unidade & Valor \\
\hline Alcalinidade $\left(2 \mathrm{CO}_{3}{ }^{2-}+\mathrm{HCO}_{3}^{-}\right)$ & $\mathrm{mg} \cdot \mathrm{L}^{-1}$ & 36,4 \\
Cloreto $\left(\mathrm{Cl}^{-}\right)$ & $\mathrm{mg} \cdot \mathrm{L}^{-1}$ & 8,1 \\
Nitrato $\left(\mathrm{N}^{-\mathrm{NO}^{-}}{ }_{3}\right)$ & $\mathrm{mg} \cdot \mathrm{L}^{-1}$ & 4,1 \\
Sulfato $\left(\mathrm{SO}_{4}{ }^{--}\right)$ & $\mathrm{mg} \cdot \mathrm{L}^{-1}$ & 48,1 \\
Fósforo $(\mathrm{P})$ & $\mathrm{mg} \cdot \mathrm{L}^{-1}$ & 0,16 \\
Nitrogênio amoniacal $\left(\mathrm{N}^{-} \mathrm{NH}_{3}^{+}\right)$ & $\mathrm{mg} \cdot \mathrm{L}^{-1}$ & 0,3 \\
Sódio $\left(\mathrm{Na}^{+}\right)$ & $\mathrm{mg} \cdot \mathrm{L}^{-1}$ & 8,9 \\
Potássio $\left(\mathrm{K}^{+}\right)$ & $\mathrm{mg} \cdot \mathrm{L}^{-1}$ & 3,4 \\
Cálcio $\left(\mathrm{Ca}{ }^{2+}\right)$ & $\mathrm{mg} \cdot \mathrm{L}^{-1}$ & 12,7 \\
Magnésio $\left(\mathrm{Mg}^{2+}\right)$ & $\mathrm{mg} \cdot \mathrm{L}^{-1}$ & 7,3 \\
Ferro $(\mathrm{Fe})$ & $\mathrm{mg} \cdot \mathrm{L}^{-1}$ & 0,2 \\
Cobre $(\mathrm{Cu})$ & $\mathrm{mg} \cdot \mathrm{L}^{-1}$ & 0,04 \\
Manganês $\left(\mathrm{Mn}^{2}\right)$ & $\mathrm{mg} \cdot \mathrm{L}^{-1}$ & 0,05 \\
Zinco $(\mathrm{Zn})$ & $\mathrm{mg} \cdot \mathrm{L}^{-1}$ & 0,03 \\
Cor & $\mathrm{PtCo}$ & 2,0 \\
Turbidez & $\mathrm{FTU}$ & 2,0 \\
Sedimentos & $\mathrm{mg} \cdot \mathrm{L}^{-1}$ & 19,0 \\
Condutividade elétrica & $\mathrm{mS} \mathrm{cm}$ & 0,16 \\
pH & $\mathrm{mg} \cdot \mathrm{L}^{-1}$ & 7,2 \\
Gás carbônico $\left(\mathrm{CO}_{2}\right)$ & $\mathrm{mg} \cdot \mathrm{L}^{-1}$ & 3,3 \\
Acidez $(\mathrm{CaCO}$ & $\mathrm{mg} \cdot \mathrm{L}^{-1}$ & 4,0 \\
Dureza total $\left(\mathrm{CaCO}_{3}\right)$ & $\mathrm{mg} \cdot \mathrm{L}^{-1}$ & 61,8 \\
\hline & &
\end{tabular}

Em cada linha de alimentação dos microtubos foi instalada uma válvula de lavagem, de modo que a cada irrigação se procedesse a limpeza da lateral, evitando com isso a acumulação de resíduo e posterior entupimento dos emissores. Com esse mesmo propósito e também visando permitir uma condição de dre nagem livre do solo, os vasos foram instalados acima do nível do solo da estufa, sobre blocos de cimento. Adicionalmente, também objetivando evitar a entrada de partículas finas de solo para o interior dos emissores, em face da ocorrência de pressões negativas por ocasião do esvaziamento das linhas de polietileno, uma válvula antivácuo foi instalada no cavalete de alimentação de água de cada tratamento. 


\subsection{Experimento sobre o efeito do vácuo no desempenho hidráulico de gotejadores na irrigação subsuperficial}

O experimento para avaliação do efeito da ocorrência de vácuo na malha hidráulica sobre o desempenho dos gotejadores foi conduzido após o término do experimento com a cultura do feijão, e fetuando-se o corte das plantas na base do caule e utilizando os gotejadores existentes - ou seja, os mesmos modelos utilizados para o experimento de intrusão radicular -, correspondentes à profundidade de instalação de $0,15 \mathrm{~m}(\mathrm{P} 15)$.

Os tratamentos consistiram da aplicação dos níveis de sucção de -26, -53 e -80 kPa. Após a aplicação de cada nível de tensão efetuava-se a leitura de vazão dos gotejadores Foram ainda consideradas como tratamento, as vazões dos gotejadores medidas anterior à aplicação da sucção (o que corresponde à última leitura de vazão do experimento de intrusão radicular com a cultura do feijão) e posterior à aplicação das tensões acima especificadas, após a execução de 3 irrigações de 1 h de duração, com intervalos de $1 \mathrm{~h}$ entre elas. Esse último tratamento objetivou avaliar o potencial de recuperação natural de vazão dos diferentes modelos, ou seja, sua característica de autolimpeza, frente ao efeito da sucção de particulados sólidos. Para efeito de apresentação, os tratamentos foram designados como: AS (Anterior ao primeiro nível de Sucção), -26, $-53,-80 \mathrm{kPa}$ e PI (Posterior às Irrigações). Os valores de vazão apresentados para cada modelo de gotejador correspondem à média de 18 repetições.

No início de cada seção de trabalho, o sistema de irrigação era ativado por um período de 1 hora, o suficiente para provocar a saturação do solo dos vasos (T1). Adicionalmente, antes da aplicação de cada nível de sucção e em cada vaso, a irrigação fera ativada por 10 minutos (T2), com o objetivo de simular o estado de saturação do solo adjacente ao orifício de saída de água do gotejador na situação de campo após um turno de irrigação. Em seguida, cada gotejador era conectado, através de um barrilete, a uma bomba de vácuo elétrica, equipada com vacuômetro, sendo ativada por 10 minutos com os níveis de sucção avaliados. Depois de finalizada a indução da sucção em cada um dos vasos, a leitura da vazão dos gotejadores era efetuada seguindo-se a mesma 
metodologia descrita no item 3.1.3. Os mesmos gotejadores receberam os tratamentos, efetuados estes em ordem crescente de valores de tensão. Esse procedimento acarretou a não-independência dos tratamentos, motivo pelo qual a estatística utilizada foi apenas descritiva.

O procedimento acima descrito foi utilizado com sucesso para aplicação dos níveis de sucção correspondentes aos tratamentos $-26 \mathrm{kPa}$ e $-53 \mathrm{kPa}$; para o tratamento -80 kPa, a bomba de vácuo utilizada foi incapaz de atingir esse nível de sucção com a utilização do barrilete, o qual permitia a indução da sucção simultânea em 14 gotejadores. Tal nível de sucção somente foi obtido com a aplicação individual de vácuo nos gotejadores, o que resultou na necessidade de reduzir o T2 para 3 minutos e a aplicação da sucção, por igual período.

Em consequiência dos resultados obtidos, decidiu-se incorporar 2 níveis de sucção, em valores inferiores ao mais baixo inicialmente estabelecido (-26 kPa). Dessa forma, seguindo metodologia idêntica à descrita para os tratamentos $-26,-53 \mathrm{e}-80 \mathrm{kPa}$, foram adicionados os tratamentos de -13 e - $20 \mathrm{kPa}$. Uma vez que, na primeira fase, cada gotejador recebeu todos os tratamentos em seqüência de ordem crescente, o que impossibilitaria a aplicação ulterior de um valor menor, foram utilizados os gotejadores instalados na profundidade $0,3 \mathrm{~m}$ dos vasos (tratamento P30 do experimento de intrusão radicular com a cultura do feijão). Da mesma forma, a aplicação da sucção foi efetuada em ordem crescente, ou seja, para cada gotejador aplicourse o nível de -13 kPa e após a leitura da vazão, o de $-20 \mathrm{kPa}$. 


\section{RESULTADOS}

A apresentação e discussão dos resultados de vazão serão conduzidas por experimento (cana-de-açúcar, feijão e efeito de vácuo). Em cada experimento, os modelos de gotejadores avaliados foram agrupados de acordo com a existência ou não da característica de compensação de vazão, sendo designados doravante como autocompensantes e não-compensantes, respectivamente. Os valores de vazão relativa, Qr, e os respectivos coeficientes de variação de vazão, CV, são apresentados nas Tabelas 5 a 8, para a cana-de-açúcar nos regimes de umidade de solo úmido e seco (CNU e CNS, respectivamente), nas Tabelas 11 a 14, para feijão nos regimes de umidade de solo úmido e seco (FJU e FJS, respectivamente) e nas Tabelas 15 e 16 para o tratamento sem cultivo (SC), todos nas duas profundidades de instalação do gotejador avaliadas (P15 e P30). Uma vez que os tratamentos são idênticos para os dois experimentos com cultura, optou-se por apresentar os resultados em separado para cada experimento e, depois, efetuar uma discussão conjunta sobre ambos.

A Figura 5 representa o potencial diário de água no solo no decorrer do experimento. Em resposta aos tratamentos de regime de umidade do solo, observa-se a alternância nos valores de potencial de água no solo para os tratamentos CNS e FJS, os quais variaram de 0 a $80 \mathrm{kPa}$, enquanto nos tratamentos CNU e FJU essa variação foi de 0 a $20 \mathrm{k} \mathrm{Pa}$. A partir de valores de potencial de $60 \mathrm{kPa}$, as plantas de cana e feijão apresentaram sintoma visual forte de déficit hídrico. Após a realização da irrigação, o desaparecimento do sintoma visual de déficit foi notado depois de aproximadamente 3 horas, para a cultura do feijão, e no dia seguinte à irrigação, na cultura da cana. 


\subsection{Experimento com a cultura da cana-de-açúcar}

\subsubsection{Gotejadores não-compensantes de pressão}

Fazem parte desse grupo os modelos AQ, CD, DI, HD, HG, TR e DL. A Figura 6 apresenta a evolução da vazão dos gotejadores não-compensantes ao longo do período do experimento. As Tabelas 5 a 8 apresentam os valores médios de vazão relativa, Qr, e do coeficiente de variação da amostra para os diversos tratamentos e ao longo do período do experimento ( $n=10$, exceto para 270 dias, onde $n=9$ ).

O efeito do enterrio na vazão dos diversos modelos pode ser avaliado com base no porcentual da vazão nominal, Qr, apresentada na primeira leitura, quando não são esperados efeitos dos fatores cultura e umidade do solo. Para a maior parte dos modelos, o efeito do enterrio foi reduzido, com variações de $\pm 3 \%$ da vazão nominal, para todos os modelos, sendo exceção o DI e o HD, os quais apresentaram variação de $\pm 9 \%$, mantendo tal comportamento até 90 dias após o início do experimento, quando os tratamentos começaram a mostrar efeitos mais evidentes. Os valores negativos representam, porcentualmente, uma vazão medida abaixo da nominal, enquanto os valores positivos, representam o oposto.

Também não foi observado, nesse momento, diferença significativa e tendência bem definida de comportamento entre as profundidades de instalação dos gotejadores.

Observa-se que, para a maior parte dos modelos, o efeito dos tratamentos somente tornou-se mais evidente a partir de 120 dias do início do experimento, com exceção apenas dos modelos HD, na posição P15, e TR, na posição P30, nos quais tal evidência se deu aos 90 dias, ambos para o tratamento Úmido (Figura 6). Para o presente caso, o aparecimento dos sintomas se deu em um período bem menor que aquele encontrado por Dalri et al. (2002), o qual trabalhando com fita gotejadora enterrada, observou declínio 


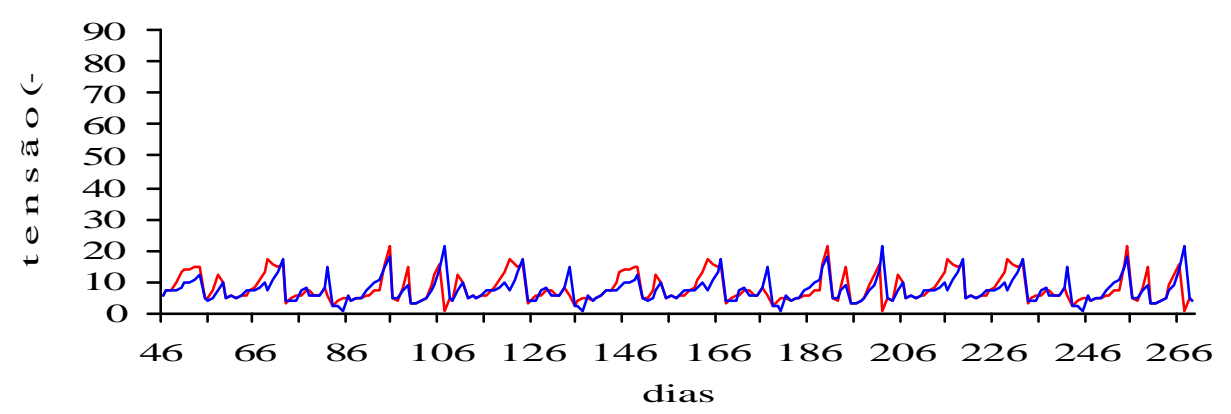

b
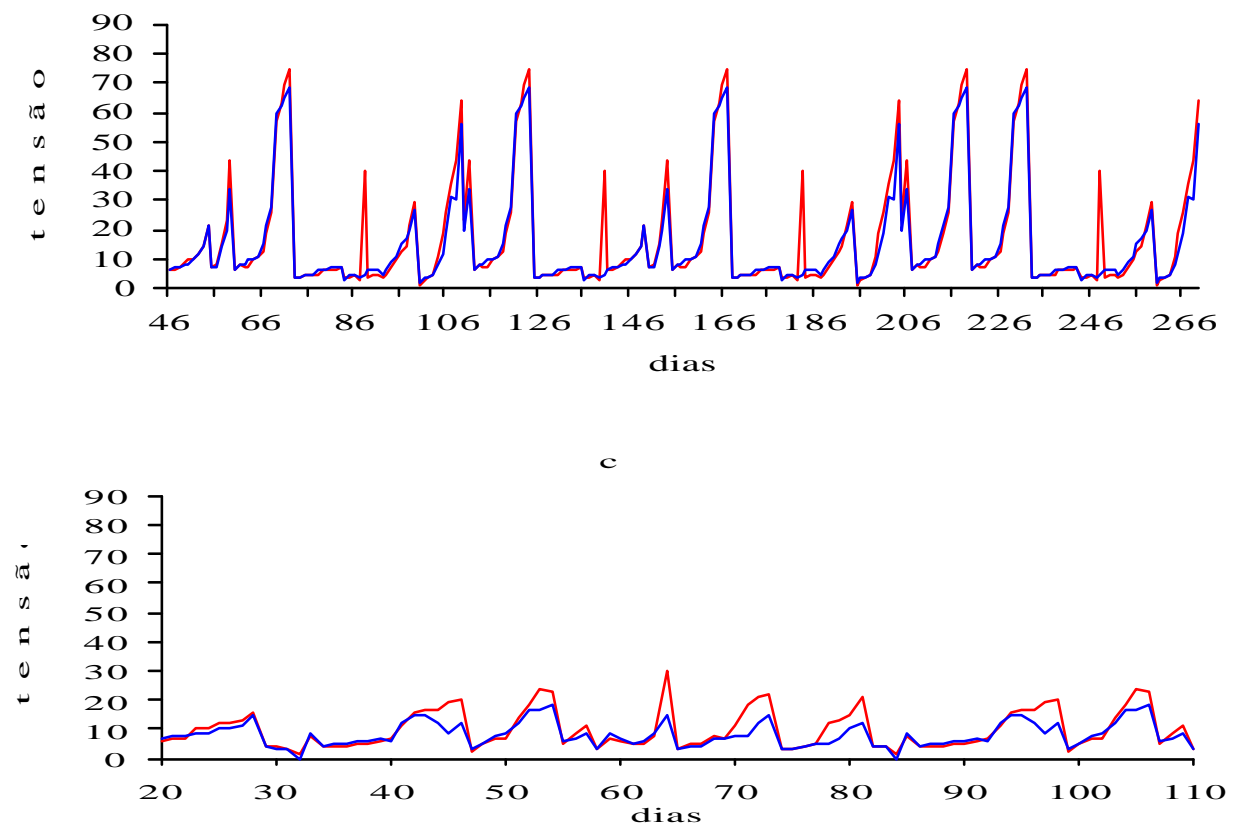

d

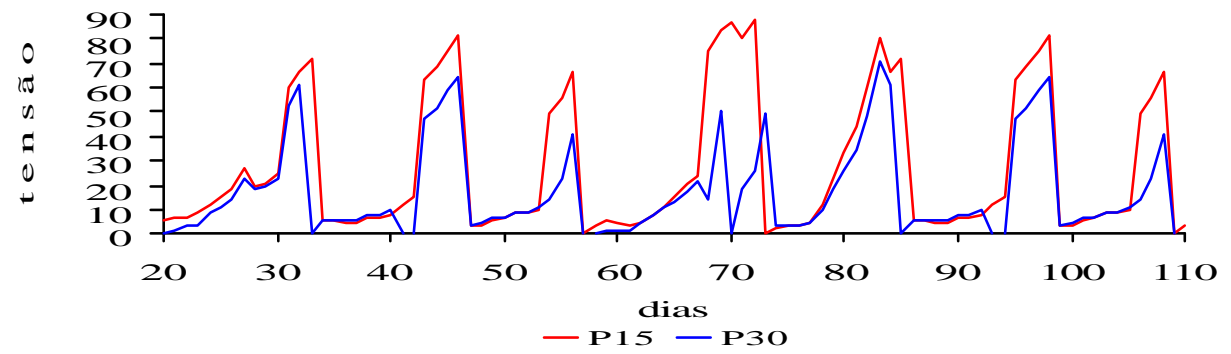

Figura 5 - Potencial da água no solo nos tratamentos Cana-Úmido (a), Cana-Seco (b), Feijão-Úmido (c) e Feijão Seco (d), para as profundidades P15 e P30 
dos valores de vazão e de coeficiente de uniformidade estatística - CUE, a partir de 240 dias do plantio da cana-de-açúcar nos emissores que não receberam aplicação do herbicida trifluralina. Essa diferença de tempo pode estar relacionada à maior densidade de raízes na condição do experimento, uma vez que as mesmas encontravam-se confinadas ao volume do vaso utilizado.

A detecção da intrusão de raízes nos gotejadores enterrados foi feita de maneira indireta (método não destrutivo), com base na variação de vazão dos gotejadores: diferença entre os valores de Qr na condição com cultivo e sem cultivo (SC). Essa assunção foi comprovada ao se incluir na análise estatística o tratamento SC, efetuar a análise de variância isolando o efeito do fator profundidade de instalação dos gotejadores e comparar as condições de enraizamento; essa análise resultou significativa para o fator condição de enraizamento nas duas profundidades de instalação dos gotejadores, sendo a média de Qr do tratamento SC superior, pelo teste de Tuckey a 5\% de probabilidade, à dos tratamentos Úmido e Seco, nas duas profundidades estudadas (Tabela 9). A interação modelo econdição de enraizamento se revelou significativa apenas na profundidade P15.

Considerando todo o período do experimento, o nível de redução de vazão dos gotejadores mostrouse diferenciado em função do regime de umidade do solo, para todos os modelos e nas duas profundidades de instalação do gotejador; o tratamento úmido resultou em maior redução de vazão, em relação ao seco, sendo exceção apenas o modelo DL, na profundidade P30.

As maiores diferenças foram, mais uma vez, observadas nos modelos AQ, CD e $\mathrm{HD}$, sendo essas de 30 (P30), 32 (P30) e 27 pontos prcentuais (P15); nos demais modelos, as maiores diferenças variaram de 7 a 9 pontos porcentuais. Para o modelo DL, como já dito, exceção à tendência citada acima, a diferença em favor do tratamento seco foi de 7 pontos porcentuais. Porém essas diferenças se reduziram no final do experimento; considerando todos os modelos e a Qr aos 270 dias, a análise de variância resultou não-significativa para todos os tratamentos de umidade do solo, além de que as 
médias de Qr para os tratamentos Úmido e Seco e SC foram idênticas, não diferindo, estatisticamente, nas profundidades P15 (76,4, 75,2 e 87,7\%, respectivamente) e P30 (75,8, 75,2 e 86,9\%, respectivamente), conforme apresentado na Tabela 9. Além disso, não foi observada interação significativa dos fatores modelo e profundidade de instalação do gotejador, para todas as condições de enraizamento avaliadas.

$\mathrm{O}$ efeito da profundidade de instalação não foi homogêneo para todos os gotejadores. Nos modelos AQ, CD e TR, o tratamento P30 apresentou os maiores níveis de redução de vazão, em relação ao tratamento P15, tendo ocorrido tanto no tratamento Úmido como no Seco, para os modelos AQ e TR; no modelo HG, esse comportamento se repetiu, embora com menor intensidade. Para o modelo $\mathrm{CD}$, no tratamento Seco não foi observado efeito da profundidade de instalação, enquanto o modelo HD mostrou comportamento oposto nos regimes úmido e seco, seguindo a tendência acima somente no regime seco.

O tratamento P15 apenas resultou em maior redução de vazão nos modelos HD e DL, no tratamento Úmido. A ocorrência do efeito da profundidade de instalação foi maior no solo com regime úmido, onde ocorreram as maiores diferenças de vazão relativa, Qr; considerando a última leitura, a diferença de Qr variou de 3 a 5 pontos porcentuais no tratamento Seco, enquanto para o tratamento Úmido essa diferença variou de 13 (AQ e TR) a 18 pontos porcentuais (CD). Do mesmo modo, para os gotejadores HD e DL, a diferença foi de 13 pontos porcentuais, tendo ocorrido somente no tratamento Úmido. Porém, quando considerando todos os modelos, a análise de variância resultou não-significativa para o efeito da profundidade, para todas as condições de umidade do solo avaliadas. Assim, não houve diferença significativa, no nível de 5\% de probabilidade, entre as médias dos tratamentos P15 e P30, para os tratamentos Úmido, Seco e Sem Cultivo.

O fator modelo de gotejador apresentou, aos 270 dias, variância significativa para todos os níveis de condição de enraizamento e profundidades avaliadas, mostrando que há diferenças entre os modelos de gotejadores avaliados quanto à suscetibilidade à intrusão de raízes. Isolando-se, seqüencialmente, o efeito do fator profundidade de instalação, déficit de umidade do solo e ambos conjuntamente (Tabela 9), a aplicação do 
teste de comparação de médias para cada um dos fatores do experimento revelou um grupo de gotejadores que se alternam entre si como de menor suscetibilidade à intrusão radicular, sendo esse formado pelos modelos HG, TR, DL e DI, e um segundo grupo, que se alternam como de maior suscetibilidade à intrusão, formado pelos modelos $\mathrm{AQ}$, CD e HD.

$\mathrm{Na}$ condição sem cultivo, tratamento SC, o modelo AQ apresenta desempenho idêntico aos modelos do primeiro grupo. A Figura 6 demonstra que essa classificação se aplica quando se consideram todas as épocas estudadas. Nos modelos AQ, CD e HD, os menores valores de $\mathrm{Qr}$ determinados na última leitura foram de 60\%, 56\% e 55\%, respectivamente, no tratamento Úmido e profundidade P30. O modelo HG mostrou o menor efeito da intrusão, com valor mínimo de Qr de 96\%, enquanto os modelos DI, DL e TR tiveram comportamento intermediário, com valores mínimos de $85 \%, 82 \%$ e $82 \%$ da vazão nominal, respectivamente.

A diferença de resposta entre os diversos modelos avaliados pode ser atribuída às diferenças na arquitetura dos emissores (Camp et al., 2000). Segundos esses autores, menores diâmetros de orifício tendem a ter menor possibilidade de intrusão de raízes, embora sejam mais susceptíveis ao entupimento por matéria particulada. Esse parâmetro de arquitetura, no entanto, não se mostra determinante, à luz dos resultados obtidos no presente experimento.

O coeficiente de variação, $\mathrm{CV}$, dos dados de vazão no início do experimento foi, para a maior parte dos modelos, abaixo de 5\%, revelando uma boa uniformidade dos gotejadores na condição de enterrio, embora considerando não se tratar de um testepadrão. Acompanhando o comportamento dos dados de vazão, os maiores incrementos nos valores CV ocorreram a partir dos 90-120 dias do início do experimento, tendo, também, predominantemente ocorrido no tratamento Úmido, onde a maioria dos modelos apresentou CV maior que 30\%. A profundidade de instalação do gotejador, por sua vez, não evidenciou diferenças tão marcantes quanto a umidade do solo. Os modelos 

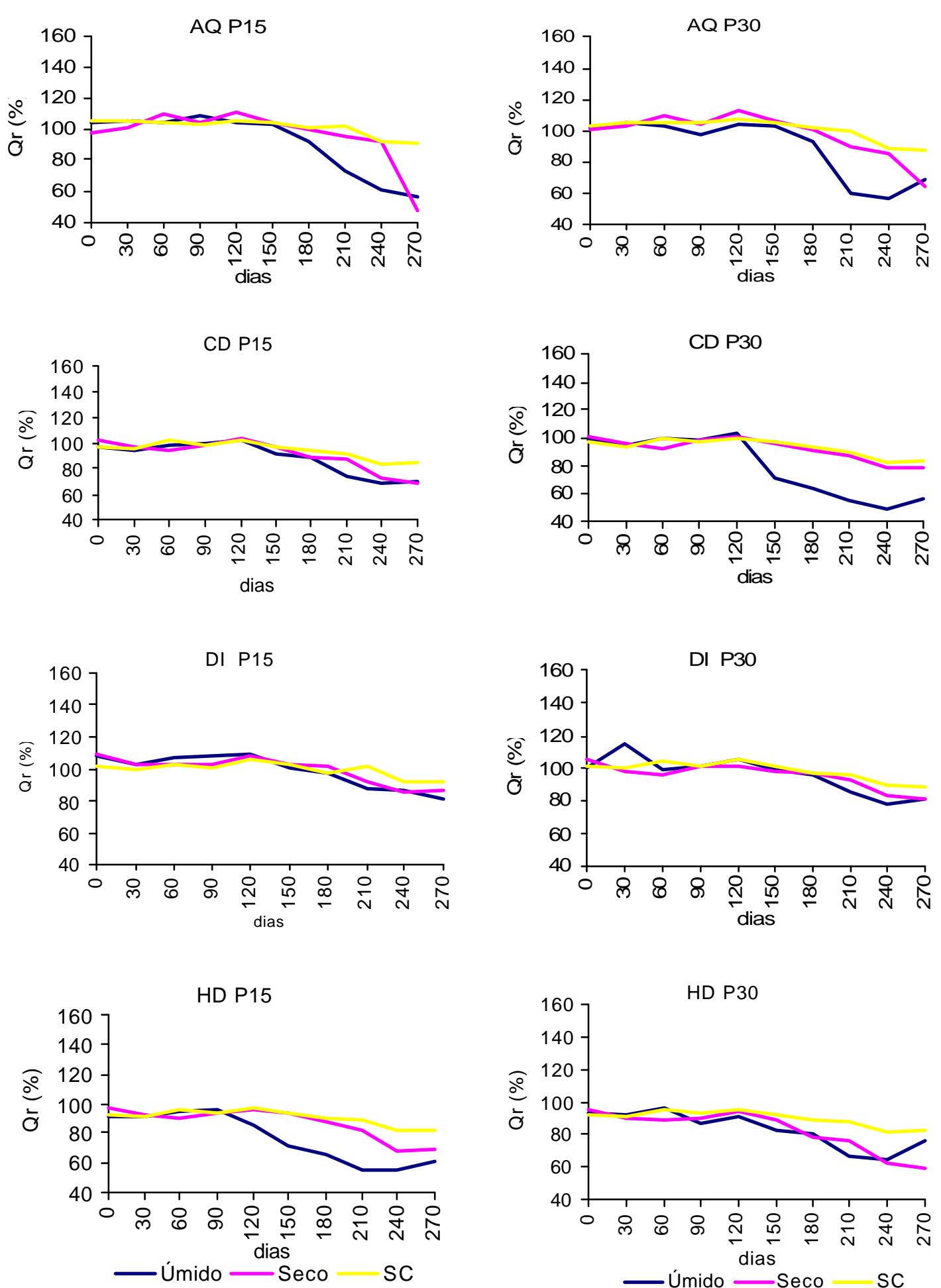

Figura 6 - Vazão relativa, Qr, ao longo do período do experimento, para gotejadores não compensantes de pressão no experimento com cana-de-açúcar 

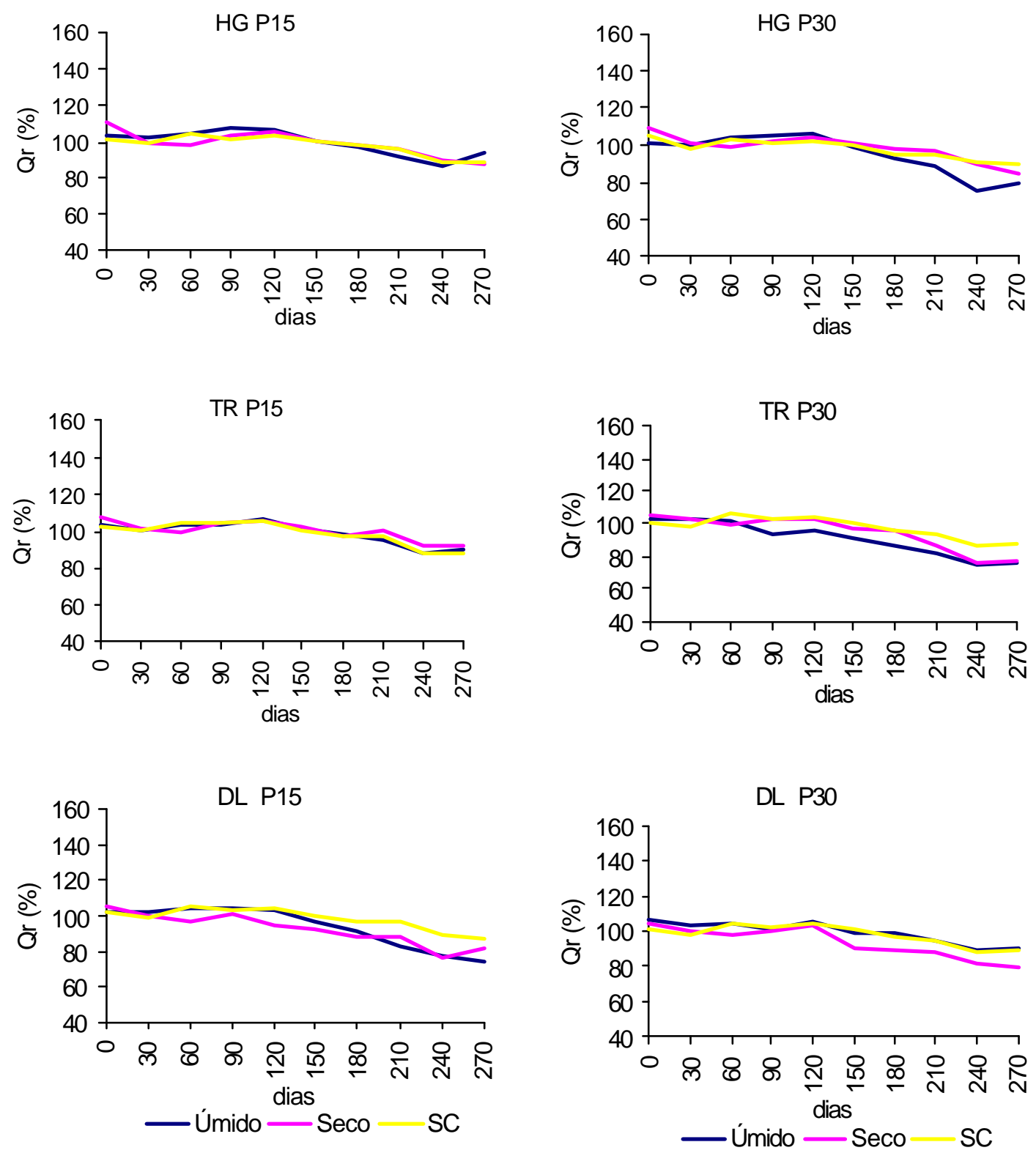

Figura 6 - Vazão relativa, Qr, ao longo do período do experimento, para gotejadores nãocompensantes de pressão no experimento com cana-de-açúcar

DI e HG apresentaram a maior uniformidade de vazão, com valores de CV mantendo-se próximos ou abaixo de $10 \%$ em todo o período do experimento, nas duas profundidades de instalação e nos dois regimes de umidade do solo estudados. Os modelos CD e HD, 
no tratamento Úmido, apresentaram os maiores níveis de variação de vazão, dentro de cada época de avaliação.

\subsubsection{Gotejadores autocompensantes de pressão}

Fazem parte desse grupo os modelos CP, DLP, DP, HP, NP, RM e VP. A Figura 7 apresenta a evolução da vazão desses modelos ao longo do experimento. As Tabelas 5 e 8 apresentam os valores médios de Qr para os diversos modelos e ao longo do período do experimento $(n=10$, exceto para a época de 270 dias, onde $n=9$ ).

A Tabela 10 apresenta o resultado da análise de variância e o teste de comparação de médias para esse grupo de gotejadores. Uma vez que a aplicação dos tratamentos resultou em um efeito duplo e oposto no parâmetro principal da análise, no caso, a vazão dos gotejadores, a realização de testes de comparação de médias não poderia definir o melhor modelo, uma vez que resultados extremos de Qr revelariam, igualmente, elevado grau de suscetibilidade aos tratamentos. Adicionalmente, deve-se levar em conta os elevados valores do coeficiente de variação da análise, que conduzem a elevados valores de diferença mínima significativa (DMS) para o teste de comparação de médias. Tal fato resulta que, mesmo diferenças que possam ser consideradas significativas na prática, não se revelam assim, estatisticamente. Esse fato é evidenciado quando da realização do teste de Tuckey para comparar modelos, ao se isolar os fatores condição de enraizamento e profundidade (Tabela 10). Essa linha de raciocínio é válida também para esse grupo de gotejadores, no experimento com a cultura do feijão.

Levando-se em conta as considerações acima e solando-se o efeito do fator profundidade de instalação, o teste $\mathrm{F}$ revelou-se significativo para a variância do fator modelo apenas na profundidade P15, não o sendo para o fator condição de enraizamento nem para a interação modelo versus condição de enraizamento, nas duas profundidades estudadas. Levando-se em conta todos os modelos, o teste de Tuckey não revelou diferença entre os tratamentos Úmido, Seco e Sem Cultivo, para as profundidades P15 e P30. De outro modo, isolando-se o efeito do fator condição de enraizamento, o teste $\mathrm{F}$ revelou-se significativo para a variância do fator modelo apenas nos tratamentos Seco e 
SC. Os fatores profundidade e a interação modelo versus profundidade resultaram em variância significativa apenas no tratamento SC. Levando-se em conta todos os modelos, o teste de Tuckey revelou diferença entre as duas profundidades apenas no Tratamento SC.

O efeito do enterrio na vazão dos gotejadores foi similar ao ocorrido no grupo dos gotejadores não-compensantes, resultando em variações de $3 \%$ a $5 \%$ da vazão nominal. No entanto os modelos DLP, NP e VP se destacaram: os dois primeiros por apresentarem vazões $7 \%$ a $12 \%$ acima da nominal e o último, $10 \%$ abaixo da nominal e mantendo tal tendência no decorrer do experimento.

O grupo dos emissores autocompensantes mostrou, no decorrer do experimento, além de maior instabilidade nas vazões medidas, magnitude de variação bem mais ampla, em relação ao grupo dos não-compensantes. Os efeitos dos tratamentos foram observados be m mais cedo, já a partir dos 30 a 60 dias do início do experimento, para a maior parte dos modelos nas profundidades de instalação estudadas.

Enquanto os modelos do grupo não-compensante mostraram uma tendência bem definida de redução de vazão, no período do experimento, o mesmo não foi observado para os gotejadores autocompensantes; os modelos CP, HP e NP apresentaram as maiores variações de vazão, com valores de Qr alcançando picos de 128\%, $182 \%$ e $134 \%$, respectivamente, enquanto os modelos DP e RM mostraram uma maior uniformidade de vazão ao longo do tempo, com tendência à redução de vazão no caso do primeiro (mínimo Qr de 85\%) e leve aumento para o segundo (máximo Qr de 111\%). Os modelos DLP e VP apresentaram comportamento diferenciado: o primeiro por uma acentuada elevação na vazão do tratamento Sem Cultivo e o segundo por manter, em todos os tratamentos avaliados, vazão inferior à nominal desde o início do experimento, com Qr de 90\%, e redução a partir de 150 dias. Tal comportamento sugere que esse modelo tenha seu desempenho hidráulico alterado pela condição de enterrio, o que 

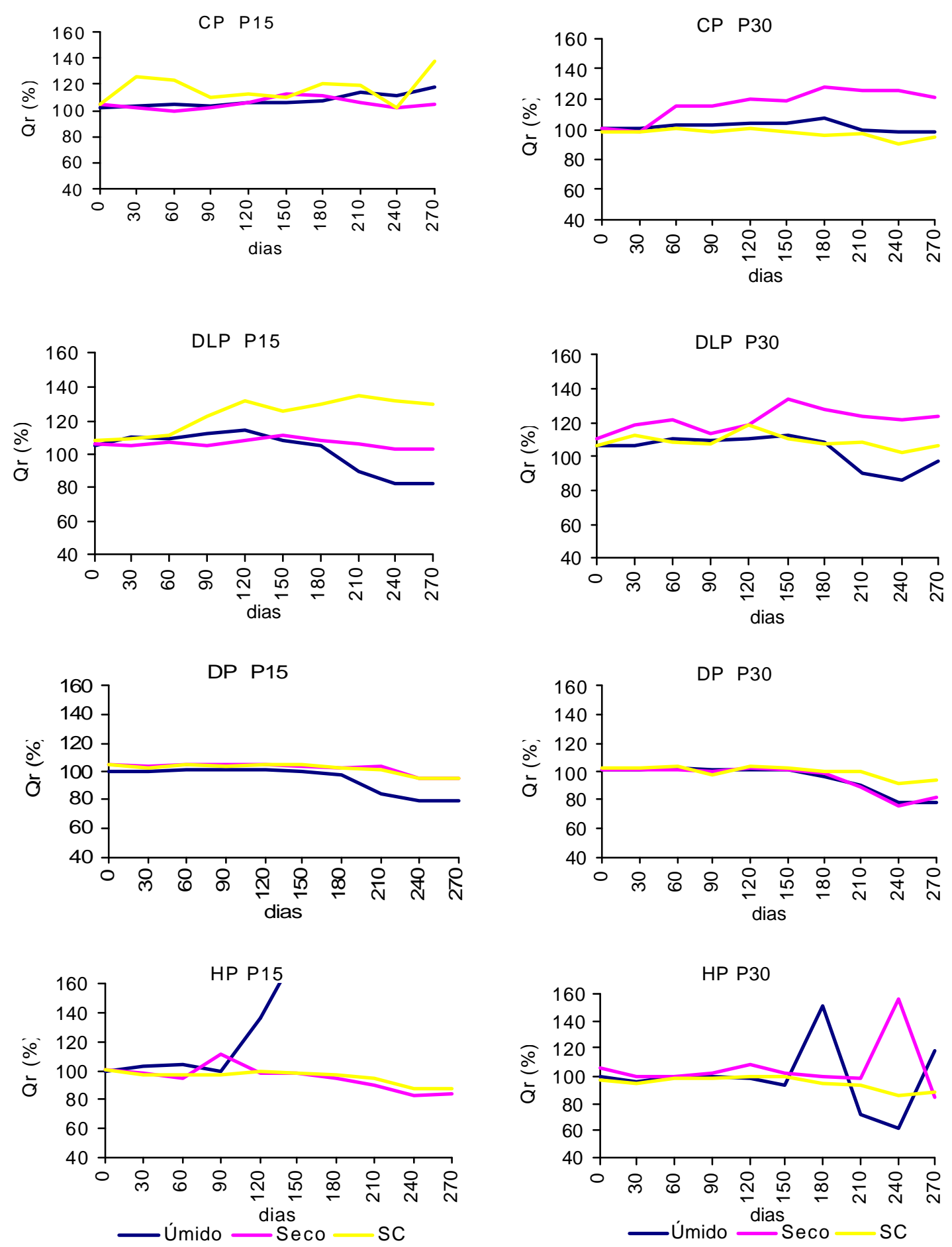

Figura 7 - Vazão relativa, Qr, ao longo do período do experimento, para gotejadores autocompensantes de pressão no experimento com cana-de-açúcar 

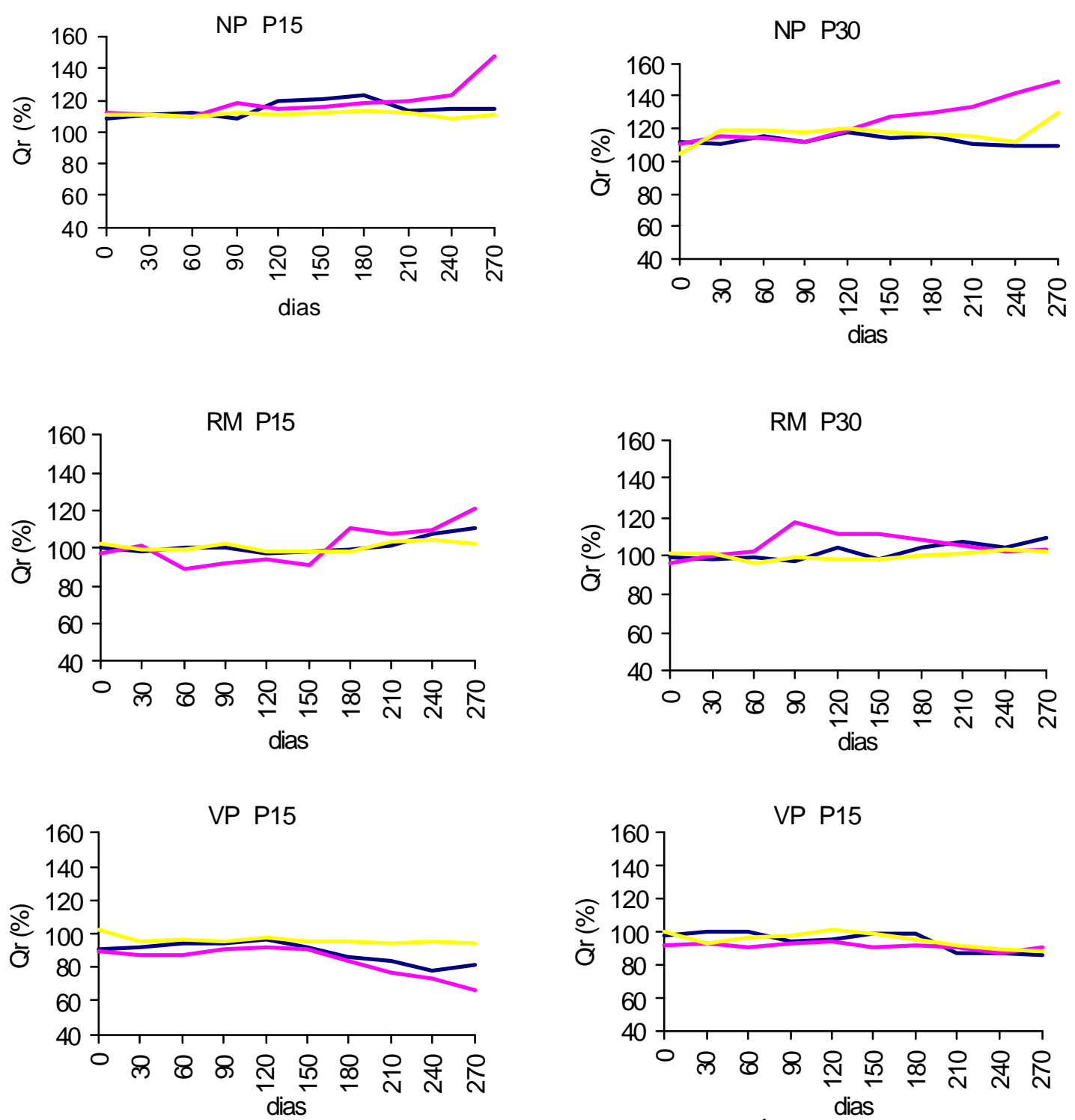

Figura 7 - Vazão relativa, Qr, ao longo do período do experimento, para gotejadores autocompensantes de pressão no experimento com cana-de-açúcar

pode estar relacionado à resistência oferecida pelo solo contra a pressão exercida pela água em uma esfera de borracha ; essa esfera tem função, segundo o fabricante, de vedar o canal de saída de água do gotejador quando da ocorrência de vácuo no interior da linha 
lateral, impedindo o succionamento de partículas de solo, o que afetaria o desempenho do gotejador.

Da mesma forma que observado para o fator modelo de gotejador, não houve, tendência bem definida do efeito do regime de umidade do solo na vazão. Os modelos CP, DLP, NP e RM, no tratamento Seco, produziram sobre-vazões, com valores máximos de Qr de 128\%, 134\%, 134\% e 118\%, respectivamente, na profundidade P30, embora, com exceção do NP, todos os demais tenham mostrado tendência de queda no final do período do experimento. No modelo HP, o maior incremento de vazão registrado, com Qr de 182\%, ocorreu no tratamento úmido; o modelo DP manteve maior regularidade na vazão, apresentando, até os 180 dias do início do experimento, Qr próximo a $100 \%$, quando houve um pequeno decréscimo, principalmente no tratamento Úmido; no modelo VP, a umidade do solo também não resultou em diferença significativa na Qr.

O efeito na vazão, como resultado da profundidade de instalação dos gotejadores, foi mais pronunciado no tratamento P30, embora, como os demais fatores, não tenha resultado em tendência tão bem definida. Essa profundidade resultou em maior variação de vazão nos modelos CP, DLP, DP e NP, todos no tratamento Seco. Para os modelos RM e HP, o comportamento das duas profundidades foi similar, enquanto somente no modelo VP o tratamento P15 resultou em variação de vazão levemente maior que o de P30.

Chama a atenção os elevados valores de Qr apresentados pelos modelos CP e DLP, na profundidade P15, e NP, na profundidade P30, no tratamento Sem Cultivo: em todos os modelos, a média das vazões foi influenciada por dois emissores (repetições) que apresentaram altos incrementos de vazão, a partir dos 30 ou 60 dias do início do experimento. Tais sobre-vazões, que variaram de $140 \%$ a $296 \%$ da vazão nominal, podem ter sido causadas pela entrada de partículas de solo no interior do gotejador ou por falha mecânica na membrana responsável pelo mecanismo de compensação da vaz̃o. A instalação de uma válvula antivácuo em cada cavalete correspondente ao tratamento de umidade do solo pode não ter sido efetivo a ponto de evitar, completamente, a ocorrência de vácuo. Metodologicamente, a instalação dos vasos em 
nível acima da linha de abastecimento de água aos gotejadores $(0,35$ a $0,50 \mathrm{~m})$, com a finalidade de minimizar e entrada de sedimentos nos tubos gotejadores e permitir a livre drenagem do excesso de água no solo do vaso, cria uma condição favorável à ocorrência de pressões negativas quando da interrupção da irrigação. Conforme apresentado no item 4.3.2, esses modelos, dentro do grupo dos emissores autocompensantes, estão entre os que apresentaram maior incidência de sobre-vazão como resultado da simulação de ocorrência de vácuo na malha hidráulica.

Como apresentado acima, os dados mostraram que nos gotejadores autocompensantes a magnitude das variações de vazão é bem maior que nos modelos não-compensantes; em algumas situações, como ocorreu, por exemplo no modelo HP, em que houve incremento individual de vazão de até $786 \%$, a variação de vazão ocorrida em apenas um emissor foi suficiente para resultar em incremento significativo do valor médio. Tal fato explica a diferença na magnitude das variações ocorridas entre os dois grupos de gotejadores. Foi também esse modelo que apresentou os maiores valores de CV, acima de $120 \%$, constatado no tratamento Úmido.

Embora os valores do CV observados no início do experimento tenham sido baixos e similares ao dos modelos não-compensantes, os gotejadores autocompensantes mostraram, de modo geral, valores de CV mais elevados ao longo da condução do trabalho. O modelo VP destacourse por apresentar, em todos os tratamentos e para todas as épocas de leitura de vazão, um elevado valor inicial de CV (média de 10\%), aumentando até o final do experimento, chegando a um valor médio de $28 \%$. O modelo DP, como já ocorrera com a vazão relativa, apresentou, até os 180 dias, os mais baixos valores de $\mathrm{CV}$, variando de $5,7 \%$ a $10,5 \%$. 
Tabela 5. Vazão relativa (Qr), em L.h ${ }^{-1}$, e coeficiente de variação de vazão (CV), em \%, dos gotejadores na cultura da cana-de-açúcar, na profundidade $\mathrm{P} 15$, no tratamento Úmido

\begin{tabular}{|c|c|c|c|c|c|c|c|c|c|c|c|c|c|c|c|c|c|c|c|c|c|c|c|c|c|c|c|c|}
\hline \multirow{2}{*}{ Dia } & \multicolumn{2}{|c|}{ AQ } & \multicolumn{2}{|c|}{$\mathrm{CD}$} & \multicolumn{2}{|c|}{$\mathrm{CP}$} & \multicolumn{2}{|c|}{ DI } & \multicolumn{2}{|c|}{$\overline{\text { DLP }}$} & \multicolumn{2}{|c|}{ DP } & \multicolumn{2}{|c|}{ HD } & \multicolumn{2}{|c|}{$\mathrm{HG}$} & \multicolumn{2}{|c|}{ HP } & \multicolumn{2}{|c|}{$\mathrm{NP}$} & \multicolumn{2}{|c|}{$\mathrm{RM}$} & \multicolumn{2}{|c|}{ TR } & \multicolumn{2}{|c|}{$\overline{\mathrm{DL}}$} & \multicolumn{2}{|c|}{$\mathrm{VP}$} \\
\hline & Qr & $\mathrm{CV}$ & $\mathrm{Qr}$ & $\mathrm{CV}$ & $\mathrm{Qr}$ & $\overline{C V}$ & $\mathrm{Qr}$ & $\mathrm{CV}$ & Qr & $\mathrm{CV}$ & $\overline{Q r}$ & $\mathrm{CV}$ & Qr & $\mathrm{CV}$ & Qr & $\mathrm{CV}$ & $\mathrm{Qr}$ & $\mathrm{CV}$ & $\mathrm{Qr}$ & $\mathrm{CV}$ & $\mathrm{Qr}$ & $\mathrm{CV}$ & Qr & $\mathrm{CV}$ & $\mathrm{Qr}$ & $\mathrm{CV}$ & Qr & $\mathrm{CV}$ \\
\hline 0 & 103 & 6,3 & 96 & 4,5 & 102 & 2,8 & 107 & 6,7 & 104 & 4,1 & 100 & 7,2 & 91 & 3,3 & 103 & 6,0 & 99 & 6,0 & 108 & 4,9 & 100 & 4,7 & 104 & 2,1 & 101 & 4,5 & 90 & 9,7 \\
\hline 30 & 100 & 5,2 & 94 & 7,9 & 103 & 7,1 & 103 & 9,0 & 110 & 15,5 & 100 & 5,9 & 91 & 5,1 & 102 & 6,3 & 103 & 6,3 & 110 & 3,5 & 98 & 3,5 & 101 & 5,2 & 101 & 6,3 & 91 & 17,3 \\
\hline 60 & 104 & 4,6 & 98 & 4,8 & 105 & 4,2 & 106 & 6,6 & 109 & 10,6 & 102 & 6,4 & 94 & 4,1 & 104 & 6,5 & 103 & 6,5 & 112 & 3,9 & 100 & 6,4 & 103 & 4,8 & 104 & 4,7 & 94 & 9,4 \\
\hline 90 & 109 & 4,4 & 100 & 6,1 & 104 & 4,4 & 107 & 7,3 & 111 & 15,9 & 102 & 5,5 & 96 & 6,7 & 108 & 4,7 & 100 & 4,7 & 108 & 4,3 & 100 & 7,9 & 104 & 3,1 & 104 & 3,3 & 94 & 17,4 \\
\hline 120 & 105 & 3,7 & 101 & 6,6 & 106 & 5,5 & 110 & 7,4 & 114 & 16,1 & 101 & 5,1 & 86 & 36,0 & 106 & 4,9 & 136 & 4,9 & 120 & 12,3 & 97 & 6,4 & 107 & 4,0 & 103 & 5,6 & 96 & 14,7 \\
\hline 150 & 103 & 11,9 & 92 & 5,8 & 106 & 5,6 & 101 & 4,3 & 109 & 11,5 & 99 & 5,9 & 72 & 50,2 & 100 & 4,3 & 181 & 4,3 & 120 & 12,9 & 98 & 3,8 & 101 & 5,0 & 97 & 11,9 & 91 & 24,9 \\
\hline 180 & 91 & 21,0 & 89 & 7,8 & 108 & 19,7 & 97 & 5,4 & 105 & 13,8 & 7 & 6,2 & 66 & 53,4 & 96 & 3,7 & 182 & 3,7 & 123 & 17,8 & 99 & 6,6 & 99 & 3,6 & 91 & 27,1 & 85 & 36,7 \\
\hline 210 & 73 & 35,2 & 74 & 32,2 & 113 & 38,0 & 88 & 9,4 & 89 & 31,9 & 85 & 34,8 & 55 & 74,3 & 92 & 4,8 & 168 & 4,8 & 112 & 9,0 & 101 & 5,6 & 95 & 3,8 & 82 & 41,3 & 83 & 37,0 \\
\hline 240 & 61 & 37,3 & 68 & 29,3 & 112 & 42,2 & 87 & 25,1 & 82 & 33,1 & 80 & 36,0 & 55 & 57,9 & 86 & 7,4 & 170 & 09,7 & 114 & 10,9 & 108 & 21,1 & 87 & 4,7 & 77 & 43,2 & 78 & 38,0 \\
\hline 270 & 56 & 44,3 & 70 & 28,6 & 117 & 45,3 & 81 & 10,5 & 82 & 31,7 & 79 & 38,5 & 61 & 47,3 & 94 & 13,4 & 187 & 118, & 114 & 12,2 & 111 & 18,1 & 89 & 6,5 & 74 & 44,6 & 82 & 38,3 \\
\hline
\end{tabular}


Tabela 6. Vazão relativa (Qr), em L.h ${ }^{-1}$, e coeficiente de variação de vazão (CV), em \%, dos gotejadores na cultura da cana-de-açúcar, na profundidade $\mathrm{P} 30$ e no tratamento Úmido

\begin{tabular}{|c|c|c|c|c|c|c|c|c|c|c|c|c|c|c|c|c|c|c|c|c|c|c|c|c|c|c|c|c|}
\hline \multirow[t]{2}{*}{ Dia } & \multicolumn{2}{|c|}{ AQ } & \multicolumn{2}{|c|}{$\mathrm{CD}$} & \multicolumn{2}{|c|}{$\mathrm{CP}$} & \multicolumn{2}{|c|}{ DI } & \multicolumn{2}{|c|}{ DLP } & \multicolumn{2}{|c|}{ DP } & \multicolumn{2}{|c|}{ HD } & \multicolumn{2}{|c|}{$\mathrm{HG}$} & \multicolumn{2}{|c|}{ HP } & \multicolumn{2}{|c|}{ NP } & \multicolumn{2}{|c|}{$\mathrm{RM}$} & \multicolumn{2}{|c|}{ TR } & \multicolumn{2}{|c|}{$\mathrm{DL}$} & \multicolumn{2}{|c|}{ VP } \\
\hline & $\mathrm{Qr}$ & $\mathrm{CV}$ & $\mathrm{Qr}$ & $\mathrm{CV}$ & $\mathrm{Qr}$ & $\mathrm{CV}$ & $\mathrm{Qr}$ & $\mathrm{CV}$ & $\mathrm{Qr}$ & $\mathrm{CV}$ & $\mathrm{Qr}$ & $\mathrm{CV}$ & $\mathrm{Qr}$ & $\mathrm{CV}$ & $\mathrm{Qr}$ & $\mathrm{CV}$ & $\mathrm{Qr}$ & $\mathrm{CV}$ & $\mathrm{Qr}$ & $\mathrm{CV}$ & $\mathrm{Qr}$ & $\mathrm{CV}$ & $\mathrm{Qr}$ & $\mathrm{CV}$ & $\mathrm{Qr}$ & $\mathrm{CV}$ & $\mathrm{Qr}$ & $\mathrm{CV}$ \\
\hline 0 & 103 & 4,9 & 98 & 6,3 & 100 & 3,2 & 100 & 7,4 & 106 & 6,3 & 102 & 8,3 & 93 & 5,5 & 101 & 2,9 & 106 & 5,7 & 112 & 4,6 & 99 & 4,6 & 103 & 2,6 & 107 & 4,4 & 97 & 11,4 \\
\hline 30 & 105 & 2,8 & 94 & 7,2 & 101 & 4,2 & 115 & 47,2 & 107 & 6,8 & 101 & 7,2 & 92 & 6,1 & 99 & 4,8 & 96 & 5,8 & 110 & 5,8 & 98 & 2,9 & 102 & 5,3 & 103 & 6,8 & 100 & 10,8 \\
\hline 60 & 103 & 5,4 & 100 & 3,8 & 103 & 3,0 & 99 & 3,9 & 111 & 14,2 & 102 & 8,8 & 97 & 5,0 & 104 & 5,3 & 99 & 8,2 & 116 & 8,0 & 99 & 4,3 & 101 & 18,9 & 104 & 3,5 & 99 &, 2 \\
\hline 90 & 97 & 31,5 & 99 & 5,5 & 103 & 6,4 & 101 & 2,4 & 110 & 11,9 & 102 & 8,4 & 86 & 35,6 & 105 & 2,5 & 99 & 6,4 & 113 & 4,7 & 97 & 61 & 93 & 35,5 & 101 & 4 & 94 & 6,8 \\
\hline 120 & 104 & 6,0 & 103 & 5,6 & 104 & 8,4 & 105 & 7,7 & 110 & 10,7 & 101 & 6,9 & 91 & 5,7 & 106 & 4,0 & 98 & 4,6 & 118 & 12,0 & 104 & 18,0 & 95 & 35,5 & 105 & 4,0 & 95 & ,3 \\
\hline 150 & 103 & 4,1 & 71 & 55,5 & 105 & 11,7 & 99 & 3,7 & 112 & 25,4 & 100 & 7,7 & 83 & 29,5 & 99 & 5,4 & 94 & 7,2 & 114 & 9,7 & 98 & 4,9 & 91 & 35,5 & 99 & 2,5 & 98 & 6,6 \\
\hline 180 & 94 & 6,7 & 63 & 62,5 & 107 & 26,4 & 96 & 9,2 & 108 & 51,1 & 96 & 10,5 & 80 & 32,8 & 93 & 7,8 & 151 & 132,7 & 116 & 10,8 & 104 & 7,0 & 86 & 35,2 & 99 & 1,6 & 98 & 3,4 \\
\hline 210 & 60 & 55,2 & 56 & 72,7 & 100 & 20,7 & 85 & 8,5 & 89 & 42,6 & 90 & 17,8 & 67 & 54,3 & 88 & 9,6 & 72 & 36,6 & 110 & 6,3 & 107 & 12,9 & 82 & 35,8 & 95 & 3,2 & 87 & 31,6 \\
\hline 240 & 56 & 55,1 & 49 & 77,8 & 98 & 34,3 & 78 & 14,4 & 86 & 14,8 & 78 & 35,1 & 65 & 52,9 & 75 & 26,1 & 61 & 62,4 & 109 & 5,1 & 104 & 5,6 & 75 & 37,8 & 90 & 2,5 & 87 & 14,3 \\
\hline 270 & 69 & 40,1 & 56 & 69,4 & 98 & 36,5 & 81 & 13,0 & 97 & 11,7 & 78 & 36,3 & 77 & 18,5 & 80 & 15,6 & 118 & 130,0 & 109 & 9,6 & 109 & 8,1 & 76 & 39,7 & 90 & 2,7 & 86 & 12,4 \\
\hline
\end{tabular}


Tabela 7. Vazão relativa (Qr), em L.h ${ }^{-1}$, e coeficiente de variação de vazão (CV), em \%, dos gotejadores na cultura da cana-de-açúcar,

na profundidade $\mathrm{P} 15$ e tratamento Seco

\begin{tabular}{|c|c|c|c|c|c|c|c|c|c|c|c|c|c|c|c|c|c|c|c|c|c|c|c|c|c|c|c|c|}
\hline \multirow[t]{2}{*}{ Dia } & \multicolumn{2}{|c|}{$\mathrm{AQ}$} & \multicolumn{2}{|c|}{$\mathrm{CD}$} & \multicolumn{2}{|c|}{$\mathrm{CP}$} & \multicolumn{2}{|c|}{ DI } & \multicolumn{2}{|c|}{ DLP } & \multicolumn{2}{|c|}{ DP } & \multicolumn{2}{|c|}{$\mathrm{HD}$} & \multicolumn{2}{|c|}{$\mathrm{HG}$} & \multicolumn{2}{|c|}{$\mathrm{HP}$} & \multicolumn{2}{|c|}{ NP } & \multicolumn{2}{|c|}{ RM } & \multicolumn{2}{|c|}{$\mathrm{TR}$} & \multicolumn{2}{|c|}{$\mathrm{DL}$} & \multicolumn{2}{|c|}{$\mathrm{VP}$} \\
\hline & $\mathrm{Qr}$ & $\mathrm{CV}$ & $\mathrm{Qr}$ & $\mathrm{CV}$ & $\mathrm{Qr}$ & $\mathrm{CV}$ & $\mathrm{Qr}$ & $\mathrm{CV}$ & $\mathrm{Qr}$ & $\mathrm{CV}$ & $\mathrm{Qr}$ & $\mathrm{CV}$ & $\mathrm{Qr}$ & $\mathrm{CV}$ & $\mathrm{Qr}$ & $\mathrm{CV}$ & $\mathrm{Qr}$ & $\mathrm{CV}$ & $\mathrm{Qr}$ & $\mathrm{CV}$ & $\mathrm{Qr}$ & $\mathrm{CV}$ & $\mathrm{Qr}$ & $\mathrm{CV}$ & $\mathrm{Qr}$ & $\mathrm{CV}$ & $\mathrm{Qr}$ & $\overline{\mathrm{CV}}$ \\
\hline 0 & 98 & 3,0 & 101 & 2,6 & 104 & 5,4 & $\begin{array}{ll}109 \\
\end{array}$ & 4,4 & 107 & 5,0 & 105 & 7,1 & 98 & 2,9 & 110 & 9,7 & 100 & 6,0 & 112 & 4,0 & 97 & 4,2 & 107 & 3,8 & 104 & 2,6 & 89 & 7,9 \\
\hline 30 & 101 & 1,4 & 96 & 4,2 & 102 & 3,8 & 102 & 3,1 & 106 & 5,6 & 103 & 5,8 & 92 & 3,5 & 100 & 2,8 & 99 & 3,1 & 111 & 3,6 & 101 & 6,9 & 101 & 3,2 & 99 & 4,9 & 87 & 10,5 \\
\hline 60 & 109 & 2,5 & 93 & 4,0 & 101 & 5,2 & 103 & 2,9 & 107 & 7,0 & 104 & 6,6 & 90 & 4,1 & 98 & 4,6 & 95 & 4,5 & 109 & 3,4 & 89 & 35,7 & 100 & 3,4 & 96 & 5,2 & 87 & 7,1 \\
\hline 90 & 104 & 2,1 & 98 & 4,8 & 102 & 6,5 & 103 & 3,5 & 104 & 5,5 & 104 & 5,0 & 93 & 4,3 & 103 & 2,9 & 111 & 39,0 & 119 & 26,5 & 92 & 20,3 & 104 & 2,0 & 101 & 3,8 & 90 & 9,5 \\
\hline 120 & 112 & 2,7 & 103 & 6,0 & 106 & 1 & 108 & 6,1 & 108 & 5,4 & 105 & 5,0 & 96 & 5,7 & 106 & 5,3 & 99 & 2,5 & 114 & 3,9 & 94 & 18,5 & 105 & 3,7 & 94 & 29,6 & 92 & 9,3 \\
\hline 150 & 105 & 1,7 & 96 & 4,0 & 113 & 25,2 & 103 & 3,6 & 111 & 12,4 & 104 & 5,7 & 93 & 2,8 & 101 & 1,7 & 98 & 4,8 & 116 & 11,6 & 91 & 22,5 & 102 & 1,8 & 92 & 23,3 & 91 & 13,1 \\
\hline 180 & 100 & 4,2 & 90 & 5,1 & 112 & 24,3 & 101 & 5,2 & 108 & 17,1 & 102 & 5,7 & 88 & 3,8 & 97 & 1,8 & 95 & 10,3 & 118 & 13,3 & 111 & 56,5 & 97 & 1,6 & 88 & 27,9 & 84 & 17,6 \\
\hline 210 & 95 & 9,4 & 87 & 12,4 & 106 & 16,8 & 92 & 11,5 & 106 & 11,6 & 103 & 6,0 & 82 & 17,0 & 96 & 3,1 & 91 & 23,1 & 120 & 20,8 & 107 & 54,2 & 100 & 5,6 & 88 & 35,3 & 77 & 42,9 \\
\hline 240 & 92 & 8,8 & 72 & 26,9 & 102 & 19,4 & 85 & 17,6 & 102 & 15,0 & 95 & 5,0 & 68 & 38,7 & 90 & 6,0 & 83 & 23,8 & 123 & 23,7 & 110 & 51,3 & 91 & 5,6 & 76 & 38,1 & 73 & 49,3 \\
\hline 270 & 48 & 61,9 & 69 & 35,8 & 105 & 20,4 & 86 & 12,3 & 103 & 15,5 & 94 & 4,3 & 69 & 39,2 & 88 & 2,8 & 84 & 25,8 & 148 & 70,2 & 121 & 47,7 & 92 & 6,5 & 82 & 23,2 & 66 & 51,5 \\
\hline
\end{tabular}


Tabela 8. Vazão relativa (Qr), em L.h ${ }^{-1}$, e coeficiente de variação de vazão (CV), em \%, dos gotejadores na cultura da cana-de-açúcar, na profundidade $\mathrm{P} 30$ e tratamento Seco

\begin{tabular}{|c|c|c|c|c|c|c|c|c|c|c|c|c|c|c|c|c|c|c|c|c|c|c|c|c|c|c|c|c|}
\hline \multirow[t]{2}{*}{ Dia } & \multicolumn{2}{|c|}{$\overline{A Q}$} & \multicolumn{2}{|c|}{$\mathrm{CD}$} & \multicolumn{2}{|c|}{$\mathrm{CP}$} & \multicolumn{2}{|c|}{$\overline{\mathrm{DI}}$} & \multicolumn{2}{|c|}{ DLP } & \multicolumn{2}{|c|}{ DP } & \multicolumn{2}{|c|}{ HD } & \multicolumn{2}{|c|}{$\mathrm{HG}$} & \multicolumn{2}{|c|}{$\mathrm{HP}$} & \multicolumn{2}{|c|}{$\mathrm{NP}$} & \multicolumn{2}{|c|}{$\mathrm{RM}$} & \multicolumn{2}{|c|}{ TR } & \multicolumn{2}{|c|}{$\mathrm{DL}$} & \multicolumn{2}{|c|}{ VP } \\
\hline & $\mathrm{Qr}$ & $\mathrm{CV}$ & $\mathrm{Qr}$ & $\mathrm{CV}$ & $\mathrm{Qr}$ & $\mathrm{CV}$ & $\mathrm{Qr}$ & $\mathrm{CV}$ & $\mathrm{Qr}$ & $\mathrm{CV}$ & $\mathrm{Qr}$ & $\mathrm{CV}$ & $\mathrm{Qr}$ & $\mathrm{CV}$ & $\mathrm{Qr}$ & $\mathrm{CV}$ & $\mathrm{Qr}$ & $\mathrm{CV}$ & $\mathrm{Qr}$ & $\mathrm{CV}$ & $\mathrm{Qr}$ & $\mathrm{CV}$ & $\mathrm{Qr}$ & $\mathrm{CV}$ & $\mathrm{Qr}$ & $\mathrm{CV}$ & $\mathrm{Qr}$ & $\mathrm{CV}$ \\
\hline 0 & 100 & 3,0 & 101 & 2,5 & 100 & 4,0 & 105 & 6,0 & 110 & 9,4 & 102 & 5,1 & 96 & 5,8 & 109 & 6,6 & 106 & 10,0 & 110 & 3,2 & 96 & 4,7 & 105 & 1,8 & 104 & 3,7 & 91 & 11,9 \\
\hline 30 & 103 & 1,6 & 96 & 2,9 & 98 & 5,4 & 98 & 5,6 & 119 & 16,0 & 100 & 5,7 & 91 & 3,9 & 100 & 4,4 & 99 & 10,0 & 116 & 15,8 & 100 & 6,1 & 104 & 12,7 & 100 & 4,0 & 92 & 10,2 \\
\hline 60 & 110 & 2,1 & 93 & 6 & 115 & 32,7 & 96 & 5,8 & 121 & 4 & 100 & 7,5 & 90 & 6,1 & 98 & 9 & 100 & 4,6 & 15 &, 7 & 102 & 57 & 99 & ,7 & 98 & 3,4 & 90 & 0 \\
\hline 90 & 104 & 1,3 & 98 & 4,3 & 115 & 34,3 & 101 & 3,3 & 114 & 13,6 & 99 & 8,9 & 90 & 4,1 & 102 & 3,7 & 102 & 20,1 & 113 & 9,6 & 118 & 44,3 & 103 & 3,3 & 100 & 4,2 & 93 & 10,5 \\
\hline 120 & 113 & 2,0 & 101 & 4,0 & 121 & 31,2 & 102 & 11,3 & 119 & 43,9 & 102 & 4,9 & 94 & 5,3 & 104 & 4,2 & 109 & 27,3 & 119 & 12,0 & 110 & 31,9 & 103 & 10,1 & 104 & 4,5 & 94 & 9,2 \\
\hline 150 & 106 & 2,8 & 96 & 4,5 & 119 & 31,7 & 99 & 8,5 & 154 & 54,6 & 107 & 4,4 & 90 & 1,9 & 101 & 3,4 & 106 & 16,0 & 27 & 32,3 & 111 & 35,6 & 97 & 6,5 & 91 & 30,8 & 90 & 9,9 \\
\hline 180 & 100 & 1,3 & 91 & 5,2 & 128 & 39,1 & 97 & 7,7 & 127 & 51,3 & 90 & 5,8 & 8 & 35,3 & 98 & 9,9 & 100 & 31,0 & 30 & 42,1 & 108 & 23,2 & 95 & 10,4 & 89 & 22,2 & 92 & 13,0 \\
\hline 210 & 90 & 17,9 & 88 & ,6 & 125 & 37,7 & 92 & 7,0 & 124 & 7,0 & 88 & 33,5 & 77 & 35,5 & 97 & 5,7 & 98 & 22,7 & 134 & 44,6 & 105 & 11,5 & 87 & 30,0 & 88 & 29,4 & 91 & 12,6 \\
\hline 240 & 86 & 20,1 & 79 & 12,9 & 125 & 39,0 & 83 & 11,3 & 122 & 51,6 & 76 & 40,0 & 2 & 53,0 & 89 & 12,0 & 156 & 49 & 1 & 52,6 & 102 & 20,5 & 77 & 37,4 & 81 & 32,4 & 87 & 9,2 \\
\hline 270 & 65 & 46,1 & 79 & 10,5 & 122 & 42,5 & 81 & 18,7 & 124 & 54,0 & 81 & 38,1 & 59 & 57,2 & 85 & 10,6 & 84 & 40,4 & 148 & 62,8 & 103 & 23,8 & 78 & 38,9 & 79 & 37,6 & 90 & 9,3 \\
\hline
\end{tabular}


Tabela 9. Resultados da análise de variância e teste de comparação de médias para os dados de vazão relativa (Qr), em L.h ${ }^{-1}$, dos gotejadores não-compensantes, aos 270 dias do início do experimento, na cultura da cana-de-açúcar

\begin{tabular}{|c|c|c|c|c|c|c|c|c|c|c|c|}
\hline \multirow[t]{2}{*}{ Fonte de Variação } & \multirow[t]{2}{*}{$\mathrm{P} 15$} & \multirow{2}{*}{ P30 } & \multirow[t]{2}{*}{ ÚMIDO } & \multirow[t]{2}{*}{ SECO } & \multirow{2}{*}{$\mathrm{SC}$} & \multicolumn{2}{|c|}{ ÚMIDO } & \multicolumn{2}{|c|}{ SECO } & \multicolumn{2}{|c|}{$\mathrm{SC}$} \\
\hline & & & & & & $\mathrm{P} 15$ & $\mathrm{P} 30$ & $\mathrm{P} 15$ & $\mathrm{P} 30$ & $\mathrm{P} 15$ & $\mathrm{P} 30$ \\
\hline 1.Isolando PROF & & & & & & & & & & & \\
\hline Modelo (M OD) & $9,7 * *$ & $2,4^{*}$ & & & & & & & & & \\
\hline C.Enraiz. (CE) & $8,8 * *$ & $10,5^{* *}$ & & & & & & & & & \\
\hline MOD x CE & $2,4 * *$ & $1,17^{\mathrm{ns}}$ & & & & & & & & & \\
\hline $\mathrm{CV}(\%))$ & 21,1 & 25,3 & & & & & & & & & \\
\hline Úmido & $75,2 b$ & $75,8 b$ & & & & & & & & & \\
\hline Seco & $76,4 b$ & $75,2 \mathrm{~b}$ & & & & & & & & & \\
\hline SC & $87,7 \mathrm{a}$ & $86,9 a$ & & & & & & & & & \\
\hline $\mathrm{DMS} /(\mathrm{N}=63)$ & 8,2 & 7,2 & & & & & & & & & \\
\hline 2.Isolando C. Enraiz. & & & & & & & & & & & \\
\hline Modelo (MOD) & & & $3,8 * *$ & $4,7 * *$ & $9,3 * *$ & & & & & & \\
\hline Profundidade (PROF) & & & $0,02^{\mathrm{ns}}$ & $0,1^{\mathrm{ns}}$ & $1,2^{\mathrm{ns}}$ & & & & & & \\
\hline MOD x PROF & & & $1,8^{\text {ns }}$ & $1,0^{\mathrm{ns}}$ & $1,0^{\mathrm{ns}}$ & & & & & & \\
\hline $\mathrm{CV}(\%)$ & & & 29,4 & 29,9 & 5,0 & & & & & & \\
\hline P15 & & & $75,2 \mathrm{a}$ & $76,4 a$ & $87,7 \mathrm{a}$ & & & & & & \\
\hline P30 & & & $75,8 \mathrm{a}$ & $75,2 \mathrm{a}$ & $86,9 \mathrm{a}$ & & & & & & \\
\hline DMS / $(\mathrm{N}=63)$ & & & 8,3 & 7,5 & 1,7 & & & & & & \\
\hline 3.Isolando Prof. e CE & & & & & & & & & & & \\
\hline Modelo & & & & & & $3,9 * *$ & $2,0^{\mathrm{ns}}$ & $5,6^{* *}$ & $1,3^{\mathrm{ns}}$ & $4,9 * *$ & $5,9 * *$ \\
\hline $\mathrm{CV}(\%)$ & & & & & & 28,5 & 30,2 & 25,8 & 32,7 & 5,8 & 4,0 \\
\hline Qr dos gotejadores & & & & & & & & & & & \\
\hline $\mathrm{AQ}$ & $67,2 d$ & $73,8 \mathrm{a}$ & $62,2 b$ & $56,2 \mathrm{~b}$ & $89,0 \mathrm{a}$ & $55,9 \mathrm{c}$ & $69,3 \mathrm{ab}$ & $47,6 \mathrm{~b}$ & $64,8 \mathrm{a}$ & $90,7 \mathrm{ab}$ & $87,3 \mathrm{ab}$ \\
\hline $\mathrm{CD}$ & $76,4 \mathrm{bcd}$ & $72,9 a$ & $63,0 \mathrm{ab}$ & $73,8 \mathrm{ab}$ & $84,2 \mathrm{bc}$ & $70,0 \mathrm{abc}$ & $56,0 \mathrm{~b}$ & $68,7 \mathrm{ab}$ & $78,9 \mathrm{a}$ & $84,4 \mathrm{bc}$ & $83,0 \mathrm{bc}$ \\
\hline DI & $86,7 \mathrm{ab}$ & $83,6 \mathrm{a}$ & $81,3 \mathrm{ab}$ & $83,9 \mathrm{a}$ & $90,2 \mathrm{a}$ & $81,2 \mathrm{abc}$ & $81,4 \mathrm{ab}$ & $86,5 \mathrm{a}$ & $81,3 \mathrm{a}$ & $92,3 a$ & $88,0 \mathrm{ab}$ \\
\hline HD & $70,7 \mathrm{~cd}$ & $72,7 \mathrm{a}$ & $69,0 \mathrm{ab}$ & $64,3 \mathrm{ab}$ & $81,7 \mathrm{c}$ & $61,4 \mathrm{bc}$ & $76,7 \mathrm{ab}$ & $69,1 \mathrm{ab}$ & $59,4 \mathrm{a}$ & $81,4 \mathrm{c}$ & $82,0 \mathrm{c}$ \\
\hline HG & $90,6 \mathrm{a}$ & $84,9 a$ & $87,0 \mathrm{a}$ & $86,5 \mathrm{a}$ & $89,7 \mathrm{a}$ & $93,8 \mathrm{a}$ & $80,2 \mathrm{ab}$ & $88,2 \mathrm{a}$ & $84,8 \mathrm{a}$ & $89,8 \mathrm{ab}$ & $89,7 \mathrm{a}$ \\
\hline TR & $90,0 \mathrm{a}$ & $80,9 a$ & $83,0 \mathrm{ab}$ & $85,0 \mathrm{a}$ & $88,2 \mathrm{ab}$ & $89,7 \mathrm{ab}$ & $76,3 \mathrm{ab}$ & $92,1 \mathrm{a}$ & $78,0 \mathrm{a}$ & $88,3 \mathrm{abc}$ & $88,1 \mathrm{ab}$ \\
\hline DL & $81,2 \mathrm{abc}$ & $86,2 \mathrm{a}$ & $82,3 \mathrm{ab}$ & $80,6 a$ & $88,1 \mathrm{ab}$ & $74,3 \mathrm{abc}$ & $90,3 \mathrm{a}$ & $82,2 \mathrm{a}$ & $79,0 \mathrm{a}$ & $87,0 \mathrm{abc}$ & $89,2 \mathrm{a}$ \\
\hline DMS & 13,7 & 16,3 & 22,3 & 22,8 & 4,4 & 30,9 & 35,0 & 28,4 & 35,4 & 7,3 & 5,0 \\
\hline $\mathrm{N}$ & 27 & 27 & 18 & 18 & 18 & 9 & 9 & 9 & 9 & 9 & 9 \\
\hline
\end{tabular}

Médias seguidas da mesma letra não diferem pelo teste de Tuckey $(\mathrm{p}<0,05)$. * - Teste F significativo no nível de $1 \%$ de probabilidade.** - Teste $\mathrm{F}$ significativo no nível de 5\% de probabilidade. DMS - Diferença Mínima Significativa no nível de 5\% de probabilidade. N - número de repetições. 
Tabela 10. Resultados da análise de variância e teste de comparação de médias para os dados de vazão relativa $(\mathrm{Qr})$, em L. $\mathrm{h}^{-1}$, dos gotejadores autocompensantes, aos 270 dias do início do experimento, na cultura da cana-de-acúcar

\begin{tabular}{|c|c|c|c|c|c|c|c|c|c|c|c|}
\hline \multirow[t]{2}{*}{ Fonte de Variação } & \multirow[t]{2}{*}{$\mathrm{P} 15$} & \multirow[t]{2}{*}{$\mathrm{P} 30$} & \multirow[t]{2}{*}{ ÚMIDO } & \multirow[t]{2}{*}{ SECO } & \multirow[t]{2}{*}{$\mathrm{SC}$} & \multicolumn{2}{|c|}{ ÚMIDO } & \multicolumn{2}{|c|}{ SECO } & \multicolumn{2}{|c|}{$\mathrm{SC}$} \\
\hline & & & & & & P15 & P30 & P15 & P30 & P15 & P30 \\
\hline \multicolumn{12}{|l|}{ 1.Isolando PROF } \\
\hline Modelo (M OD) & $2,3 *$ & $1,7^{\mathrm{ns}}$ & & & & & & & & & \\
\hline C.Enraiz. (CE) & $0,2^{\mathrm{ns}}$ & $1,0^{\mathrm{ns}}$ & & & & & & & & & \\
\hline MOD x CE & $2,2 *$ & $0,8^{\text {ns }}$ & & & & & & & & & \\
\hline $\mathrm{CV}(\%))$ & 54,4 & 48,0 & & & & & & & & & \\
\hline Úmido & $110,3 a$ & $97,6 \mathrm{a}$ & & & & & & & & & \\
\hline Seco & $103,2 \mathrm{a}$ & $107,4 \mathrm{a}$ & & & & & & & & & \\
\hline $\mathrm{SC}$ & $108,9 \mathrm{a}$ & $98,2 \mathrm{a}$ & & & & & & & & & \\
\hline DMS / $(\mathrm{N}=63)$ & 30,1 & 19,5 & & & & & & & & & \\
\hline \multicolumn{12}{|l|}{ 2.Isolando C. Enraiz. } \\
\hline Modelo (MOD) & & & $1,9^{\mathrm{ns}}$ & $4,0^{* *}$ & $9,5^{* *}$ & & & & & & \\
\hline Profundidade (PROF) & & & $0,7^{\mathrm{ns}}$ & $0,3^{\mathrm{ns}}$ & $7,3^{*}$ & & & & & & \\
\hline MOD x PROF & & & $0,6^{\mathrm{ns}}$ & $0,5^{\mathrm{ns}}$ & $4,7 * *$ & & & & & & \\
\hline $\mathrm{CV}(\%)$ & & & 72,8 & 48,4 & 17,5 & & & & & & \\
\hline P15 & & & $110,3 a$ & $103,2 \mathrm{a}$ & $108,9 \mathrm{a}$ & & & & & & \\
\hline P30 & & & $97,6 \mathrm{a}$ & $107,4 \mathrm{a}$ & $98,2 b$ & & & & & & \\
\hline DMS / $(\mathrm{N}=63)$ & & & 32,4 & 16,5 & 8,5 & & & & & & \\
\hline \multicolumn{12}{|l|}{ 3.Isolando Prof e CE } \\
\hline Modelo & & & & & & $1,6^{\mathrm{ns}}$ & $0,4^{\mathrm{ns}}$ & $2,6^{*}$ & $2,0^{\mathrm{ns}}$ & $6,4 * *$ & $7,7 * *$ \\
\hline $\mathrm{CV}(\%)$ & & & & & & 80,0 & 65,8 & 47,0 & 47,9 & 22,3 & 10,8 \\
\hline \multicolumn{12}{|l|}{ Qr dos gotejadores } \\
\hline $\mathrm{CP}$ & $112,1 \mathrm{a}$ & $104,7 \mathrm{a}$ & $107,4 \mathrm{a}$ & $113,6 \mathrm{ab}$ & $119,3 a$ & $117,3 \mathrm{a}$ & $97,6 \mathrm{a}$ & $105,4 \mathrm{ab}$ & $121,7 \mathrm{a}$ & $143,6 \mathrm{a}$ & $93,8 \mathrm{bc}$ \\
\hline DLP & $104,8 \mathrm{a}$ & $109,6 a$ & $90,0 \mathrm{a}$ & $113,4 \mathrm{ab}$ & $118,1 \mathrm{a}$ & $82,6 a$ & $97,4 a$ & $124,1 \mathrm{ab}$ & $124,1 \mathrm{a}$ & $129,0 \mathrm{ab}$ & $107,2 \mathrm{ab}$ \\
\hline $\mathrm{DP}$ & $89,7 \mathrm{a}$ & $84,5 \mathrm{a}$ & $78,9 \mathrm{a}$ & $87,8 b$ & $94,6 b c$ & $79,1 \mathrm{a}$ & $78,7 \mathrm{a}$ & $94,6 a b$ & $81,1 \mathrm{a}$ & $95,3 b c$ & $93,8 b c$ \\
\hline HP & $119,6 a$ & $96,8 \mathrm{a}$ & $152,2 \mathrm{a}$ & $83,9 b$ & $88,4 \mathrm{c}$ & $186,6 \mathrm{a}$ & $117,9 a$ & $84,0 \mathrm{ab}$ & $83,9 \mathrm{a}$ & $88,1 \mathrm{c}$ & $88,7 \mathrm{c}$ \\
\hline NP & $124,4 \mathrm{a}$ & $119,4 a$ & $105,3 \mathrm{a}$ & $147,9 \mathrm{a}$ & $112,5 \mathrm{ab}$ & $114,2 \mathrm{a}$ & $96,4 \mathrm{a}$ & $147,8 \mathrm{a}$ & $148,0 \mathrm{a}$ & $111,1 \mathrm{abc}$ & $113,9 \mathrm{a}$ \\
\hline $\mathrm{RM}$ & $116,6 \mathrm{a}$ & $104,4 a$ & $110,0 \mathrm{a}$ & $112,1 \mathrm{ab}$ & $102,0 \mathrm{abc}$ & $110,9 \mathrm{a}$ & $109,1 \mathrm{a}$ & $121,3 \mathrm{ab}$ & $102,9 \mathrm{a}$ & $102,7 b c$ & $101,3 \mathrm{abc}$ \\
\hline VP & $80,3 \mathrm{a}$ & $87,9 a$ & $83,9 a$ & $78,3 b$ & $90,1 \mathrm{c}$ & $81,7 \mathrm{a}$ & $86,2 \mathrm{a}$ & $66,3 b$ & $90,3 \mathrm{a}$ & $92,9 \mathrm{c}$ & $87,2 \mathrm{c}$ \\
\hline DMS & 45,6 & $39,5 a$ & 76,0 & 51,2 & 18,2 & 127,3 & 65,8 & 70,0 & 74,8 & 35,0 & 15,3 \\
\hline $\mathrm{N}$ & 27 & 27 & 18 & 18 & 18 & 9 & 9 & 9 & 9 & 9 & 9 \\
\hline
\end{tabular}

significativo no nível de 5\% de probabilidade. DMS - Diferença Mínima Significativa no nível de 5\% de probabilidade. N - número de repetições. 


\subsection{Experimento com a cultura do feijão}

\subsubsection{Gotejadores não-compensantes de pressão}

A Figura 8 apresenta a evolução da vazão dos gotejadores desse grupo ao longo do experimento. As Tabelas 11 a 14 apresentam os valores médios de Qr e o coeficiente de variação de vazão para os diversos modelos, ao longo do período do experimento ( $\mathrm{n}=$ $10)$.

A análise de variância efetuada para a leitura de vazão aos 90 dias do início do experimento, isolando-se o efeito do fator profundidade de instalação dos gotejadores e comparando as condições de enraizamento não resultou significativa nas duas profundidades, nem acusou diferença entre as médias de Qr, pelo teste de Tuckey a 5\% de probabilidade, dos tratament os Úmido, Seco e SC, nas duas profundidades estudadas (Tabela 17). Do mesmo modo, a interação entre modelo e condição de enraizamento não se revelou significativa nas duas profundidades. Resultados idênticos foram obtidos quando da realização da análise is olando-se o efeito do fator condição de enraizamento e comparando-se as profundidades de instalação.

Tanto nas análises acima descritas quanto naquela isolando-se os efeitos de umidade e profundidade, conjuntamente, o efeito do fator modelo somente não foi significativo para a condição de solo úmido. Para as demais condições, o comportamento dos modelos foi similar, embora com menores valores absolutos de redução de vazão que os obtidos no experimento da cana-de-açúcar, onde um grupo de modelos se revezava com menores reduções de vazão, mas sem que houvesse diferença significativa entre eles; um segundo grupo, nesse caso formado apenas pelos modelos $\mathrm{CD}$ e $\mathrm{HD}$, apresentou, de forma significativa em relação ao primeiro grupo, maiores níveis de redução de vazão.

A vazão nos gotejadores apresentou pequena variação ao longo do ciclo da cultura. Os modelos AQ, CD e DI e HD apresentaram as maiores reduções de vazão, com Qr mínima de 88\%, 81\%, 90\% e 85\%, respectivamente. Esses níveis de redução de vazão, 

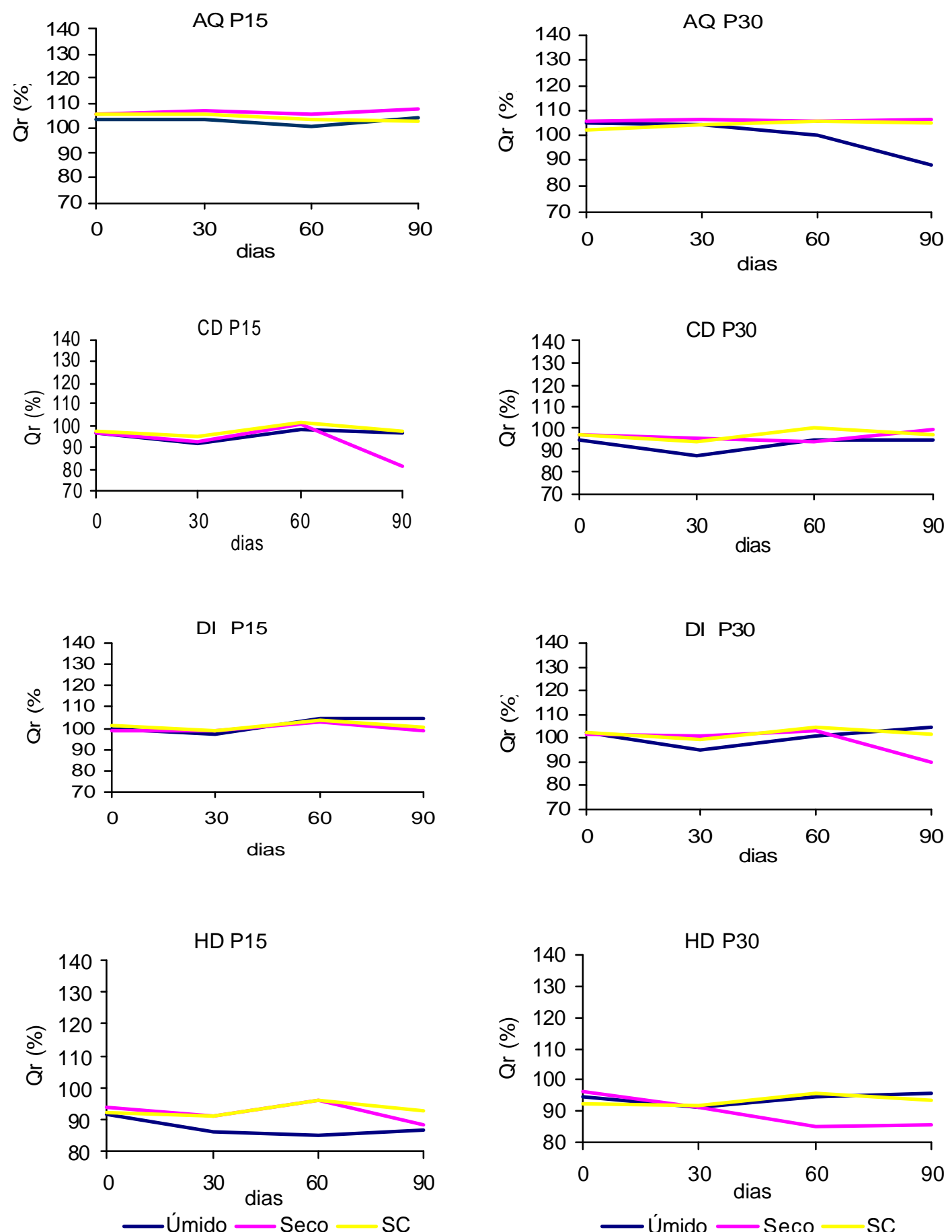

Figura 8 - Vazão relativa, Qr, ao longo do período do experimento, para gotejadores não compensantes de pressão, no experimento com a cultura do feijão 

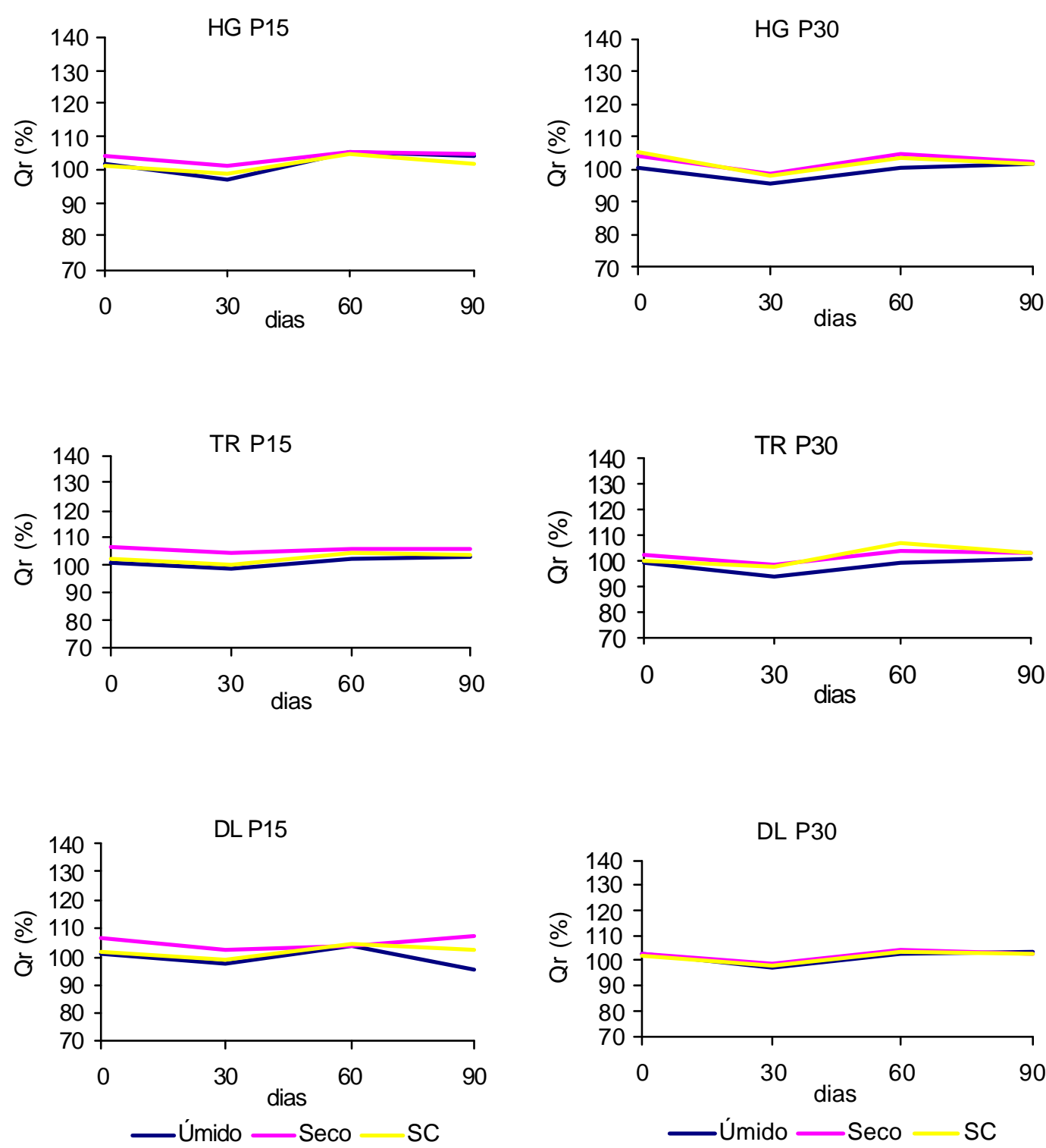

Figura 8 - Vazão relativa, Qr, ao longo do período do experimento, para gotejadores não compensantes de pressão, no experimento com a cultura do feijão

além de menores que os observados na cultura da cana-de-açúcar, não apresentaram tendência bem definida para os fatores regime de umidade do solo e profundidade de instalação dos gotejadores. Os modelos TR, DL e HG não apresentaram variações de 
vazão maior que $5 \%$, podendo-se admitir que tais variações podem estar relacionadas à variação de fabricação do emissor, dado que todos os modelos podem ser classificados dentro dessa faixa de Coeficiente de Variação de Fabricação.

No aspecto de uniformidade de aplicação de água, os modelos CD e HD, como já ocorrera na cultura da cana, apresentaram os mais altos valores de CV. Os modelos HG e TR mostraram o melhor desempenho, apresentando valores de CV variando de 1,3\% a $11,9 \%$ em todos os tratamentos e épocas de avaliação. Os demais modelos mostraram comportamento similar.

\subsubsection{Gotejadores autocompensantes de pressão}

A Figura 9 apresenta a evolução da vazão dos gotejadores desse grupo ao longo do experimento. As Tabelas 11 a 14 apresentam os valores médios de Qr e coeficientes de variação de vazão para os diversos modelos e ao longo do período do experimento (n $=10)$.

As considerações apontadas para o grupo de gotejadores autocompensantes na cultura da cana-de-açúcar são válidas para o presente caso, dado os elevados valores de coeficiente de variação dos dados analisados.

A análise de variância efetuada para a leitura de vazão aos 90 dias do início do experimento, isolando o efeito do fator profundidade de instalação dos gotejadores e comparando condições de enraizamento, mostrou-se significativa apenas para a profundidade P30; nessa profundidade e através do teste de Tuckey, o tratamento SC apresentou uma Qr superior aos tratamentos Úmido e Seco, os quais não diferiram entre si, evidenciando o efeito da ação das raízes na vazão dos gotejadores avaliados. Igualmente, a interação entre modelo e condição de enraizamento se revelou significativa apenas no tratamento P30 (Tabela 18).

Em nenhuma das condições de déficit de umidade do solo houve efeito da profundidade de instalação dos gotejadores, revelados pelos testes F e Tuckey (Tabela 18). 
Os gotejadores apresentaram comportamento idêntico, em termos de magnitude de variação de vazão, ao observado na cultura da cana-de-açúcar, mesmo considerando o período mais curto de tomada de dados. Para a maior parte dos modelos, significativa variação de vazão foi observada já aos 30 e 60 dias do início do experimento, e dessa forma também similar ao ocorrido com esse grupo de gotejadores no experimento com a cultura da cana. Os modelos CP, DLP, HP e NP apresentaram as maiores variações, com valores máximos de $\mathrm{Qr}$ de 133\%, 120\%, 338\% e 177\%, respectivamente. Um comportamento bem mais regular foi observado nos modelos VP, RM e DP, que mantiveram um valor de Qr próximo a 100\%, ao longo do período do experimento.

Da mesma forma que na cultura da cana, embora não tenha havido um comportamento uniforme quanto ao efeito dos fatores regime de umidade do solo e profundidade de instalação dos gotejadores, os dados mostram que, no geral, a variação de vazão foi mais evidente nos tratamentos Úmido e P30.

Os modelos HP e NP apresentaram a maior desuniformidade de aplicação de água, com valores de CV máximos de $127 \%$ e $61 \%$, respectivamente. Repetindo o mesmo comportamento observado com a cana-de-açúcar, o modelo VP apresentou valores de CV em torno de $10 \%$, que se mantiveram do início ao final do experimento, para todos os tratamentos e épocas de leitura de vazão. O modelo DP apresentou os menores valores de $\mathrm{CV}$, em todos os tratamento e épocas, enquanto os demais modelos mostraram comportamento intermediário. 

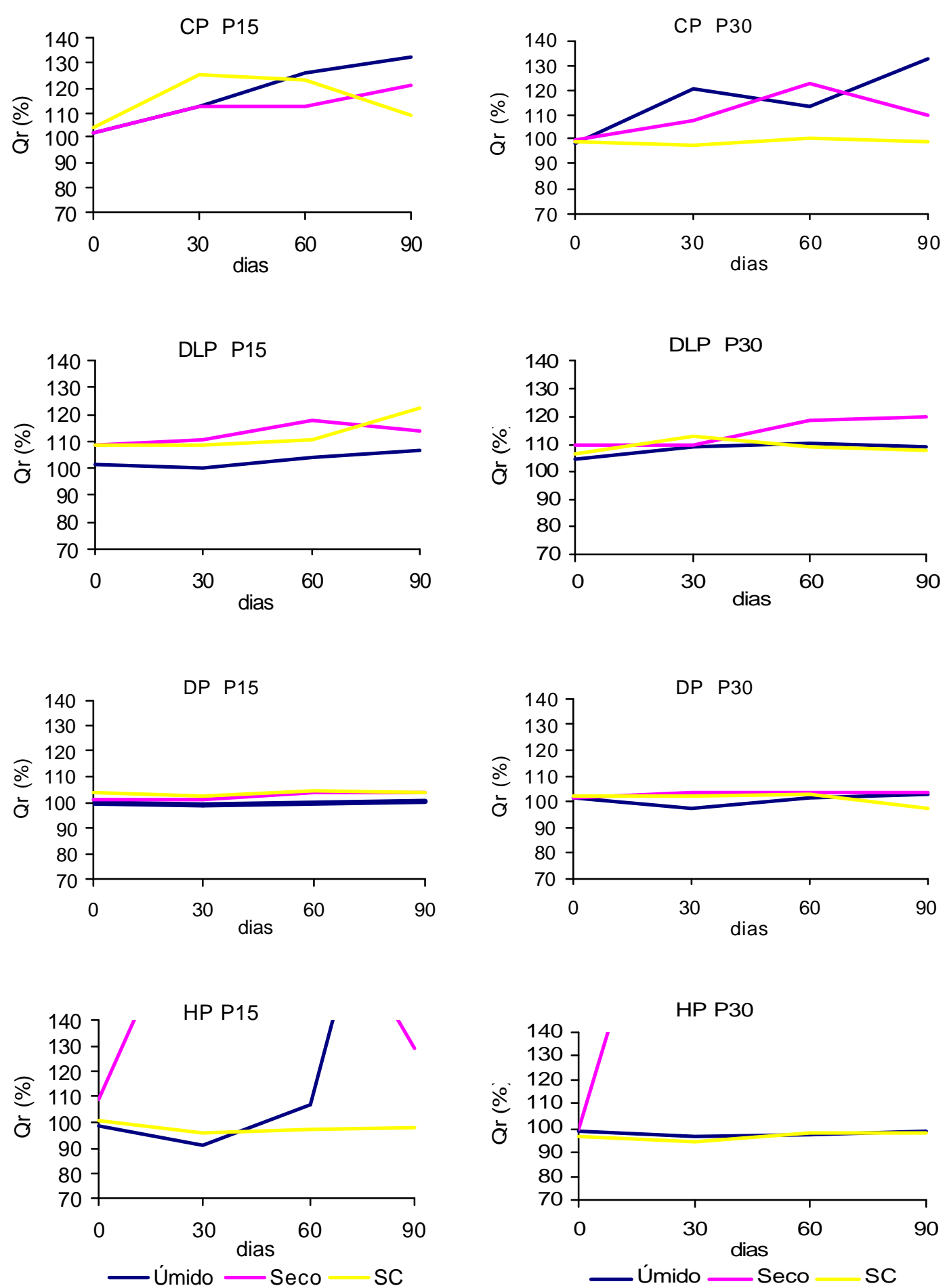

Figura 9 - Vazão relativa, Qr, ao longo do período do experimento, para gotejadores autocompensantes de pressão, no experimento com a cultura do feijão 

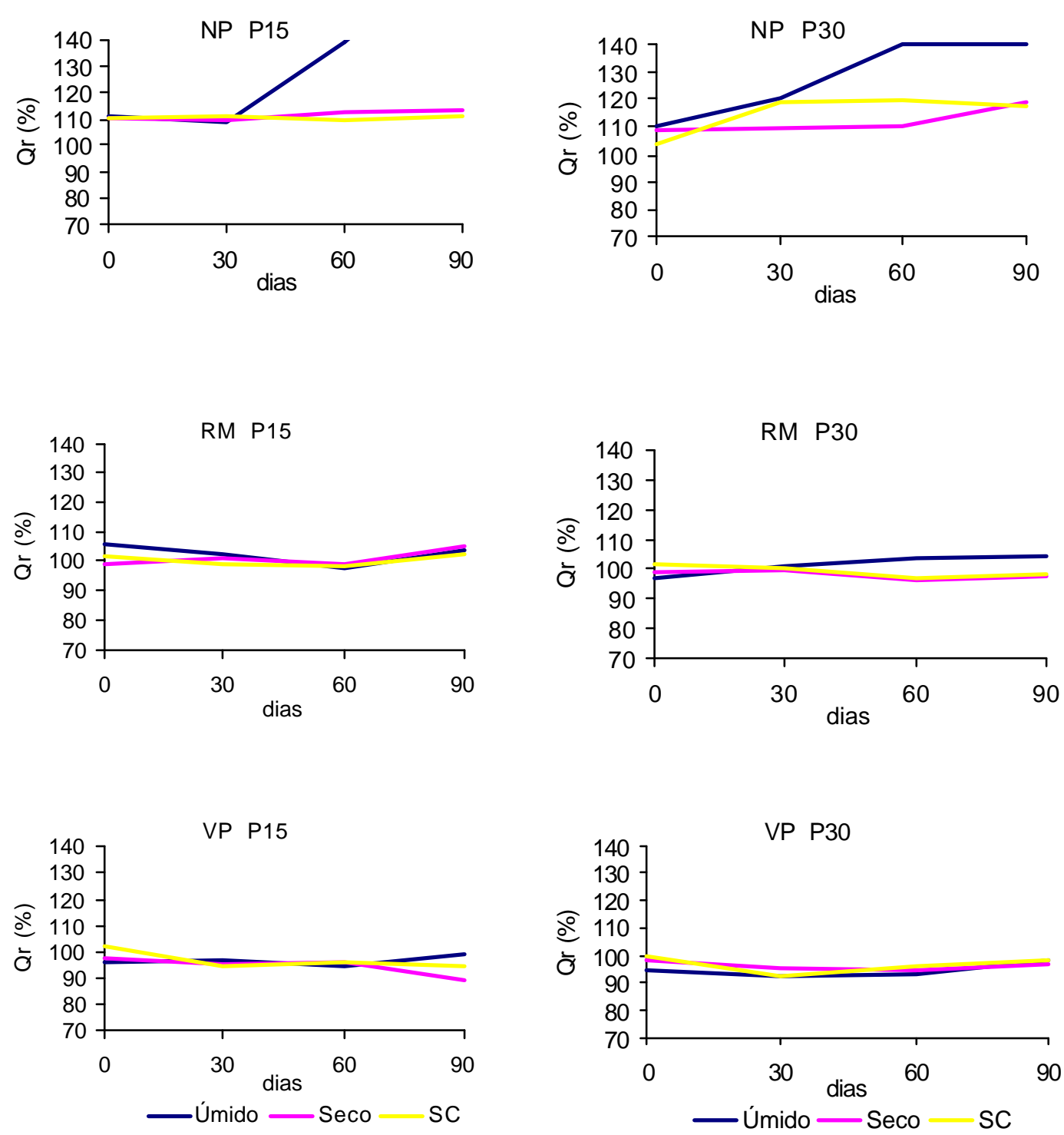

Figura 9 - Vazão relativa, Qr, ao longo do período do experimento, para gotejadores autocompensantes de pressão, no experimento com a cultura do feijão 
Tabela 11. Vazão relativa (Qr), em L.h ${ }^{-1}$, e coeficiente de variação dos valores de vazão (CV), em \%, dos gotejadores na cultura do feijão, na profundidade P15 e condição de enraizamento Úmido

\begin{tabular}{|c|c|c|c|c|c|c|c|c|c|c|c|c|c|c|c|c|c|c|c|c|c|c|c|c|c|c|c|c|}
\hline \multirow[t]{2}{*}{ Dias } & \multicolumn{2}{|c|}{$\overline{\mathrm{AQ}}$} & \multicolumn{2}{|c|}{$\mathrm{CD}$} & \multicolumn{2}{|c|}{$\mathrm{CP}$} & \multicolumn{2}{|c|}{$\overline{D I}$} & \multicolumn{2}{|c|}{$\overline{\text { DLP }}$} & \multicolumn{2}{|c|}{ DP } & \multicolumn{2}{|c|}{ HD } & \multicolumn{2}{|c|}{$\mathrm{HG}$} & \multicolumn{2}{|c|}{ HP } & \multicolumn{2}{|c|}{ NP } & \multicolumn{2}{|c|}{$\overline{R M}$} & \multicolumn{2}{|c|}{ TR } & \multicolumn{2}{|c|}{$\overline{\mathrm{DL}}$} & \multicolumn{2}{|c|}{$\overline{V P}$} \\
\hline & $\mathrm{Qr}$ & $\mathrm{CV}$ & $\mathrm{Qr}$ & $\mathrm{CV}$ & Qr & $\mathrm{CV}$ & $\mathrm{Qr}$ & $\mathrm{CV}$ & $\mathrm{Qr}$ & $\mathrm{CV}$ & $\mathrm{Qr}$ & $\mathrm{CV}$ & $\mathrm{Qr}$ & $\mathrm{CV}$ & $\mathrm{Qr}$ & $\mathrm{CV}$ & $\mathrm{Qr}$ & $\mathrm{CV}$ & $\mathrm{Qr}$ & $\mathrm{CV}$ & $\mathrm{Qr}$ & $\mathrm{CV}$ & $\mathrm{Qr}$ & $\mathrm{CV}$ & Qr & $\mathrm{CV}$ & $\mathrm{Qr}$ & $\mathrm{CV}$ \\
\hline 0 & 104 & 1,7 & 97 & 6,0 & 101 & 5,6 & 100 & 3,9 & 101 & 3,8 & 100 & 5,2 & 91 & 9,3 & 102 & 4,1 & 99 & 5,4 & 111 & 6,4 & 106 & 9,8 & 102 & 3,3 & 101 & 4,8 & 96 & 15,9 \\
\hline 30 & 104 & 3,5 & 92 & 6,1 & 112 & 28,6 & 97 & 6,3 & 100 & 3,7 & 99 & 5,1 & 86 & 10,6 & 97 & 4,2 & 91 & 16,0 & 109 & 4,1 & 103 & 8,5 & 98 & 1,3 & 97 & 3,0 & 97 & 7,9 \\
\hline 60 & 101 & 11,4 & 98 & 4,1 & 126 & 31,4 & 105 & 6,4 & 104 & 2,9 & 100 & 6,3 & 85 & 31,5 & 105 & 2,9 & 107 & 54,0 & 138 & 36,7 & 98 & 7,0 & 103 & 3,4 & 104 & 10,5 & 95 & 11,1 \\
\hline 90 & 104 & 2,7 & 97 & 7,5 & 133 & 35,6 & 105 & 6,8 & 106 & 6,9 & 101 & 5,2 & 87 & 30,3 & 104 & 4,3 & 262 & 130,5 & 177 & 61,5 & 104 & 12,0 & 103 & 3,2 & 95 & 34,1 & 100 & 10,9 \\
\hline
\end{tabular}

Tabela 12. Vazão relativa (Qr), em L.h ${ }^{-1}$, e coeficiente de variação dos valores de vazão (CV), em \%, dos gotejadores na cultura do feijão, na profundidade P30 e condição de enraizamento Úmido

\begin{tabular}{|c|c|c|c|c|c|c|c|c|c|c|c|c|c|c|c|c|c|c|c|c|c|c|c|c|c|c|c|c|}
\hline \multirow[t]{2}{*}{ Dias } & \multicolumn{2}{|c|}{$\mathrm{AQ}$} & \multicolumn{2}{|c|}{$\mathrm{CD}$} & \multicolumn{2}{|c|}{$\mathrm{CP}$} & \multicolumn{2}{|c|}{$\overline{D I}$} & \multicolumn{2}{|c|}{ DLP } & \multicolumn{2}{|c|}{$\overline{\mathrm{DP}}$} & \multicolumn{2}{|c|}{ HD } & \multicolumn{2}{|c|}{$\mathrm{HG}$} & \multicolumn{2}{|c|}{$\overline{\mathrm{HP}}$} & \multicolumn{2}{|c|}{$\mathrm{NP}$} & \multicolumn{2}{|c|}{$\mathrm{RM}$} & \multicolumn{2}{|c|}{ TR } & \multicolumn{2}{|c|}{$\overline{\mathrm{DL}}$} & \multicolumn{2}{|c|}{ VP } \\
\hline & $\mathrm{Qr}$ & $\mathrm{CV}$ & $\mathrm{Qr}$ & $\mathrm{CV}$ & $\mathrm{Qr}$ & $\mathrm{CV}$ & $\mathrm{Qr}$ & $\mathrm{CV}$ & $\mathrm{Qr}$ & $\mathrm{CV}$ & $\mathrm{Qr}$ & $\mathrm{CV}$ & $\mathrm{Qr}$ & $\mathrm{CV}$ & $\mathrm{Qr}$ & $\mathrm{CV}$ & $\mathrm{Qr}$ & $\mathrm{CV}$ & $\mathrm{Qr}$ & $\mathrm{CV}$ & $\mathrm{Qr}$ & $\mathrm{CV}$ & $\mathrm{Qr}$ & $\mathrm{CV}$ & $\mathrm{Qr}$ & $\mathrm{CV}$ & $\mathrm{Qr}$ & $\mathrm{CV}$ \\
\hline 0 & 105 & 2,8 & 95 & 11,0 & 98 & 7,9 & 102 & 6,8 & 104 & 5,7 & 102 & 6,1 & 94 & 4,9 & 101 & 5,1 & 99 & 6,0 & 111 & 5,5 & 97 & 3,9 & 99 & 3,2 & 102 & 4,5 & 94 & 4,5 \\
\hline 30 & 105 & 2,8 & 87 & 17,3 & 121 & 65,8 & 95 & 5,7 & 109 & 16,0 & 98 & 6,2 & 91 & 6,2 & 95 & 5,8 & 96 & 6,1 & 121 & 13,6 & 101 & 4,6 & 94 & 4,3 & 97 & 2,5 & 93 & 2,5 \\
\hline 60 & 100 & 18,2 & 95 & 16,1 & 114 & 40,4 & 101 & 4,9 & 110 & 13,2 & 102 & 6,4 & 94 & 2,2 & 101 & 9,7 & 97 & 3,7 & 140 & 39,2 & 104 & 23,2 & 99 & 5,7 & 102 & 2,9 & 93 & 2,9 \\
\hline 90 & 88 & 40,9 & 95 & 19,9 & 133 & 71,0 & 104 & 6,1 & 110 & 11,6 & 103 & 6,5 & 96 & 3,9 & 102 & 11,9 & 98 & 4,3 & 140 & 38,4 & 104 & 20,3 & 101 & 6,3 & 104 & 3,4 & 98 & 3,4 \\
\hline
\end{tabular}


Tabela 13. Vazão relativa (Qr), em L.h ${ }^{-1}$, e coeficiente de variação dos valores de vazão (CV), em \%, dos gotejadores na cultura do feijão, na profundidade $\mathrm{P} 15$ e condição de enraizamento Seco

\begin{tabular}{|c|c|c|c|c|c|c|c|c|c|c|c|c|c|c|c|c|c|c|c|c|c|c|c|c|c|c|c|c|}
\hline \multirow[t]{2}{*}{ Dias } & \multicolumn{2}{|c|}{$\overline{\mathrm{AQ}}$} & \multicolumn{2}{|c|}{$\mathrm{CD}$} & \multicolumn{2}{|c|}{$\overline{\mathrm{CP}}$} & \multicolumn{2}{|c|}{$\overline{\mathrm{DI}}$} & \multicolumn{2}{|c|}{$\overline{\text { DLP }}$} & \multicolumn{2}{|c|}{$\overline{\mathrm{DP}}$} & \multicolumn{2}{|c|}{ HD } & \multicolumn{2}{|c|}{$\mathrm{HG}$} & \multicolumn{2}{|c|}{ HP } & \multicolumn{2}{|c|}{$\mathrm{NP}$} & \multicolumn{2}{|c|}{$\overline{\mathrm{RM}}$} & \multicolumn{2}{|c|}{ TR } & \multicolumn{2}{|c|}{$\overline{\mathrm{DL}}$} & \multicolumn{2}{|c|}{$\overline{V P}$} \\
\hline & $\mathrm{Qr}$ & $\mathrm{CV}$ & Qr & $\mathrm{CV}$ & $\mathrm{Qr}$ & $\mathrm{CV}$ & $\mathrm{Qr}$ & $\mathrm{CV}$ & $\mathrm{Qr}$ & $\mathrm{CV}$ & $\mathrm{Qr}$ & $\mathrm{CV}$ & $\mathrm{Qr}$ & $\mathrm{CV}$ & $\mathrm{Qr}$ & $\mathrm{CV}$ & Qr & $\mathrm{CV}$ & $\mathrm{Qr}$ & $\mathrm{CV}$ & $\mathrm{Qr}$ & $\mathrm{CV}$ & $\mathrm{Qr}$ & $\mathrm{CV}$ & $\mathrm{Qr}$ & $\mathrm{CV}$ & $\mathrm{Qr}$ & $\mathrm{CV}$ \\
\hline 0 & 106 & 2,6 & 97 & 6,6 & 101 & 8,4 & 99 & 5,5 & 109 & 5,4 & 101 & 6,5 & 94 & 8,7 & 104 & 7,6 & 109 & 20,1 & 110 & 5,6 & 99 & 4,1 & 107 & 6,0 & 106 & 8,4 & 98 & 17,0 \\
\hline 30 & 107 & 4,2 & 93 & 4,5 & 112 & 29,0 & 99 & 4,5 & 111 & 6,3 & 102 & 6,2 & 91 & 5,8 & 101 & 5,3 & 201 & 127,1 & 10 & 2,3 & 102 & 3,5 & 105 & 7,2 & 102 & 5,6 & 95 & 11,6 \\
\hline 60 & 106 & 1,3 & 100 & 5,5 & 112 & 22,2 & 103 & 5,4 & 117 & 10,2 & 104 & 5,8 & 96 & 4,7 & 105 & 4,8 & 199 & 108,9 & 112 & 7,2 & 99 & 5,4 & 106 & 3,6 & 104 & 3,0 & 96 & 12,7 \\
\hline 90 & 107 & 2,8 & 81 & 51,4 & 121 & 32,8 & 99 & 9,3 & 114 & 7,9 & 104 & 5,6 & 88 & 24,2 & 105 & 4,3 & 129 & 57,6 & 113 & 8,7 & 105 & 19,9 & 106 & 4,1 & 107 & 6,4 & 89 & 13,4 \\
\hline
\end{tabular}

Tabela 14. Variação da vazão relativa (Qr), em L.h ${ }^{-1}$, e coeficiente de variação dos valores de vazão (CV), em \%, dos gotejadores na cultura do feijão, na profundidade P30 e condição de enraizamento Seco

\begin{tabular}{|c|c|c|c|c|c|c|c|c|c|c|c|c|c|c|c|c|c|c|c|c|c|c|c|c|c|c|c|c|}
\hline \multirow[t]{2}{*}{$\overline{\text { Dias }}$} & \multicolumn{2}{|c|}{$\overline{\mathrm{AQ}}$} & \multicolumn{2}{|c|}{$\mathrm{CD}$} & \multicolumn{2}{|c|}{$\mathrm{CP}$} & \multicolumn{2}{|c|}{ DI } & \multicolumn{2}{|c|}{$\overline{D L P}$} & \multicolumn{2}{|c|}{$\overline{\mathrm{DP}}$} & \multicolumn{2}{|c|}{ HD } & \multicolumn{2}{|c|}{ HG } & \multicolumn{2}{|c|}{ HP } & \multicolumn{2}{|c|}{$\mathrm{NP}$} & \multicolumn{2}{|c|}{$\mathrm{RM}$} & \multicolumn{2}{|c|}{ TR } & \multicolumn{2}{|c|}{$\overline{D L}$} & \multicolumn{2}{|c|}{$\mathrm{VP}$} \\
\hline & $\mathrm{Qr}$ & $\mathrm{CV}$ & $\mathrm{Qr}$ & $\mathrm{CV}$ & $\mathrm{Qr}$ & $\mathrm{CV}$ & $\mathrm{Qr}$ & $\mathrm{CV}$ & $\mathrm{Qr}$ & $\mathrm{CV}$ & $\mathrm{Qr}$ & $\mathrm{CV}$ & $\mathrm{Qr}$ & $\mathrm{CV}$ & $\mathrm{Qr}$ & $\mathrm{CV}$ & $\mathrm{Qr}$ & $\mathrm{CV}$ & $\mathrm{Qr}$ & $\mathrm{CV}$ & $\mathrm{Qr}$ & $\mathrm{CV}$ & $\mathrm{Qr}$ & $\mathrm{CV}$ & $\mathrm{Qr}$ & $\mathrm{CV}$ & $\mathrm{Qr}$ & $\mathrm{CV}$ \\
\hline 0 & 105 & 2,7 & 97 & 6,7 & 100 & 3,7 & 102 & 3,9 & 110 & 7,0 & 102 & 7,4 & 96 & 5,9 & 104 & 4,5 & 99 & 3,8 & 109 & 3,5 & 99 & 7,1 & 102 & 5,8 & 103 & 6,9 & 98 & 11,7 \\
\hline 30 & 107 & 2,1 & 96 & 6,4 & 108 & 37,5 & 101 & 5,1 & 110 & 7,2 & 104 & 5,8 & 91 & 3,9 & 99 & 2,5 & 261 & 100,3 & 110 & 4,1 & 99 & 3,1 & 98 & 3,9 & 99 & 5,2 & 95 & 14,7 \\
\hline 60 & 105 & 9,3 & 93 & 28,3 & 122 & 40,1 & 103 & 7,8 & 119 & 19,8 & 104 & 5,9 & 85 & 36,1 & 104 & 5,8 & 276 & 126,7 & 110 & 5,5 & 96 & 4,7 & 104 & 5,7 & 104 & 2,8 & 95 & 28,1 \\
\hline 90 & 107 & 10,9 & 99 & 4,8 & 110 & 34,6 & 90 & 35,8 & 120 & 27,9 & 104 & 4,5 & 85 & 31,6 & 102 & 2,9 & 338 & 104,1 & 119 & 20,1 & 98 & 4,6 & 103 & 3,5 & 103 & 3,8 & 97 & 16,6 \\
\hline
\end{tabular}


Tabela 15. Variação da vazão relativa (Qr), em L.h ${ }^{-1}$, e coeficiente de variação de vazão (CV), em \%, dos gotejadores para a condição de enraizamento Sem Cultivo na profundidade P15

\begin{tabular}{|c|c|c|c|c|c|c|c|c|c|c|c|c|c|c|c|c|c|c|c|c|c|c|c|c|c|c|c|c|}
\hline \multirow[t]{2}{*}{ Dias } & \multicolumn{2}{|c|}{ AQ } & \multicolumn{2}{|c|}{$\overline{C D}$} & \multicolumn{2}{|c|}{$\mathrm{CP}$} & \multicolumn{2}{|c|}{$\overline{\mathrm{DI}}$} & \multicolumn{2}{|c|}{$\overline{\mathrm{DLP}}$} & \multicolumn{2}{|c|}{ DP } & \multicolumn{2}{|c|}{ HD } & \multicolumn{2}{|c|}{$\mathrm{HG}$} & \multicolumn{2}{|c|}{ HP } & \multicolumn{2}{|c|}{ NP } & \multicolumn{2}{|c|}{$\overline{\mathrm{RM}}$} & \multicolumn{2}{|c|}{ TR } & \multicolumn{2}{|c|}{$\overline{\mathrm{DL}}$} & \multicolumn{2}{|c|}{$\mathrm{VP}$} \\
\hline & $\mathrm{Qr}$ & $\mathrm{CV}$ & Qr & $\mathrm{CV}$ & $\overline{\mathrm{Qr}}$ & $\mathrm{CV}$ & $\mathrm{Qr}$ & $\mathrm{CV}$ & Qr & $\mathrm{CV}$ & $\mathrm{Qr}$ & $\mathrm{CV}$ & $\mathrm{Qr}$ & $\mathrm{CV}$ & $\mathrm{Qr}$ & $\mathrm{CV}$ & $\mathrm{Qr}$ & $\mathrm{CV}$ & $\mathrm{Qr}$ & $\mathrm{CV}$ & $\mathrm{Qr}$ & $\mathrm{CV}$ & $\mathrm{Qr}$ & $\mathrm{CV}$ & $\mathrm{Qr}$ & $\mathrm{CV}$ & Qr & $\mathrm{CV}$ \\
\hline 0 & 105 & 7,1 & 98 & 3,1 & 104 & 8,7 & 101 & 4,5 & 108 & 2,8 & 104 & 6,4 & 92 & 3,4 & 101 & 5,2 & 101 & 7,6 & 111 & 4,2 & 102 & 7,2 & 103 & 2,4 & 101 & 4,8 & 102 & 10,8 \\
\hline 30 & 105 & 2,0 & 95 & 4,7 & 126 & 48,9 & 99 & 6,4 & 109 & 4,8 & 103 & 7,2 & 91 & 5,0 & 99 & 4,5 & 96 & 4,5 & 111 & 3,9 & 99 & 2,3 & 101 & 4,9 & 99 & 6,4 & 95 & 9,7 \\
\hline 60 & 104 & 2,9 & 102 & 3,2 & 123 & 32,7 & 104 & 4,8 & 111 & 3,7 & 104 & 6,4 & 96 & 4,1 & 104 & 6,0 & 97 & 2,9 & 110 & 3,5 & 99 & 6,2 & 105 & 5,0 & 104 & 5,4 & 96 & 8,2 \\
\hline 90 & 103 & 2,7 & 98 & 3,4 & 109 & 17,3 & 101 & 5,0 & 122 & 21,3 & 104 & 5,6 & 93 & 5,3 & 102 & 6,0 & 98 & 4,6 & 112 & 4,2 & 102 & 13,0 & 104 & 3,6 & 102 & 5,0 & 95 & 11,1 \\
\hline 120 & 106 & 1,9 & 101 & 6,2 & 113 & 16,5 & 106 & 5,8 & 131 & 22,4 & 104 & 6,5 & 97 & 7,7 & 104 & 4,3 & 99 & 4,9 & 111 & 5,3 & 98 & 5,2 & 106 & 6,7 & 104 & 7,6 & 97 & 11,3 \\
\hline 150 & 105 & 2,2 & 97 & 1,9 & 111 & 15,5 & 102 & 5,3 & 125 & 18,0 & 104 & 5,6 & 93 & 2,2 & 100 & 3,2 & 99 & 4,9 & 112 & 4,3 & 98 & 5,1 & 100 & 3,3 & 100 & 5,0 & 96 & 9,5 \\
\hline 180 & 101 & 2,2 & 93 & 1,5 & 121 & 30,9 & 98 & 5,6 & 129 & 23,5 & 103 & 6,5 & 90 & 2,5 & 98 & 3,0 & 96 & 3,8 & 113 & 6,1 & 98 & 5,7 & 98 & 3,5 & 96 & 2,9 & 95 & 12,3 \\
\hline 210 & 102 & 3,4 & 92 & 1,8 & 119 & 30,9 & 101 & 9,9 & 135 & 32,2 & 102 & 6,7 & 89 & 3,0 & 96 & 2,5 & 95 & 3,5 & 112 & 4,5 & 103 & 10,8 & 97 & 3,8 & 96 & 5,2 & 94 & 10,8 \\
\hline 240 & 91 & 7,4 & 84 & 2,2 & 102 & 19,0 & 92 & 12,2 & 132 & 26,6 & 95 & 7,0 & 81 & 2,8 & 89 & 5,3 & 87 & 3,7 & 108 & 3,8 & 104 & 11,8 & 88 & 2,9 & 89 & 4,1 & 95 & 9,3 \\
\hline 270 & 90 & 3,8 & 85 & 2,2 & 138 & 38,2 & 92 & 12,1 & 130 & 23,5 & 96 & 6,2 & 82 & 3,1 & 89 & 4,9 & 88 & 4,4 & 111 & 5,3 & 102 & 7,8 & 88 & 2,6 & 87 & 3,2 & 93 & 11,2 \\
\hline
\end{tabular}


Tabela 16. Variação da vazão relativa (Qr), em L.h ${ }^{-1}$, e coeficiente de variação de vazão (CV), em \%, dos gotejadores para a condição de enraizamento Cem Cultivo na profundidade P30

\begin{tabular}{|c|c|c|c|c|c|c|c|c|c|c|c|c|c|c|c|c|c|c|c|c|c|c|c|c|c|c|c|c|}
\hline \multirow[t]{2}{*}{ Dias } & \multicolumn{2}{|c|}{ AQ } & \multicolumn{2}{|c|}{$\mathrm{CD}$} & \multicolumn{2}{|c|}{$\mathrm{CP}$} & \multicolumn{2}{|c|}{ DI } & \multicolumn{2}{|c|}{ DLP } & \multicolumn{2}{|c|}{$\overline{D P}$} & \multicolumn{2}{|c|}{ HD } & \multicolumn{2}{|c|}{$\mathrm{HG}$} & \multicolumn{2}{|c|}{ HP } & \multicolumn{2}{|c|}{ NP } & \multicolumn{2}{|c|}{ RM } & \multicolumn{2}{|c|}{ TR } & \multicolumn{2}{|c|}{$\mathrm{DL}$} & \multicolumn{2}{|c|}{ VP } \\
\hline & $\mathrm{Qr}$ & $\mathrm{CV}$ & $\mathrm{Qr}$ & $\mathrm{CV}$ & $\mathrm{Qr}$ & $\mathrm{CV}$ & Qr & $\mathrm{CV}$ & $\mathrm{Qr}$ & $\mathrm{CV}$ & Qr & $\mathrm{CV}$ & $\mathrm{Qr}$ & $\mathrm{CV}$ & $\mathrm{Qr}$ & $\mathrm{CV}$ & Qr & $\mathrm{CV}$ & $\mathrm{Qr}$ & $\mathrm{CV}$ & $\mathrm{Qr}$ & $\mathrm{CV}$ & $\mathrm{Qr}$ & $\mathrm{CV}$ & $\mathrm{Qr}$ & $\mathrm{CV}$ & Qr & $\mathrm{CV}$ \\
\hline 0 & 103 & 4,0 & 97 & 4,2 & 99 & 4,3 & 102 & 7,3 & 106 & 4,5 & 103 & 6,4 & 92 & 2,7 & 105 & 8,4 & 97 & 3,8 & 104 & 4,9 & 101 & 6,7 & 100 & 3,8 & 101 & 3,0 & 100 & 9,8 \\
\hline 30 & 104 & 2,1 & 94 & 5,7 & 98 & 4,3 & 100 & 6,3 & 112 & 16,0 & 102 & 6,9 & 92 & 4,2 & 98 & 7,1 & 95 & 4,1 & 119 & 24,0 & 101 & 5,8 & 98 & 7,3 & 98 & 4,4 & 93 & 11,4 \\
\hline 60 & 106 & 8,6 & 100 & 3,8 & 100 & 3,5 & 104 & 8,0 & 109 & 6,8 & 103 & 5,5 & 95 & 5,0 & 103 & 5,9 & 98 & 3,3 & 120 & 16,5 & 96 & 4,0 & 107 & 8,9 & 104 & 5,6 & 96 & 6,1 \\
\hline 90 & 105 & 6,4 & 97 & 5,6 & 99 & 4,1 & 101 & 4,7 & 108 & 6,3 & 98 & 16,6 & 93 & 3,8 & 102 & 5,1 & 98 & 2,1 & 118 & 17,6 & 99 & 5,4 & 102 & 4,0 & 102 & 2,6 & 98 & 12,9 \\
\hline 120 & 107 & 2,1 & 100 & 7,1 & 100 & 3,3 & 106 & 6,7 & 119 & 21,7 & 104 & 7,4 & 96 & 6,2 & 102 & 7,4 & 98 & 2,9 & 121 & 20,4 & 98 & 4,9 & 104 & 7,3 & 105 & 5,6 & 101 & 14,1 \\
\hline 150 & 106 & 3,9 & 97 & 4,1 & 99 & 2,1 & 102 & 3,7 & 110 & 10,0 & 102 & 5,0 & 92 & 2,6 & 100 & 3,6 & 99 & 2,8 & 118 & 11,0 & 98 & 4,5 & 101 & 3,2 & 101 & 2,8 & 98 & 10,9 \\
\hline 180 & 102 & 3,2 & 94 & 6,0 & 96 & 2,9 & 96 & 4,8 & 107 & 11,4 & 100 & 5,7 & 90 & 1,0 & 95 & 5,1 & 95 & 2,9 & 117 & 15,1 & 100 & 3,5 & 96 & 4,0 & 97 & 2,0 & 94 & 10,3 \\
\hline 210 & 100 & 3,1 & 90 & 5,6 & 97 & 6,3 & 95 & 3,7 & 109 & 13,0 & 99 & 6,2 & 88 & 1,3 & 95 & 4,6 & 94 & 3,8 & 116 & 13,4 & 101 & 3,6 & 94 & 3,5 & 95 & 3,5 & 92 & 9,21 \\
\hline 240 & 89 & 4,2 & 83 & 6,9 & 90 & 2,9 & 90 & 10,7 & 103 & 14,3 & 92 & 6,1 & 82 & 1,2 & 91 & 17,2 & 85 & 4,5 & 111 & 12,1 & 103 & 3,6 & 87 & 3,8 & 88 & 3,5 & 89 & 10,4 \\
\hline 270 & 88 & 2,3 & 84 & 4,3 & 95 & 7,3 & 89 & 6,6 & 106 & 15,7 & 94 & 6,2 & 82 & 1,7 & 89 & 5,8 & 89 & 4,6 & 130 & 41,1 & 102 & 4,2 & 88 & 3,7 & 89 & 2,1 & 88 & 8,6 \\
\hline
\end{tabular}


Tabela 17. Resultados da análise de variância e teste de comparação de médias para os dados de vazão relativa (Qr), em L.h ${ }^{-1}$, dos gotejadores não-compensantes, aos 90 dias do início do experimento, na cultura do feijão

\begin{tabular}{|c|c|c|c|c|c|c|c|c|c|c|c|}
\hline \multirow{2}{*}{ Fonte de Variação } & \multirow[t]{2}{*}{ P15 } & \multirow[t]{2}{*}{ P30 } & \multirow[t]{2}{*}{ ÚMIDO } & \multirow[t]{2}{*}{ SECO } & \multirow[t]{2}{*}{$\mathrm{SC}$} & \multicolumn{2}{|c|}{ ÚMIDO } & \multicolumn{2}{|c|}{ SECO } & \multicolumn{2}{|c|}{$\mathrm{SC}$} \\
\hline & & & & & & P15 & P30 & P15 & P30 & P15 & P30 \\
\hline \multicolumn{12}{|l|}{ 1.Isolando PROF } \\
\hline Modelo (M OD) & $5,7 * *$ & $2,6^{*}$ & & & & & & & & & \\
\hline C.Enraiz. (CE) & $0,1^{\mathrm{ns}}$ & $0,5^{\mathrm{ns}}$ & & & & & & & & & \\
\hline MOD x CE & $1,2^{\mathrm{ns}}$ & $1,6^{\mathrm{ns}}$ & & & & & & & & & \\
\hline CV (\%)) & 14,4 & 14,0 & & & & & & & & & \\
\hline Úmido & $99,5 \mathrm{a}$ & $98,5 \mathrm{a}$ & & & & & & & & & \\
\hline Seco & $99,2 \mathrm{a}$ & $98,4 a$ & & & & & & & & & \\
\hline $\mathrm{SC}$ & $100,4 a$ & $100,4 \mathrm{a}$ & & & & & & & & & \\
\hline \multicolumn{12}{|l|}{ DMS / $(\mathrm{N}=70)$} \\
\hline \multicolumn{12}{|l|}{ 2.Isolando C. Enraiz. } \\
\hline Modelo (MOD) & & & $1,6^{\mathrm{ns}}$ & $4,4 * *$ & $15,0 * *$ & & & & & & \\
\hline Profundidade (PROF) & & & $0,1^{\mathrm{ns}}$ & $0,05^{\mathrm{ns}}$ & $0,00^{\mathrm{ns}}$ & & & & & & \\
\hline MOD x PROF & & & $1,3^{\mathrm{ns}}$ & $1,2^{\mathrm{ns}}$ & $0,3^{\text {ns }}$ & & & & & & \\
\hline $\mathrm{CV}(\%)$ & & & 16,7 & 17,7 & 4,5 & & & & & & \\
\hline $\mathrm{P} 15$ & & & $99,5 \mathrm{a}$ & $99,2 \mathrm{a}$ & $100,4 a$ & & & & & & \\
\hline P30 & & & $98,5 \mathrm{a}$ & $98,5 \mathrm{a}$ & $100,4 a$ & & & & & & \\
\hline \multirow{2}{*}{\multicolumn{12}{|c|}{$\begin{array}{l}\text { DMS / }(\mathrm{N}=70) \\
\text { 3.Isolando Prof e } \mathbf{C E}\end{array}$}} \\
\hline & & & & & & & & & & & \\
\hline Modelo & & & & & & $1,6^{\mathrm{ns}}$ & $1,3^{\text {ns }}$ & $3,3 * *$ & $2,2 *$ & $7,4 * *$ & $6,8 * *$ \\
\hline $\mathrm{CV}(\%)$ & & & & & & 16,5 & 16,7 & 18,5 & 17.0 & 4,5 & 4,8 \\
\hline \multicolumn{12}{|l|}{ Qr dos gotejadores } \\
\hline AQ & $104,9 a$ & $100,1 \mathrm{ab}$ & $96,3 a$ & $107,2 \mathrm{a}$ & $103,9 a$ & $104,3 \mathrm{a}$ & $88,4 a$ & $107,4 a$ & $107,0 \mathrm{a}$ & $103,0 \mathrm{ab}$ & $104,9 a$ \\
\hline $\mathrm{CD}$ & $92,0 \mathrm{bc}$ & $96,9 \mathrm{ab}$ & $96,0 \mathrm{a}$ & $90,0 \mathrm{bc}$ & $97,4 \mathrm{~b}$ & $97,2 \mathrm{a}$ & $94,8 \mathrm{a}$ & $81,0 \mathrm{~b}$ & $99,0 \mathrm{a}$ & $97,9 \mathrm{bc}$ & $96,9 b c$ \\
\hline DI & $101,6 a b$ & $98,5 \mathrm{ab}$ & $104,8 \mathrm{a}$ & $94,4 \mathrm{abc}$ & $101,0 \mathrm{ab}$ & $105,3 \mathrm{a}$ & $104,3 \mathrm{a}$ & $98,8 \mathrm{ab}$ & $90,0 \mathrm{a}$ & $100,7 \mathrm{ab}$ & $101,3 \mathrm{ab}$ \\
\hline HD & $89,4 \mathrm{c}$ & $91,2 b$ & $91,2 \mathrm{a}$ & $86,7 \mathrm{c}$ & $93 \mathrm{c}$ & $87,1 \mathrm{a}$ & $95,4 a$ & $88,4 \mathrm{ab}$ & $85,1 \mathrm{a}$ & $92,8 \mathrm{c}$ & $93,2 \mathrm{c}$ \\
\hline $\mathrm{HG}$ & $103,7 \mathrm{a}$ & $102,0 \mathrm{a}$ & $102,9 \mathrm{a}$ & $103,9 \mathrm{ab}$ & $101,7 \mathrm{a}$ & $104,1 \mathrm{a}$ & $101,8 \mathrm{a}$ & $105,2 \mathrm{ab}$ & $105,6 a$ & $101,8 \mathrm{ab}$ & $101,7 \mathrm{ab}$ \\
\hline $\mathrm{TR}$ & $104,6 \mathrm{a}$ & $102,0 \mathrm{a}$ & $102,1 \mathrm{a}$ & $104,5 \mathrm{ab}$ & $103,3 \mathrm{a}$ & $103,5 \mathrm{a}$ & $100,7 \mathrm{a}$ & $106,2 \mathrm{a}$ & $102,8 \mathrm{a}$ & $104,2 \mathrm{a}$ & $102,5 \mathrm{ab}$ \\
\hline DL & $101,5 \mathrm{ab}$ & $103,1 \mathrm{a}$ & $99,6 \mathrm{a}$ & $104,9 \mathrm{ab}$ & $102,3 \mathrm{a}$ & $95,1 \mathrm{a}$ & $104,1 \mathrm{a}$ & $107,1 \mathrm{a}$ & $102,8 \mathrm{a}$ & $102,3 \mathrm{ab}$ & $102,3 \mathrm{ab}$ \\
\hline DMS & 11,0 & 10,7 & 15,7 & 16,5 & 4,3 & 22,4 & 16,8 & 18,5 & 17,0 & 4,5 & 4,8 \\
\hline $\mathrm{N}$ & 30 & 30 & 20 & 20 & 20 & 10 & 10 & 10 & 10 & 10 & 10 \\
\hline
\end{tabular}

Médias seguidas da mesma letra não diferem pelo teste de Tuckey $(\mathrm{p}<0,05) . *$ - Teste $\mathrm{F}$ significativo no nível de $1 \%$ de probabilidade. ** _ Teste $\mathrm{F}$

significativo no nível de 5\% de probabilidade. DMS - Diferença Mínima Significativa no nível de 5\% de probabilidade. N - número de repetições. 
Tabela 18. Resultados da análise de variância e teste de comparação de médias para os dados de vazão relativa (Qr), em L.h ${ }^{-1}$, dos gotejadores autocompensantes, aos 90 dias do início do experimento, na cultura do feijão

\begin{tabular}{|c|c|c|c|c|c|c|c|c|c|c|c|}
\hline \multirow[t]{2}{*}{ Fonte de Variação } & \multirow[t]{2}{*}{$\mathrm{P} 15$} & \multirow[t]{2}{*}{ P30 } & \multirow[t]{2}{*}{ ÚMIDO } & \multirow[t]{2}{*}{ SECO } & \multirow[t]{2}{*}{$\mathrm{SC}$} & \multicolumn{2}{|c|}{ ÚMIDO } & \multicolumn{2}{|c|}{ SECO } & \multicolumn{2}{|c|}{$\mathrm{SC}$} \\
\hline & & & & & & $\mathrm{P} 15$ & P30 & $\mathrm{P} 15$ & P30 & P15 & P30 \\
\hline 1.Isolando PROF & & & & & & & & & & & \\
\hline Modelo (M OD) & $2,5^{*}$ & $3,5 * *$ & & & & & & & & & \\
\hline C.Enraiz. (CE) & $3,2 \mathrm{~ns}$ & $4,0 *$ & & & & & & & & & \\
\hline MOD x CE & $1,7 \mathrm{~ns}$ & $4,2 * *$ & & & & & & & & & \\
\hline $\mathrm{CV}(\%))$ & 67,9 & 68,9 & & & & & & & & & \\
\hline Úmido & $140,2 \mathrm{a}$ & $112,3 \mathrm{ab}$ & & & & & & & & & \\
\hline Seco & $110,8 \mathrm{a}$ & $140,7 \mathrm{a}$ & & & & & & & & & \\
\hline $\mathrm{SC}$ & $106,0 \mathrm{a}$ & $102,2 b$ & & & & & & & & & \\
\hline DMS / $(\mathrm{N}=70)$ & 36,4 & 35,0 & & & & & & & & & \\
\hline 2.Isolando C.Enraiz. & & & & & & & & & & & \\
\hline Modelo (MOD) & & & $2,0^{\mathrm{ns}}$ & $4,9 * *$ & $6,8 * *$ & & & & & & \\
\hline Profundidade (PROF) & & & $2,5^{\mathrm{ns}}$ & $2,9^{\mathrm{ns}}$ & $3,2^{\mathrm{ns}}$ & & & & & & \\
\hline MOD x PROF & & & $1,8^{\mathrm{ns}}$ & $3,3 * *$ & $1,5^{\mathrm{ns}}$ & & & & & & \\
\hline $\mathrm{CV}(\%)$ & & & 79,8 & 77,4 & 12,5 & & & & & & \\
\hline P15 & & & $140,2 \mathrm{a}$ & $110.8 \mathrm{a}$ & $105,9 \mathrm{a}$ & & & & & & \\
\hline $\mathrm{P} 30$ & & & $112,3 \mathrm{a}$ & $140,7 \mathrm{a}$ & $102,2 \mathrm{a}$ & & & & & & \\
\hline DMS / $(\mathrm{N}=70)$ & & & 37,0 & 36,8 & 4,4 & & & & & & \\
\hline 3.Isolando Prof e CE & & & & & & & & & & & \\
\hline Modelo & & & & & & $1,9^{\mathrm{ns}}$ & $1,6^{\mathrm{ns}}$ & $1,5^{\mathrm{ns}}$ & $4,2 * *$ & $4,3 * *$ & $4,3 * *$ \\
\hline $\mathrm{CV}(\%)$ & & & & & & 97,6 & 37,7 & 30,3 & 95,8 & 13,3 & 11,3 \\
\hline Qr dos gotejadores & & & & & & & & & & & \\
\hline $\mathrm{CP}$ & $120,8 \mathrm{ab}$ & $113,8 b$ & $132,5 \mathrm{a}$ & $115,5 \mathrm{~b}$ & $103,9 \mathrm{ab}$ & $132,5 \mathrm{a}$ & $132,6 \mathrm{a}$ & $121,1 \mathrm{a}$ & $109,8 \mathrm{~b}$ & $108,9 \mathrm{ab}$ & $99,0 \mathrm{~b}$ \\
\hline DLP & $114,1 \mathrm{ab}$ & $112,3 b$ & $107,9 a$ & $116,8 \mathrm{~b}$ & $114,8 \mathrm{a}$ & $106,4 a$ & $109,5 \mathrm{a}$ & $113,7 \mathrm{a}$ & $119,9 b$ & $122,3 \mathrm{a}$ & $107,4 \mathrm{ab}$ \\
\hline $\mathrm{DP}$ & $102,7 \mathrm{ab}$ & $101,6 b$ & $101,9 a$ & $103,7 b$ & $100,9 b$ & $100,6 a$ & $103,2 \mathrm{a}$ & $103,7 \mathrm{a}$ & $103,8 b$ & $103,9 \mathrm{ab}$ & $97,9 b$ \\
\hline $\mathrm{HP}$ & $162,7 \mathrm{a}$ & $178,0 \mathrm{a}$ & $179,9 \mathrm{a}$ & $233,5 \mathrm{a}$ & $97,6 b$ & $261,3 a$ & $98,5 \mathrm{a}$ & $129,0 \mathrm{a}$ & $338,1 \mathrm{a}$ & $97,8 b$ & $97,5 b$ \\
\hline NP & $133,9 \mathrm{ab}$ & $125,4 \mathrm{ab}$ & $158,4 \mathrm{a}$ & $116,0 \mathrm{~b}$ & $114,5 \mathrm{a}$ & $177,0 \mathrm{a}$ & $139,8 \mathrm{a}$ & $113,3 \mathrm{a}$ & $118,8 \mathrm{~b}$ & $111,6 \mathrm{ab}$ & $117,5 \mathrm{a}$ \\
\hline $\mathrm{RM}$ & $103,7 \mathrm{ab}$ & $100,3 b$ & $104,0 \mathrm{a}$ & $101,4 b$ & $100,6 b$ & $103,8 \mathrm{a}$ & $104,2 \mathrm{a}$ & $105,0 \mathrm{a}$ & $97,9 \mathrm{~b}$ & $102,4 b$ & $98,8 b$ \\
\hline VP & $94,7 b$ & $97,6 b$ & $99,0 \mathrm{a}$ & $93,1 \mathrm{~b}$ & $96,3 b$ & $99,6 \mathrm{a}$ & $98,4 \mathrm{a}$ & $89,5 \mathrm{a}$ & $96,7 \mathrm{~b}$ & $95,0 b$ & $97,6 b$ \\
\hline DMS & 62,3 & 62,9 & 95,7 & 92,5 & 12,3 & 186,3 & 57,9 & 45,7 & 183,7 & 19,2 & 15,8 \\
\hline $\mathrm{N}$ & 30 & 30 & 20 & 20 & 20 & 10 & 10 & 10 & 10 & 10 & 10 \\
\hline
\end{tabular}

Médias seguidas da mesma letra não diferem pelo teste de Tuckey $(\mathrm{p}<0,05)$ * - Teste F significativo no nível de $1 \%$ de probabilidade. ** - Teste $\mathrm{F}$ significativo no nível de 5\% de probabilidade. DMS - Diferença Mínima Significativa no nível de 5\% de probabilidade. N - número de repetições. 


\subsection{Experimento com a ocorrência de vácuo sobre o desempenho hidráulico de gotejadores em irrigação subsuperficial}

Da mesma forma que no experimento com intrusão de raízes, os resultados serão apresentados e discutidos dividindo-se os modelos de gotejadores avaliados em dois grupos, segundo sua característica de compensação de vazão. Uma vez que primeiramente simularam-se os níveis de vácuo de -26, -53 e -80 kPa e posteriormente tomou-se a decisão de reduzir o patamar inicial das tensões, simulando os níveis de - 13 e $-20 \mathrm{kPa}$, os resultados e a discussão também serão conduzidas nessa seqüência, devendo ser consideradas as seguintes questões: 1- uma vez que para o tratamento AS a Qr do gotejador corresponde à última leitura do experimento com a cultura do feijão, ocorrerá casos em que o valor de Qr de referência, ou seja, o próprio tratamento AS, esteja acima ou abaixo de 100\%. 2- os gotejadores utilizados para realizar os níveis de vácuo de $15 \mathrm{e}$ $20 \mathrm{kPa}$, os quais pertenciam aos vasos do tratamento FJP15, são oriundos de amostra diferente daquela utilizada para realização dos níveis de vácuo de $-20,-53$ e $-80 \mathrm{kPa}$, procedentes dos vasos do tratamento (FJP30); isso faz com que se tenha valores de Qr diferentes, no tratamento AS, para o primeiro e o segundo grupo de níveis de sucção. A utilização de vazões relativas, Qr, no entanto, permite que se faça as comparações entre tratamentos, aqui efetuadas.

Os valores de Qr para todos os tratamento e respectivos coeficientes de variação de vazão, CV, são apresentados nas Tabelas 19 e 20, para os gotejadores não compensante e autocompensantes, respectivamente.

\subsubsection{Gotejadores não-compensantes de pressão}

O efeito do vácuo nesse grupo de gotejadores resultou na redução da vazão, para a maior parte dos modelos avaliados (Figura 10). Apenas o modelo HD não sofreu redução de vazão nas tensões de -26, -53 e -80 kPa, permanecendo com Qr de 87\%; já para os níveis de vácuo menos intenso, o mesmo modelo sofreu redução de $13 \%$ e um leve aumento de vazão (3\%), quando da aplicação do vácuo de -20 kPa. Aumentos de 
vazão após a aplicação de um nível de vácuo superior ao anteriormente aplicado podem ser causados por dois fatores: $a$ ) erro na medida e $b$ ) como procedimento metodológico, o sistema de irrigação foi ativado (por um tempo T2), anteriormente a cada aplicação de determinado nível de vácuo, visando simular o estado de saturação do solo que ocorre no campo ao finalizar o tempo de irrigação da parcela, justo no ponto de saída de água do gotejador; assim, há a probabilidade de esse procedimento ter atuado como uma lavagem, retirando material já depositado. Tal hipótese tem seu contraponto porquanto as irrigações realizadas para estabelecimento do tratamento PI tiveram efeito reduzido na Qr do gotejadores.

O modelo AQ mostrou comportamento semelhante ao HD, apresentando, para os vácuos de $-26,-53$ e $-80 \mathrm{kPa}$, pequena redução de vazão. Por se tratar de uma fita gotejadora, com pequena espessura de parede $(0,15 \mathrm{~mm})$, o modelo AQ tende a colapsar no início da linha lateral quando da aplicação dos níveis mais altos de sucção, o que, supõe-se, impediu que o vácuo atuasse na saída de água do emissor, não ocorrendo sucção de partículas. Nos níveis de vácuo de -13 e $-20 \mathrm{kPa}$, foi observado que não ocorria colapso da fita, o que resultou em redução de vazão de $10 \%$.

Reduções de vazão de 5\% a $13 \%$ foram observadas nos demais modelos, os quais, com exceção do $\mathrm{CD}$, apresentaram pequenos incrementos de redução de vazão em resposta aos níveis -26, -53 e -80 kPa de vácuo. Os níveis de mais baixos de vácuo , - 13 e $-20 \mathrm{kPa}$, resultaram em maiores taxas de redução de vazão que as observadas para os níveis mais altos $(-26,-53$ e $-80 \mathrm{kPa})$. As maiores reduções ocorreram nos modelos AQ e DI, com $16 \%$ e $23 \%$, respectivamente, e entre $8 \%$ e $13 \%$, para os demais modelos.

O maior nível de redução de vazão para os menores níveis de vácuo (-13 e -20 $\mathrm{kPa}$ ) pode estar relacionado com a possibilidade de que quando sob o efeito dos níveis de sucção mais altos $(-53$ e $-80 \mathrm{kPa})$, a mistura solo-água imediatamente adjacente ao orifício de saída de água diminua rapidamente sua umidade, enrijecedo-se e formando um selo físico, impedindo a sucção da pasta de solo que se encontra mais distante do orifício, reduzindo a quantidade total de solo succionada. 

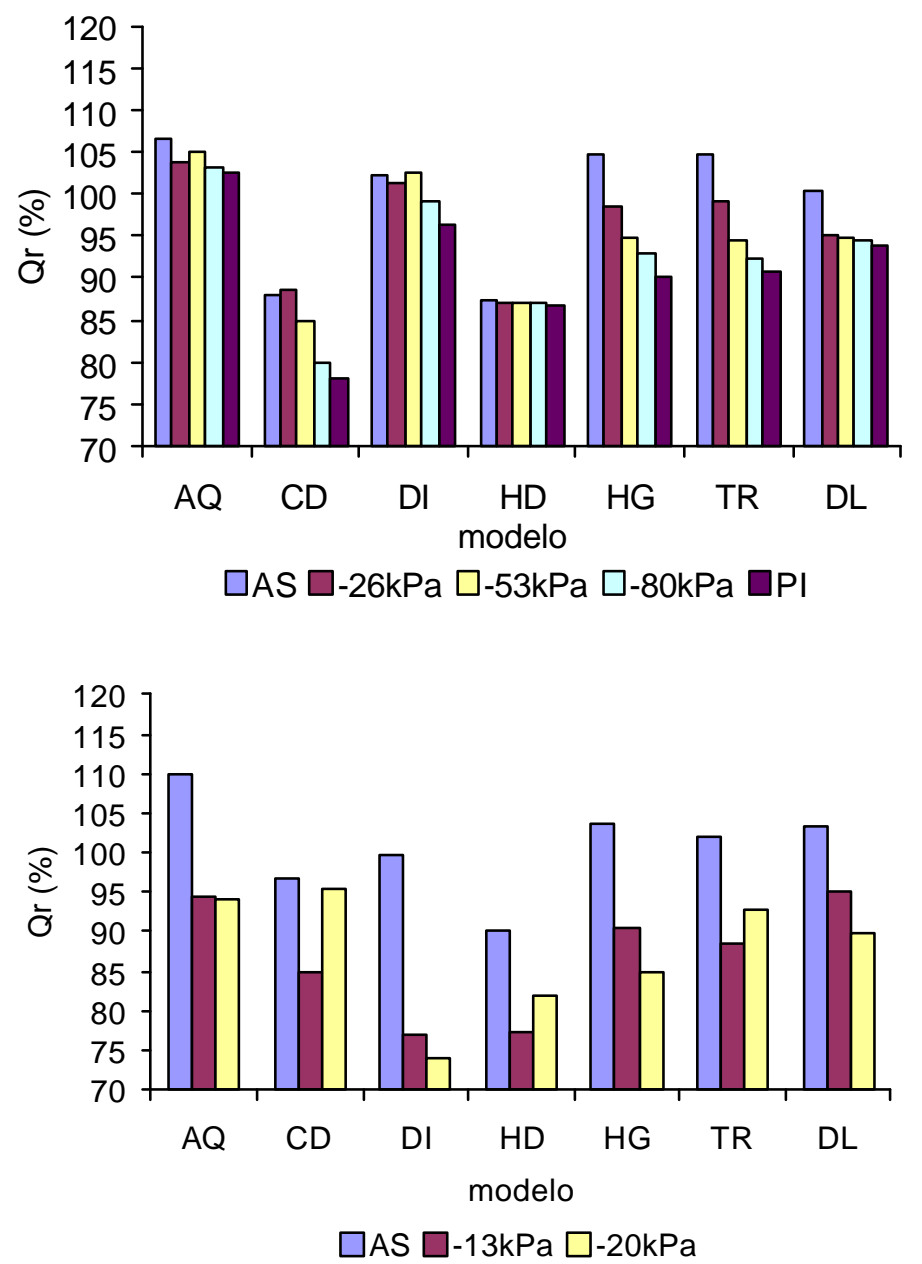

Figura 10 - Vazão relativa dos gotejadores não-compensantes em função dos níveis de vácuo avaliados

As reduções de vazão observadas em função da aplicação dos diversos níveis de vácuo mostraram um caráter irreversível, uma vez que em nenhum dos modelos ocorre u aumento de vazão depois de efetuadas 3 irrigações de 1 hora cada (tratamento PI). Ao contrário, houve tendência de redução da vazão após as irrigações, embora de valor não significativo. Trabalhando com um modelo de gotejador não-compensante em irrigação subsuperficial, Smajstrla et al. (2000) observaram redução de vazão de até 10\% quando o sistema era mantido não inoperante por vários dias. Entretanto a vazão nominal era 
recuperada após o sistema operar regularmente por dois a três dias. Tal comportamento sugere a existência de uma propriedade de autolimpeza do modelo, embora a natureza do entupimento não tenha sido determinada pelos autores, devendo estar, provavelmente, relacionada à causa biológica.

Tabela 19. Vazão relativa (Qr), em L.h ${ }^{-1}$, e coefic iente de variação de vazão $(\mathrm{CV})$, em $\%$, dos gotejadores não-compensantes, em \%, para os níveis de vácuo avaliados

\begin{tabular}{|c|c|c|c|c|c|c|c|c|c|c|c|c|c|c|}
\hline \multirow{2}{*}{$\begin{array}{c}\text { Mod./ } \\
\text { Trat. }\end{array}$} & \multicolumn{2}{|c|}{$\mathrm{AO}$} & \multicolumn{2}{|c|}{ CD } & \multicolumn{2}{|c|}{ DI } & \multicolumn{2}{|c|}{$\mathrm{HD}$} & \multicolumn{2}{|c|}{$\mathrm{HC}$} & \multicolumn{2}{|c|}{$\mathrm{TR}$} & \multicolumn{2}{|c|}{ DI. } \\
\hline & Qr & $\mathrm{CV}$ & Qr & $\mathrm{CV}$ & Qr & $\mathrm{CV}$ & Qr & $\mathrm{CV}$ & Qr & $\mathrm{CV}$ & Qr & $\mathrm{CV}$ & Qr & $\mathrm{CV}$ \\
\hline AS & 106 & ? & 88 & 36 & 102 & $x$ & 87 & $2 x$ & 105 & 4 & 105 & 4 & 100 & 25 \\
\hline$-26 \mathrm{kPa}$ & 104 & 3 & 88 & 15 & 101 & 9 & 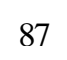 & 12 & 99 & 5 & 99 & 3 & 95 & 20 \\
\hline$-53 \mathrm{kPa}$ & 105 & 3 & 85 & 27 & 102 & 7 & 81 & 12 & 95 & 20 & 94 & 22 & 95 & 19 \\
\hline$-80 \mathrm{kPa}$ & 103 & 3 & 80 & 34 & 99 & 7 & 87 & 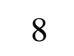 & 93 & 24 & 92 & 23 & 95 & 19 \\
\hline PI & 103 & 3 & 78 & 37 & 96 & 7 & 87 & 10 & 90 & 23 & 91 & 22 & 94 & 18 \\
\hline $\mathrm{A}$ & 110 & 30 & 97 & 1. & 100 & 26 & & 2 & 104 & & 102 & & 103 & 4 \\
\hline$-13 \mathrm{kPa}$ & 94 & 8 & 85 & 22 & 77 & 39 & 77 & 38 & 90 & 32 & 89 & 12 & 95 & 3 \\
\hline$-20 \mathrm{kPa}$ & 94 & 7 & 95 & 51 & 74 & 48 & 82 & 28 & 85 & 37 & 93 & 8 & 90 & 24 \\
\hline
\end{tabular}

\subsubsection{Gotejadores autocompensantes de pressão}

Contrariamente ao observado no grupo dos gotejadores não-compensantes, os gotejadores autocompensantes mostraram, para a maioria dos modelos, um aumento de vazão em resposta aos tratamentos de aplicação de vácuo.

Os maiores incrementos de vazão, observados já com a aplicação do vácuo de $-26 \mathrm{kPa}$, ocorreram com os modelo CP, NP e HP, com incrementos de 74\%, $128 \%$ e 401\%, em relação à vazão anterior à aplicação do vácuo. Para esses modelos, o nível de vácuo de $-53 \mathrm{kPa}$ somente proporcionou novo incremento de vazão no modelo $\mathrm{CP}$, sendo de 22 pontos porcentuais, em relação à vazão medida para o tratamento $-26 \mathrm{kPa}$; 
nos modelos NP e HP, de modo inverso, os tratamentos de -56 e -80 kPa redundaram em redução de vazão.
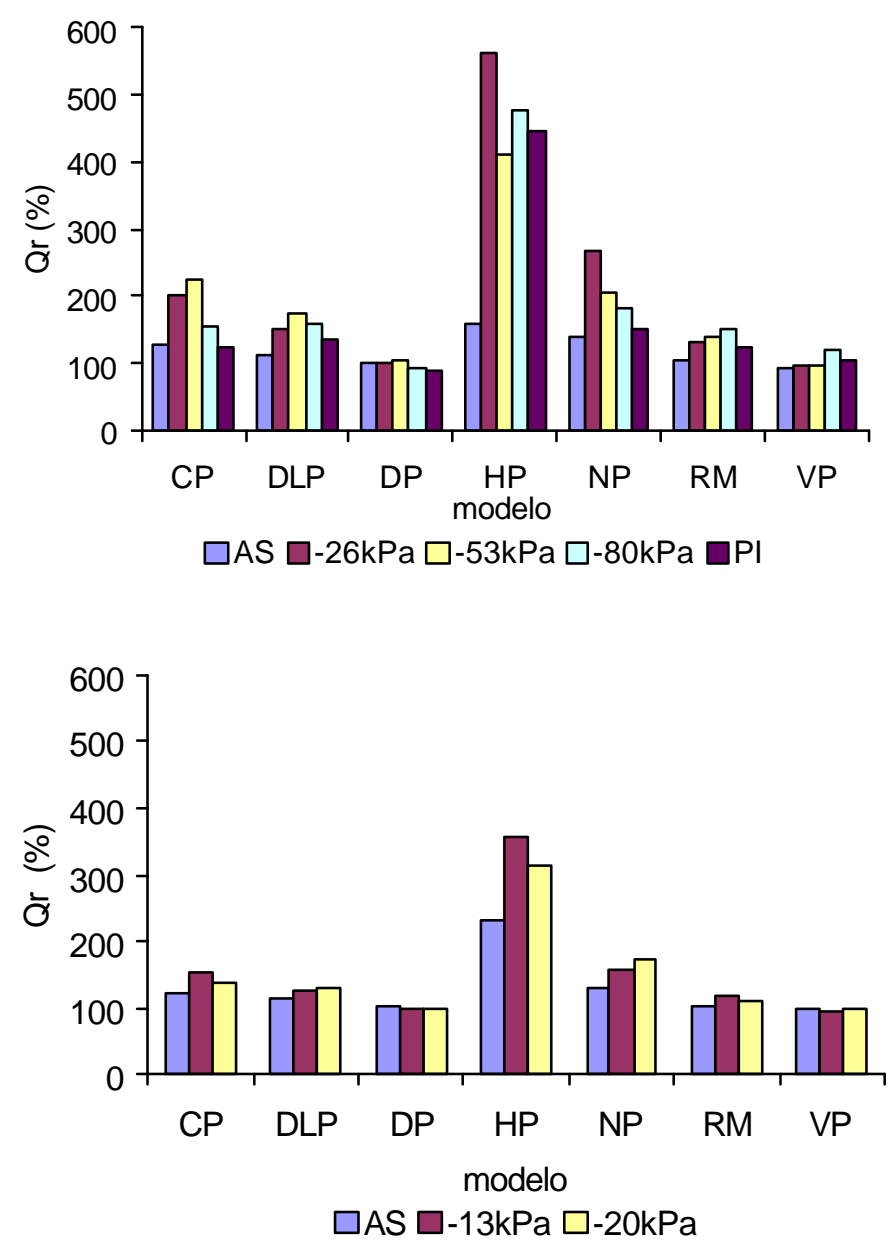

Figura 11 - Vazão relativa dos gotejadores autocompensantes em função dos níveis de vácuo avaliados

Nos modelos DP e VP, o efeito dos níveis de vácuo de -13, -20, -26, -53 e $-80 \mathrm{kPa}$ foi inexistente para o primeiro modelo, ou de pequena magnitude para o segundo, e neste somente o vácuo de $-80 \mathrm{kPa}$ foi o que provocou significativo incremento de vazão (20\%) em relação à vazão medida para o tratamento $-56 \mathrm{kPa}$. 
Um comportamento intermediário foi observado nos modelos DLP e RM, os quais apresentaram incrementos de vazão de $42 \%$ e $28 \%$, respectivamente, para o tratamento $-26 \mathrm{kPa}$. Ambos os modelos apresentaram incrementos de vazão para o tratamento $-53 \mathrm{kPa}$, conforme apresentado na Figura 11. Em experimento conduzido por Vilela et al. (2001), foi observado aumento de 33\% na vazão do modelo RM, em função da simulação da entrada de partículas de solo (de textura franco-arenosa) na malha hidráulica.

De modo inverso ao ocorrido para o grupo de gotejadores não compensantes, os tratamentos de -13 e $-20 \mathrm{kPa}$ resultaram em menores incrementos de vazão para os modelo autocompensantes. No modelo HP, em que o efeito foi mais intenso, o incremento foi de $127 \%$ em relação à vazão no tratamento AS. Mais uma vez, os modelos DP e VP praticamente não foram afetados pelo vácuo, enquanto os modelos CP, DLP, NP e RM mostraram comportamento intermediário, com incrementos de vazão, para o tratamento de $-13 \mathrm{kPa}$, de $31 \%, 10 \%, 26 \%$ e $15 \%$, respectivamente, em relação ao tratamento AS. Somente no modelo NP, o tratamento $-20 \mathrm{kPa}$ resultou aumento de vazão em relação ao tratamento - $13 \mathrm{kPa}(14 \%)$.

Tabela 20. Vazão relativa (Qr), em L.h ${ }^{-1}$, e coeficiente de variação de vazão $(\mathrm{CV})$, em $\%$, dos gotejadores autocompensantes, em \%, para os níveis de vácuo avaliados

\begin{tabular}{|c|c|c|c|c|c|c|c|c|c|c|c|c|c|c|}
\hline \multirow{2}{*}{ Mod./ } & \multicolumn{2}{|c|}{$\mathrm{CP}$} & \multicolumn{2}{|c|}{ DLP } & \multicolumn{2}{|c|}{ DP } & \multicolumn{2}{|c|}{ HP } & \multicolumn{2}{|c|}{ NP } & \multicolumn{2}{|c|}{$\mathrm{RM}$} & \multicolumn{2}{|c|}{ VP } \\
\hline & $\mathrm{nr}$ & rV & $\mathrm{nr}$ & rV & Or & $r \mathrm{~V}$ & $\cap r$ & rV & $\mathrm{nr}$ & rV & Or & $r \mathrm{~V}$ & $\mathrm{nr}$ & $r \mathrm{~V}$ \\
\hline AS & 127 & 35 & 110 & 8 & 103 & 5 & 160 & 122 & 140 & 57 & 105 & 17 & 95 & 13 \\
\hline$-26 \mathrm{kPa}$ & 202 & 52 & 152 & 50 & 103 & 6 & 562 & 78 & 268 & 79 & 133 & 27 & 99 & 11 \\
\hline$-53 \mathrm{kPa}$ & 224 & 52 & 173 & 46 & 105 & 15 & 411 & 90 & 206 & 89 & 139 & 29 & 99 & 12 \\
\hline$-80 \mathrm{kPa}$ & 154 & 50 & 159 & 72 & 95 & 36 & 476 & 80 & 184 & 47 & 151 & 33 & 119 & 36 \\
\hline PI & 125 & 48 & 136 & 61 & 89 & 40 & 445 & 91 & 152 & 45 & 123 & 32 & 105 & 13 \\
\hline AS & 123 & 60 & 116 & 23 & 104 & 5 & 231 & 123 & 131 & 33 & 102 & 16 & 99 & 13 \\
\hline$-13 \mathrm{kPa}$ & 155 & 84 & 126 & 24 & 98 & 6 & 358 & 104 & 158 & 52 & 117 & 34 & 97 & 23 \\
\hline$-20 \mathrm{kPa}$ & 140 & 79 & 129 & 34 & 98 & 10 & 314 & 118 & 172 & 65 & 112 & 22 & 98 & 12 \\
\hline
\end{tabular}


Os modelos autocompensantes também apresentaram comportamento inverso aos não-compensantes quanto ao efeito das irrigações sucessivas (tratamento PI) efetuadas após a aplicação dos tratamentos -26, -53 e -80 kPa. Para todos os modelos houve redução de vazão que variaram de $28 \%$ a $32 \%$ em relação à vazão do tratamento -80 kPa, exceto para os modelos DP e VP, nos quais a redução foi de $6 \%$ e 14\%, respectivamente. A eficiência da irrigação como um fator minimizador do efeito do vácuo, ou seja, uma ação de limpeza das partículas intrusas, não é conclusiva, uma vez que, como se observa na Figura 11, as vazões já apresentavam, para alguns modelos, reduções nos níveis mais altos de vácuo $(-80 \mathrm{kPa})$. No modelo HP, por exemplo, embora a redução tenha ocorrido, não foi suficiente para resultar em uma Qr próxima a 100\%. 


\section{DISCUSSÃO}

\subsection{Interação sistema radicular $x$ umidade do solo $x$ profundidade de instalação}

As diferenças estatisticamente significativas da Qr entre o tratamento SC e os tratamentos com presença de raiz (Úmido e Seco), ocorridas no experimento da cultura da cana e para o grupo dos gotejadores não-compensantes, evidenciam que o processo de intrusão de raízes foi um dos fatores que determinaram a redução da vazão, nesse grupo de gotejadores. Os elevados valores de $\mathrm{CV}$ das vazões indicam que o processo de intrusão assume caráter aleatório, ou seja, está relacionado à densidade do sistema radicular próximo ao orifício de saída de água do gotejador, elevando a probabilidade de entrada de raízes, semelhantemente ao processo de interceptação radicular relacionado à nutrição das plantas. Embora não tenha havido, para a última leitura de vazão do experimento, diferença estatisticamente significativa entre as médias de Qr dos tratamentos Úmido e Seco, a observação de todas as épocas de medição de vazão nos modelos que apresentaram maior redução de Qr, evidenciam que o processo de intrusão foi mais intenso e precoce no tratamento Úmido (Figura 6 e 7), porquanto, associado a um maior desenvolvimento da parte aérea da planta observou-se maior volume de raízes e, conseqüentemente, maior probabilidade de estas "interceptarem" o orifício do gotejador.

Uma vez que, após o encerramento da coleta seqüencial de dados, foi dada continuidade ao experimento com a cultura da cana, não foi possível obter dados de massa de raiz para os tratamentos Úmido e Seco. No entanto, a pesagem de colmos para esses tratamentos revelou diferença significativa de produção com um peso médio por vaso de $6,15 \mathrm{~kg}(\mathrm{n}=10 ;$ ó = 1,92) para o tratamento Úmido e 2,44 kg ( $\mathrm{n}=10$; ó = 
0,63) para o Seco. Como acima mencionado, a maior produção de colmo deve ter induzido à maior produção de massa de raiz no tratamento Úmido e esta certamente deve ter contribuído para a maior ocorrência de redução de vazão, em relação ao tratamento Seco. Tomando-se por base a área do vaso utilizado no experimento $(0,26$ $\mathrm{m}^{2}$ ), a produtividade da cultura foi de $233,6 \mathrm{Mg} \cdot \mathrm{ha}^{-1}$ de colmos para o tratamento Úmido e de 92,7 Mg.ha-1 para o Seco.

Através da Figura 12, pode-se visualizar a alta densidade de raízes encontrada junto aos gotejadores nas duas profundidades de instalação avaliadas. Tal condição se mostra mais agressiva que a que seria encontrada em campo, porém, em termos relativos, em se observando diferença de desempenho entre os modelos de gotejador nessa condição, tal comportamento, provavelmente, também se observará em campo.

Dessa forma, os resultados obtidos no experimento com a cana-de-açúcar e em menor grau com o feijão, contrariam a hipótese normalmente apresentada em literatura de que a alta freqüência da irrigação, não permitindo elevadas alternâncias no regime de umidade do solo, seria uma estratégia de preve nção da intrusão de raízes na irrigação por gotejamento subsuperficial. Essa suposição foi apontada por Casaño, (1995), para o qual dependendo da textura do solo e da freqüência de irrigação, a intrusão de raízes pode não ocorrer. Igualmente, a hipótese foi também citada por Camp et. al. (2000), embora esses autores tenham ressalvado que isso pode não ser verdadeiro para todas as culturas.

A aleatoriedade do processo de intrusão das raízes e a maior ocorrência sob condição de umidade de solo mais favorável foram também observadas por Faria (2002), que trabalhou com gotejamento subsuperficial nas culturas de café e laranja.

$\mathrm{O}$ pressuposto de que o déficit de umidade eleva o potencial de intrusão de raízes nos emissores baseia-se na assunção de que a característica de hidrotropismo positivo atua nas raízes, o que resultaria em um deslocamento das radicelas para o orifício de saída de água do gotejador, onde, supostamente, ter-se-ia o solo com maior grau de umidade. A esse respeito, Carmi et al. (1991), trabalhando com a cultura do algodão, concluíram que os mais altos níveis de irrigação resultaram no aumento do crescimento das raízes mas não levaram a um aprofundamento do sistema radicular, a despeito do aprofundamento da zona úmida nos tratamentos que receberam mais água. 
Do mesmo modo e também para a cultura do algodão, Plaut et al. (1996), cultivando plantas em colunas de solo com suprimento de água por meio de emissores instalados à profundidade de $0,45 \mathrm{~m}$, não observaram evidência de hidrotropismo - definido por eles como o crescimento da raiz através de uma camada de solo seco até uma camada de solo úmido. Segundo esses autores, o crescimento foi predominantemente para baixo, mas, provavelmente, potencializado pelo geotropismo positivo.

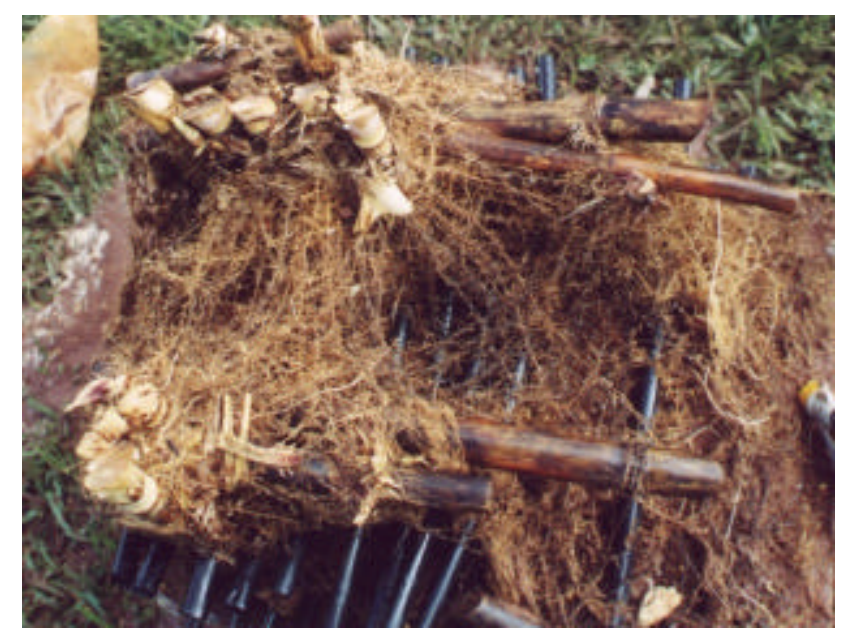

Figura 12 - Sistema radicular da cana-de-açúcar, no tratamento com solo úmido

Outra hipótese levantada é a de que haveria maior desenvolvimento das raízes, isolando-se outros fatores, justamente na região do solo com melhor condição de umidade, ou seja, no volume de solo próximo ao orifício de saída de água do gotejador, aumentando a probabilidade de intrusão. Trabalhando com imposição de déficit hídrico na cultura do feijão, NunezBarrios, citado por Graham \& Ranalli (1997), notou rápida expansão das raízes no início do período de déficit hídrico, seguindo-se a morte dessas raízes e um crescimento compensatório em camadas mais profundas. Na verdade, no momento em que as condições de umidade tornam-se inadequadas na superfície, o crescimento passa a ocorrer em locais mais favoráveis, isto é, nas camadas mais profundas, com maior umidade. Contrariamente a essa linha de raciocínio, Suarez-Rey et al. (2000), através da inspeção visual dos gotejadores, correlacionaram a ocorrência de 
stress hídrico em parcelas com maior conteúdo de areia à intrusão de raízes em emissores instalados em parcelas de grama Bermuda [Cynodom dactylon (L.) Pers. x $C$. transvaalensis].

Deve-se levar em conta, na análise do comportamento do sistema radicular nesse experimento, o fato de o déficit hídrico imposto ao tratamento Seco ter sido severo (Figura 5), o que, hipoteticamente, resultaria em menor volume de raiz em relação ao tratamento Úmido, reduzindo a probabilidade de intrusão das raízes, quando comparado à ocorrência de déficits menos severos, que normalmente ocorrem em cultivos irrigados por sistemas localizados. De acordo com Ehlers (1980), citado por Klepper (1991), o potencial de água no qual cessa a elongação da raiz varia de acordo com a textura e densidade global do solo, mas se espera que essa taxa seja mínima em solos com potencial de água em torno de $-0,8 \mathrm{MPa}$. No presente trabalho, essa condição não foi encontrada no solo dos vasos do tratamento Seco, já que a irrigação era efetuada quando o potencial de água no solo atingia $-80 \mathrm{kPa}$. Entretanto, as plantas desse tratamento apresentavam sintoma visual evidente de déficit hídrico .

A semelhança das médias de Qr para os gotejadores instalados nas profundidades P15 e P30, que resultou em variância não-significativa desse fator para os dois grupos de gotejadores e as três condições de enraizamento estudados, pode estar relacionada à pequena diferença nas profundidades estabelecidas como tratamento. Pode ter ocorrido também que o elevado número de plantas por vaso tenha favorecido uma densidade de raízes de tal magnitude que o efeito da profundidade tenha sido anulado. De todo modo, a inexistência de diferença significativa para o efeito da profundidade de instalação dos gotejadores indica, para esse fator, a não-intervenção da condição experimental, no princípio da independência dos tratamentos.

No experimento com o feijão, o menor efeito dos tratamentos na vazão dos emissores não-compensantes parece estar mais relacionado ao ciclo curto da cultura, uma vez que para esse grupo de gotejadores também foi reduzido o efeito dos tratamentos na cultura da cana-de-açúcar até os 90 dias do início do experimento.

Como o sistema radicular do feijão é superficial, com a grande maioria das raízes nos primeiros 0,2 m do perfil do solo (Vieira, 1967; Avilan Ronvira \& Neptune, 
1976a), o incremento de vazão observado nos gotejadores autocompensantes do tratamento P30 sugere que para esse grupo de emissores o efeito da sucção de partículas do solo seja mais preponderante que a intrusão de raízes, atingindo a câmara de compensação dos mesmos.

Outro aspecto se refere à espessura das raízes, que se apresentaram predominantemente finas, conforme pôde ser visualizado quando da lavagem para determinação do peso seco em 6 vasos utilizados no experimento (dados não apresentados) após o corte da parte aérea, o que concorda com o afirmado por Vieira (1967) quanto ao comportamento típico de sistema radicular fasciculado, embora com raiz pivotante, característico do feijoeiro: a pequena espessura das raízes pode não ter sido suficiente para obstruir o orifício ou labirinto de passagem de água do gotejador, embora o tenha sido para provocar incremento de vazão nos gotejadores autocompensantes.

No entupimento de emissores por causa química, física ou biológica, o impacto da ocorrência do entupimento afeta a vazão do emissor individualmente, sendo que o efeito final dessas causas de entupimento na malha hidráulica será função do número e do nível de entupimento dos emissores afetados. Já, no processo de intrusão radicular, além do efeito individual na vazão do emissor, as raízes podem se desenvolver internamente na linha lateral após atravessar todo o labirinto do gotejador, conforme ocorrido no experimento e apresentado na Figura 13. Nesse caso, haverá comprometimento das condições de fluxo em todo segmento à jusante do ponto de intrusão, resultando em impacto de maior magnitude na hidráulica da parcela. Esse impacto será tanto mais significativo quanto mais próximo do início da linha lateral ocorra o enovelamento no interior do tubo. Dessa forma, no desenvolvimento de novos modelos de gotejadores, o estudo de estratégias de prevenção à intrusão deve-se basear também em arranjos de arquitetura que impeçam ou dificultem a penetração da raiz intrusa no interior do tubo gotejador. 

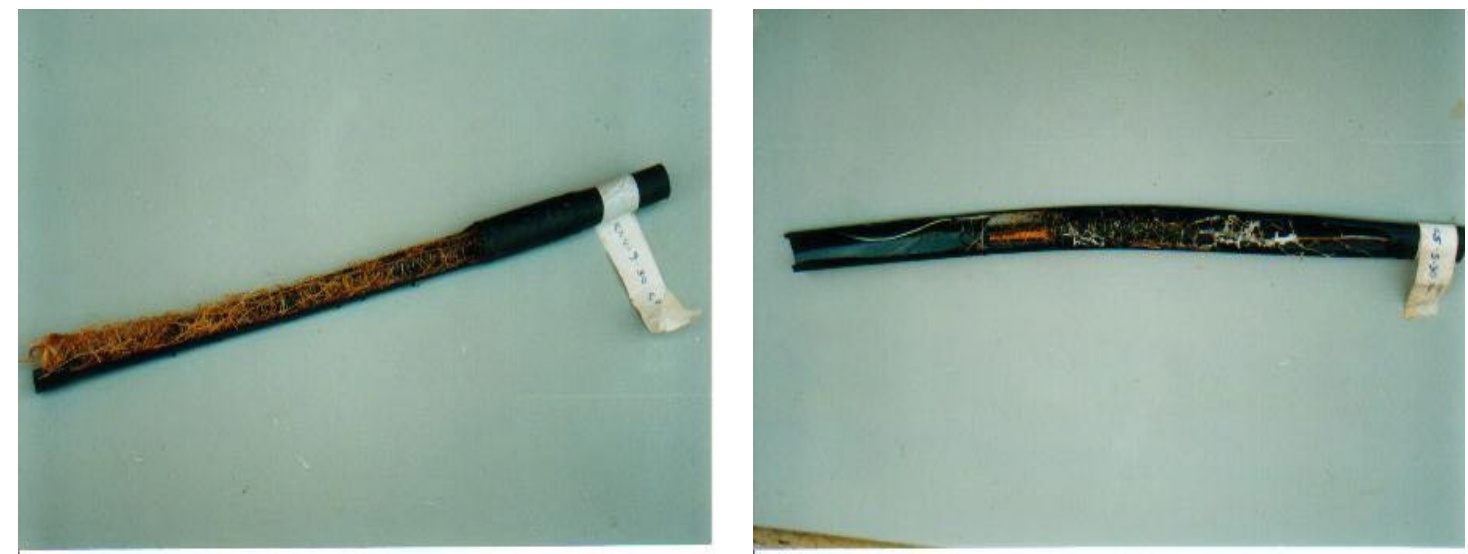

Figura 13 - Enovelamento de raízes no interior do tubo gotejador

No planejamento metodológico do experimento não foi prevista a medição da temperatura da água no momento da medição de vazão. Parchomckuck (1976) observou variações de vazão ao longo de uma linha de gotejadores em conseqüência do aquecimento progressivo da água no interior da linha lateral Para a condição do experimento, dado que não há linha lateral longa o suficiente para resultar em aquecimento da água, o mesmo pode ocorrer em função da variação estacional de temperatura ambiente. Segundo esse autor, esse fator incide, principalmente, em gotejadores de regime de fluxo do tipo laminar e, em menor grau, os de fluxo turbulento, como os utilizados no experimento. Não se espera, portanto, interferência significativa nas medidas da vazão efetuadas no decorrer do experimento, em função da variação estacional de temperatura ambiente.

\subsection{Arquitetura do gotejadores}

A hipótese básica do experimento considera determinados aspectos da arquitetura de cada modelo de gotejador como fator importante no grau de suscetibilidade do mesmo ao processo de intrusão de raízes. O processo de intrus ivo $\mathbf{m}$ orifício de entrada do tubo gotejador pode resultar em dois efeitos de caráter seqüencial e aditivo: o primeiro se refere à redução ou aumento da vazão do emissor (efeito 
pontual); o segundo é decorrente do enovelamento da raiz na linha lateral (Figura 13), o que afeta o fluxo de água à jusante do ponto de intrusão.

Os aspectos da arquitetura considerados na discussão dos resultados são:

1. Comprimento do labirinto de passagem de água, cuja função é atuar como dissipador de energia, reduzindo a pressão reinante no interior do tubo a uma pressão muito próxima à atmosférica, na saída do gotejador;

2. Área de filtragem, local onde se efetua a filtragem da água que penetra no gotejador. A área bruta se refere à área total ocupada pelo filtro; a área líquida foi calculada, quando possível, levando-se em conta apenas a secção livre de passagem da água;

3. Número, área e função das câmaras que funcionam como estabilizadoras do fluxo;

4. Número e posicionamento do ou dos orifícios de saída de água.

5. Ponto crítico ao fluxo da água, o qual se constitui no primeiro ponto onde uma vez a raiz o tenha atingido, causará efeito no fluxo de água, mesmo que haja outros caminhos à montante deste esteja livre.

As correlações dos resultados obtidos com os aspectos acima citados são analisadas para cada modelo avaliado.

Todos os modelos avaliados foram desenhados em escala e em formato bidimensional, com auxílio de um software de desenho, que permite o cálculo de áreas e medidas do comprimento do labirinto e do percurso da água. No caso específico da distância entre a saída do labirinto e o orifício de saída de água nos modelos cilíndricos, trata-se de uma medida não-fixa, uma vezque há variabilidade significativa no processo de fabricação do gotejador, tanto do ponto do perímetro da câmara de saída de água onde é perfurado o orifício do tubo de polietileno, como o lado da câmara onde é efetuado o furo, para os modelos que apresentam esses furos em apenas um lado do seu comprimento. A largura do labirinto se refere à distância entre as pontas dos "dentes" que atuam como dissipadores de energia.

A linha azul, nos desenhos dos modelos, representa o percurso percorrido pela água desde sua entrada na área de filtragem até sua saída para atmosfera. Nos modelos 
do tipo pastilha (TR, DL, HD) ou fita gotejadora (AQ) esse caminho é único. Nos modelos do tipo cilíndrico o caminhamento da água é único somente até o final do labirinto ou até a saída da câmara de compensação, sendo exceção os modelos CP, DP, DLP e VP.

O percurso percorrido pela raiz, desde o início do processo de intrusão, através do orifício de saída de água até sua entrada no interior do tubo, presume-se ser o mesmo do da água, sendo que em sentido oposto. Para efeito de discussão, adotou-se caminhamento idêntico ao do fluxo da água, assim, o filtro se constitui no marco referencial. Uma descrição qualitativa da arquitetura dos mesmos gotejadores utilizados no presente experimento foi efetuada por Mousinho et al. (2003).

\subsubsection{Gotejadores não-compensantes de pressão}

\subsubsection{Modelo AQ}

Uma vez que se trata de uma fita gotejadora, o modelo AQ apresenta um percurso de fluxo de água retilíneo, conforme apresentado na Figura 14. A água penetra por uma série de filtros em um canalículo com $122 \mathrm{~mm}$ de comprimento e depois passa por um labirinto com $65 \mathrm{~mm}$ de comprimento, que deságua em um canal livre de $42,5 \mathrm{~mm}$, o qual se comunica com o corte de saída da água. Assim, o comprimento total do percurso da água é de $229,5 \mathrm{~mm}$.

Uma característica do modelo AQ que poderia representar uma proteção potencial contra intrusão de raízes baseada em barreira física se refere ao orifício de saída de água, o qual é constituído por um corte transversal na parede da fita; quando em operação, a modificação do formato da secção faz o orifício assumir um formato semiesférico e quando fora de operação as bordas do corte permanecem unidas, evitando a penetração das raízes. Um segundo mecanismo de proteção, também baseado em barreira física, foi apresentado por Barth (1999), no qual um flap (tampão) cobre o orifício de saída de água quando fora de operação, impedindo a intrusão de raízes. 


\section{Corte de saída da}

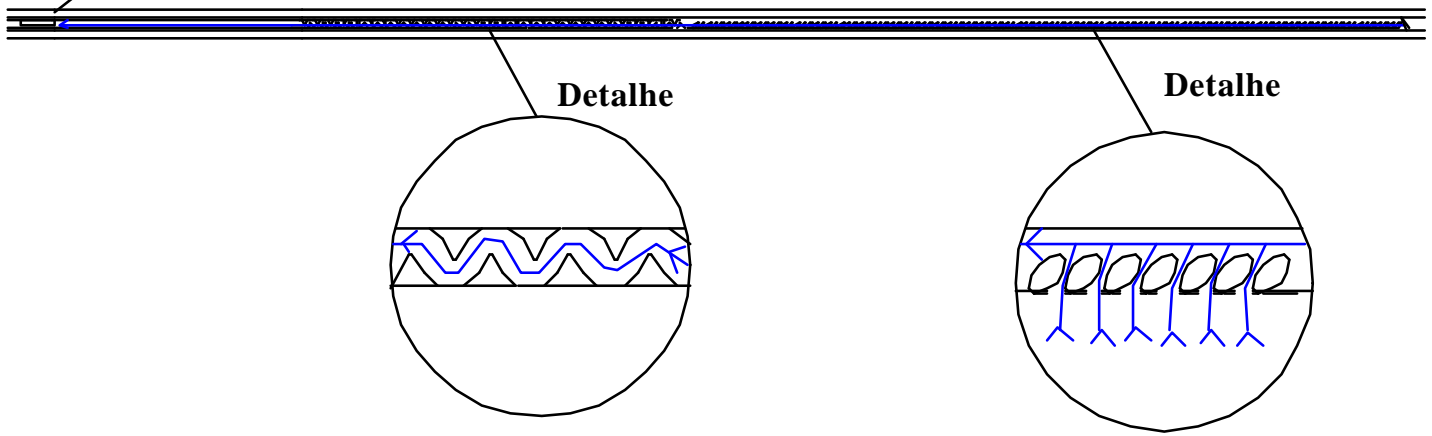

Figura 14 - Desenho esquemático do modelo AQ

Como mostrado na apresentação dos resultados, esse modelo apresentou um dos maiores níveis de redução de vazão no final do experimento. Dessa forma, embora a ação das raízes tenha se pronunciado mais tardiamente (180 dias) que nos demais modelos (120 dias em média), como se vê na Figura 6, o mecanismo de barreira física não foi efetivo para evitar o processo intrusivo. Essa hipótese é corroborada pelo desempenho do modelo nos vasos sem presença de raiz (tratamento $\mathrm{SC}$ ), em que o decréscimo de vazão foi bem menor que naqueles com cultivo.

A largura total do canal de passagem de água é de $2 \mathrm{~mm}$, maior que no demais modelos, os quais têm um máximo de $1 \mathrm{~mm}$. Embora não se tenha conseguido efetuar medições, a profundidade do canal é pequena, o que resulta em uma pequena secção de passagem de água. Como conseqüência, a intrusão, mesmo de raízes bem finas, é suficiente para provocar significativa redução de vazão.

Nesse modelo, a possibilidade de a raiz penetrar no interior da secção e causar enovelamento é mínima, uma vez que a filtragemé efetuada por um grande número de orifícios de pequeno diâmetro (64 filtros por saída para o espaçamento entre cortes de 
saída da água de 0,2 e 0,4 m e 200 filtros por saída para as fitas com espaçamento de $0,3 \mathrm{~m}$ e $0,6 \mathrm{~m}$, segundo catálogo do fabricante).

\subsubsection{Modelo CD}

Nesse modelo, o comprimento do percurso, da saída do filtro até o final do labirinto, é de $115 \mathrm{~mm}$; a área de filtragem total é de $17,7 \mathrm{~mm}^{2}$, porém a área líquida é de apenas $3 \mathrm{~mm}^{2}$. Possui três orifícios de saída de água, os quais se localizam em uma única câmara das duas existentes, tornando a outra uma câmara morta. O ponto crítico do fluxo é a saída do labirinto, distante, aproximadamente, 24,2 mm do orifício de saída de água mais próximo; uma vez a raiz tenha atingido esse local, a ponto de comprometer significativamente sua secção de passagem, obstruirá o emissor, independentemente de o outro orifício de saída de água estar livre de intrusão. A área da câmara de saída de água é de $181 \mathrm{~mm}^{2}$. A segunda câmara, que não tem a função de saída da água, tem o mesmo valor de área. Ressalte-se que no processo de fabricação do gotejador o local onde é efetuado o orifício de saída da água não é fixo em relação às câmaras de saída. Assim as medidas apresentadas acima podem sofrer variação em função da localização do orifício. Uma vez que em amostras dissecadas a maioria dos orifícios se encontrava na câmara adjacente ao filtro, essa foi a configuração adotada na Figura 15.

Após penetrar em qualquer dos dois orifícios de saída de água, a raiz se desenvolve inicialmente na câmara de saída. Para se expandir, ela passará, necessariamente, pelo ponto final do labirinto (ponto crítico do fluxo), podendo penetrar neste, como ocorreu na Figura 16, ou passar perpendicularmente, indo em direção à câmara morta e, posteriormente, penetrar no labirinto como sugere a Figura 17. 


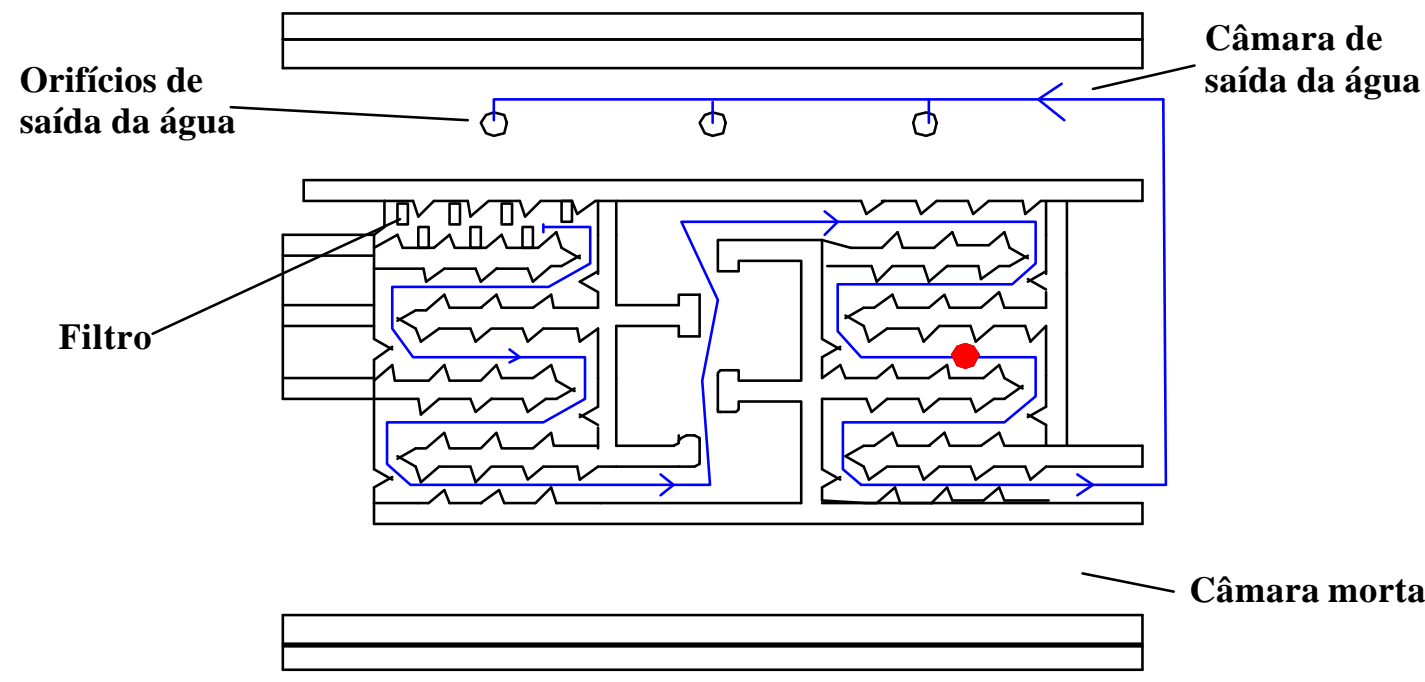

Figura 15 - Desenho esquemático do modelo CD

Os gráficos da evolução da vazão desses gotejadores denotam claramente o momento em que o processo de intrusão refletiu na vazão. $\mathrm{O}$ círculo vermelho na Figura 15, localiza o ponto do labirinto onde se encontrava a coifa de uma raiz secundária no gotejador apresentado na Figura 16b. Embora o avanço se verifique com uma raiz fina, a porção anterior do labirinto e da câmara morta já se encontra totalmente tomada por uma massa densa resultante do desenvolvimento da raiz no interior do gotejador.

O desenvolvimento da raiz no interior do gotejador é favorecido pela presença de solo succionado e depositado na câmara de saída de água (Figura 17); a sucção de solo se constitui em fator adicional de variação de vazão dos gotejadores.

Para os dois gotejadores apresentados nas Figuras 16 e 17, o início do processo de intrusão ocorreu entre 150 e 180 dias do início do experimento, sendo esse período comum para a maioria dos modelos, como já discutido anteriormente. 


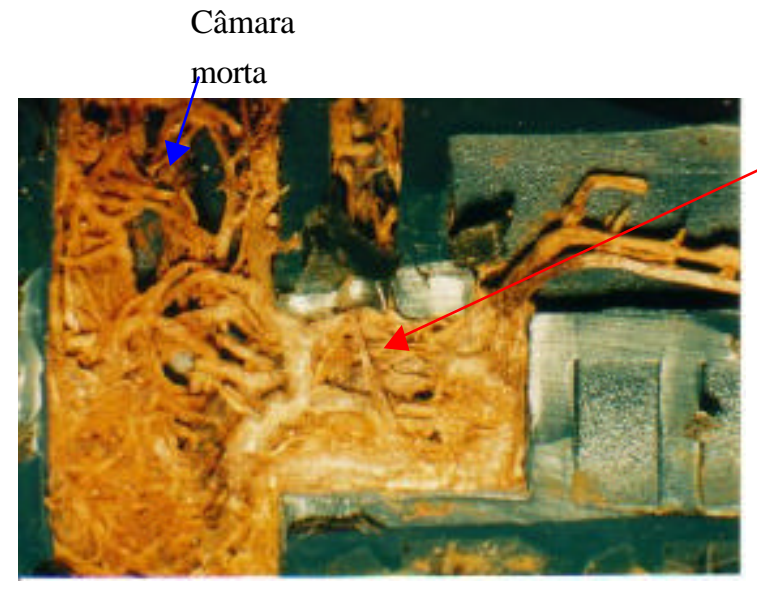

a

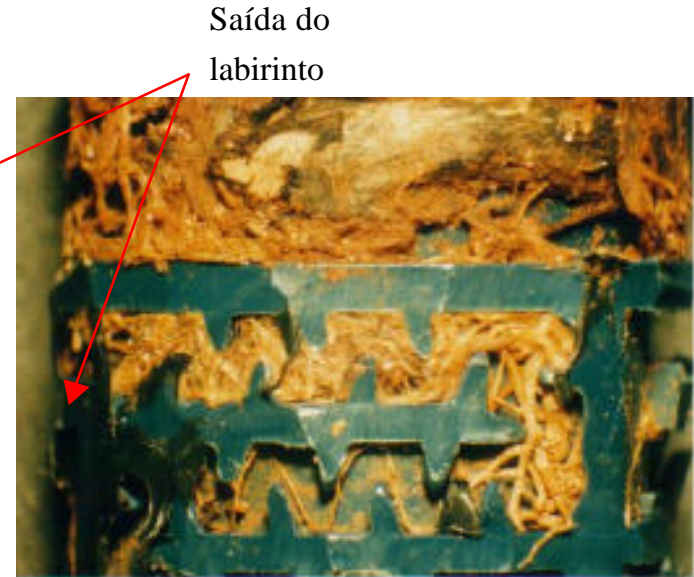

b

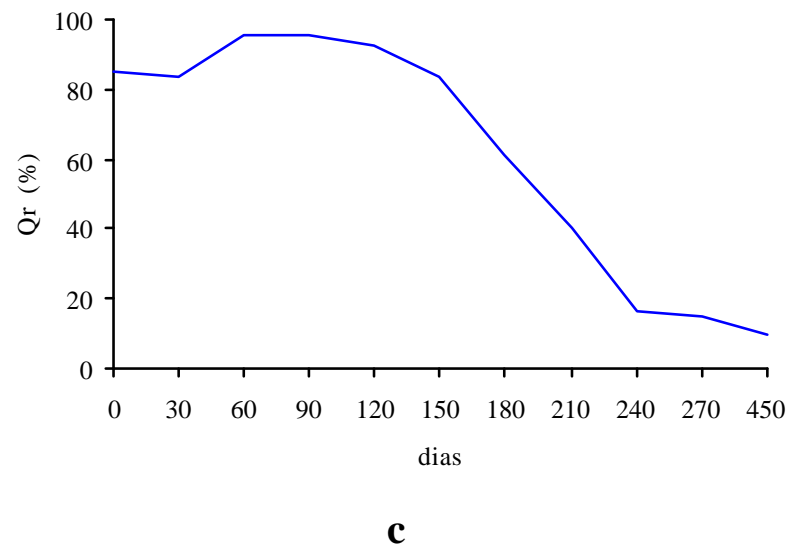

Figura 16 - Desenvolvimento de raízes, no modelo CD, na câmara de saída de água (a), na saída do labirinto (b) e evolução da vazão em função do tempo (c) 


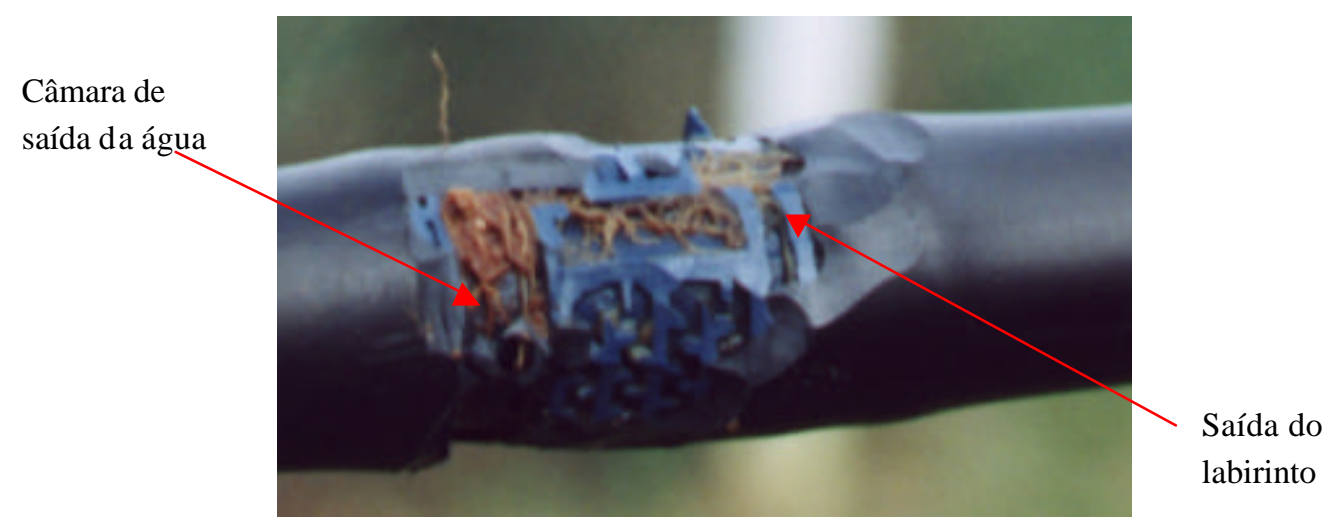

a

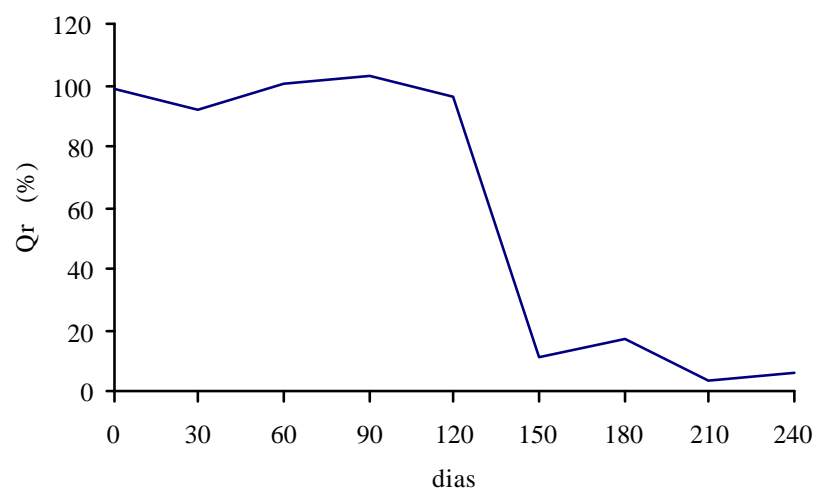

b

Figura 17 - Desenvolvimento de raízes, no modelo $\mathrm{CD}$, na câmara de saída de água com presença de solo (a) e evolução da vazão em função do tempo (b)

\subsubsection{Modelo DI}

É o que apresenta maior comprimento de percurso de água, com $242 \mathrm{~mm}$ da saída do filtro à saída do labirinto, além de aproximadamente $44 \mathrm{~mm}$ daí até o orifício de saída de água; a área de filtragem é de $18,7 \mathrm{~mm}^{2}$. Da mesma forma que o modelo $\mathrm{CD}$, as duas câmaras existentes se comunicam, mas apenas uma é funcional, onde se localizam os dois orifícios de saída de água, formando um ângulo de $90^{\circ}$ entre si; a área da câmara de saída de água é de 206,5 mm², sendo a câmara morta de mesmo tamanho (Figura 18). 
O percurso possível de ser seguido pela raiz, após a intrusão, também é semelhante ao do modelo CD: estando dentro da câmara de saída de água, a raiz atinge um labirinto largo que comunica as duas câmaras; aí a raiz poderá entrar no canal de acesso do labirinto dissipador de energia ou passar em direção à câmara morta.

Para alcançar o filtro do gotejador e penetrar no interior do tubo, potencializando o efeito da intrusão na hidráulica da parcela, a raiz teria que percorrer os $242 \mathrm{~mm}$ de comprimento do labirinto, mais a menor distância entre o orifício de saída de água e a entrada do labirinto, que é de aproximadamente $44 \mathrm{~mm}$.

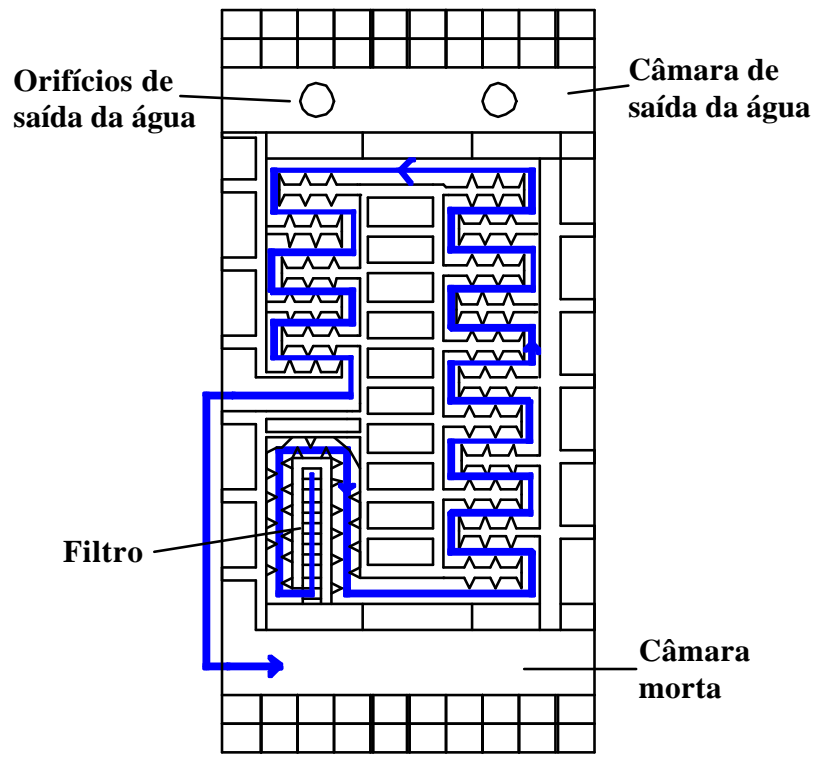

Figura 18 - Desenho esquemático do modelo DI

\subsubsection{Modelo HD}

Do tipo plano, apresenta comprimento do labirinto de $22 \mathrm{~mm}$ e um comprimento total de percurso de água de aproximadamente $26 \mathrm{~mm}$. A área bruta de filtragem é de $11 \mathrm{~mm}^{2}$ e a área líquida de $8,4 \mathrm{~mm}^{2}$. A distância entre o ponto de entrada da raiz e a entrada do labirinto (ponto crítico do fluxo) é de $4 \mathrm{~mm}$; a área da câmara de 
saída de água mede $28,4 \mathrm{~mm}^{2}$ e a largura do labirinto é de aproximadamente $0,5 \mathrm{~mm}$. O desenho esquemático desse modelo é apresentado na Figura 19.

Depois da intrusão a raiz pode apresentar um crescimento inicial na câmara de saída de água e daí percorrer um caminho único, através do labirinto, até a área de filtragem, onde poderá penetrar no interior do tubo (Figura 20); a probabilidade de essa penetração vir a ocorrer é, como no modelo DL, mais elevada, em consequiência do pequeno percurso a ser percorrido pela raiz, aliado ao caminho único existente. Essa probabilidade se mostra menor no modelo TR, dado o maior percurso $(123,6 \mathrm{~mm})$ a ser percorrido pela raiz. Por serem pequena s a secção de passagem do labirinto e a área da câmara de saída de água, o modelo HD tende a sofrer mais rápido o efeito decorrente da intrusão. Além disso, raízes mais finas podem redundar em decréscimo de vazão.

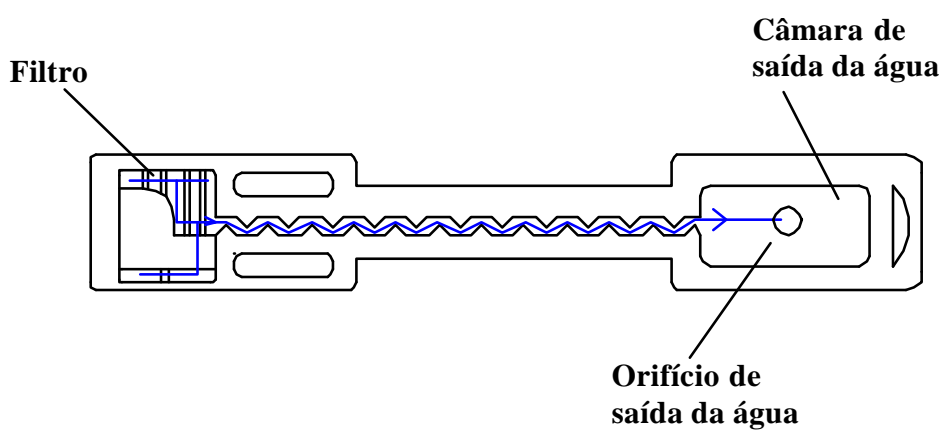

Figura 19 - Desenho esquemático do modelo HD 


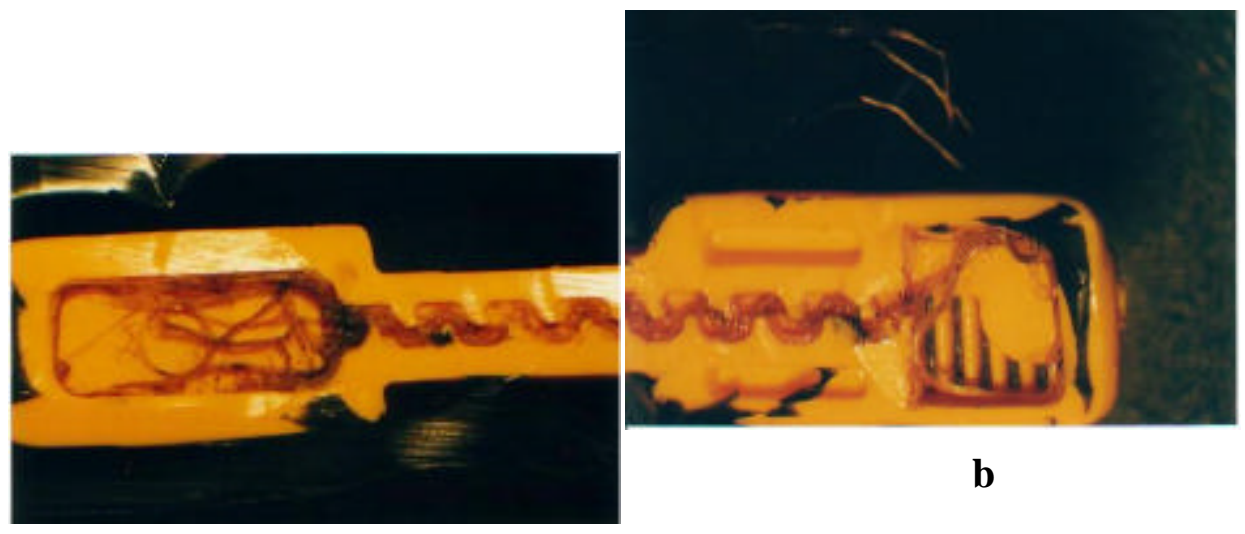

$\mathbf{a}$

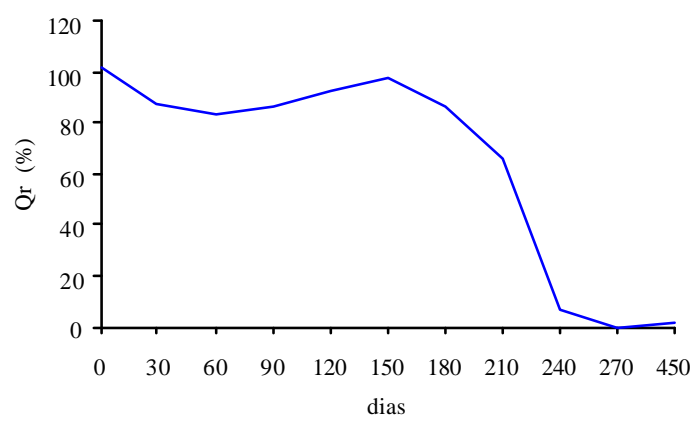

c

Figura 20 - Desenvolvimento de raízes, no modelo HD, na câmara de saída de água (a), na saída do labirinto (b) e evolução da vazão em função do tempo (c)

\subsubsection{Modelo HG}

No modelo, as duas câmaras existentes são funcionais, atuando como câmaras de saída de água, com um orifício de saída por câmara e área conjunta de $456 \mathrm{~mm}^{2}$. O comprimento e largura do labirinto são de aproximadamente $141 \mathrm{~mm}$ e $0,9 \mathrm{~mm}$, respectivamente. Da saída do labirinto até o orifício mais próximo a água percorre aproximadamente $37 \mathrm{~mm}$. A área bruta de filtragem é de $65,8 \mathrm{~mm}^{2}$ e a líquida, $55,4 \mathrm{~mm}^{2}$. O ponto crítico do fluxo de água, nesse modelo, é a saída do labirinto. Uma 
vez obstruído esse local, a vazão do gotejador fica comprometida para os dois orifícios (Figura 21).

O fato de os dois orifícios de saída de água estarem posicionados em cada uma das câmaras faz cm que, hipoteticamente, a probabilidade de redução de vazão seja reduzida em relação aos demais modelos avaliados Essa característica da arquitetura, pode ter tido papel preponderante para explicar o melhor desempenho deste modelo em relação aos demais não-compensantes. Acrescente-se o fato de a distância entre o ponto de intrusão e o ponto crítico de fluxo de água ter, juntamente com o gotejador DI, a maior do grupo dos não-compensantes.

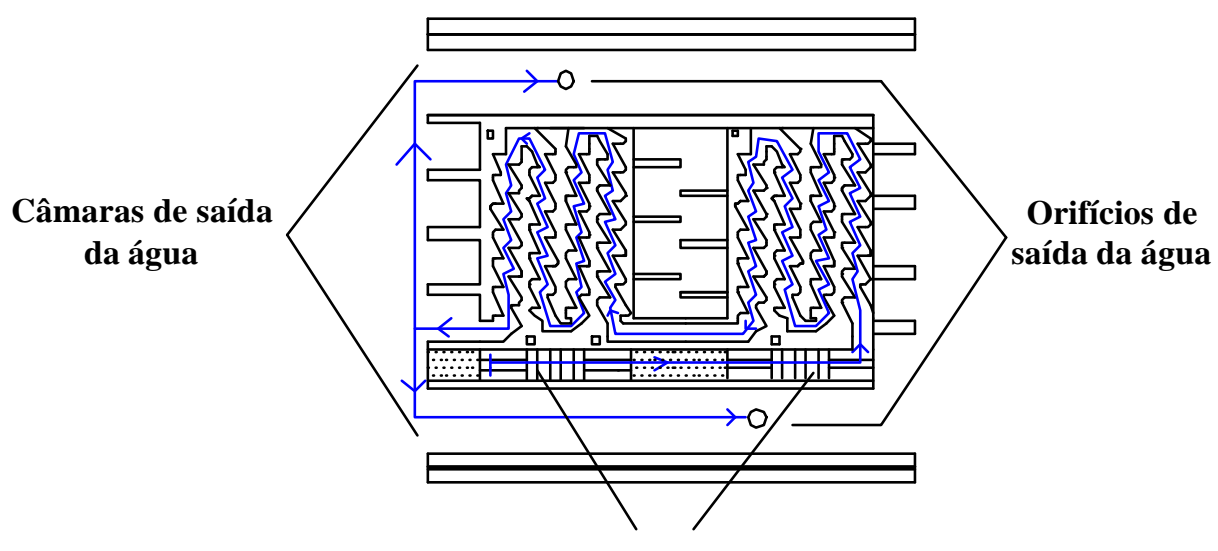

Filtro

Figura 21 - Desenho esquemático do modelo HG

\subsubsection{Modelo TR}

O modelo TR tem configuração similar ao DL e HD, diferenciando-se destes por apresentar a maior dimensão dentre os modelos do tipo plano; o comprimento do labirinto é $113,4 \mathrm{~mm}$ e o comprimento total de percurso de água mede, aproximadamente, $123,6 \mathrm{~mm}$. A área bruta de filtragem mede $51,4 \mathrm{~mm}^{2}$ e a área líquida, aproximadamente $37,4 \mathrm{~mm}^{2}$, sendo a distância entre o ponto de entrada da raiz e a 
entrada do labirinto (ponto crítico do fluxo) 10,2 mm e a área da câmara de saída de água de $96 \mathrm{~mm}^{2}$. A largura do labirinto mede, aproximadamente, 1,0 mm.

Para o fator comprimento do labirinto, o modelo é semelhante ao do tipo cilíndrico do grupo dos gotejadores não-compensantes. Tal característica se supõe não influenciar no potencial de intrusão de raízes no interior do gotejador, mas reduz a probabilidade de a raiz atingir o interior do tubo, com reflexo na hidráulica da linha lateral, efeito esse já discutido anteriormente. $\mathrm{O}$ desenho esquemático desse modelo é apresentado na Figura 22.

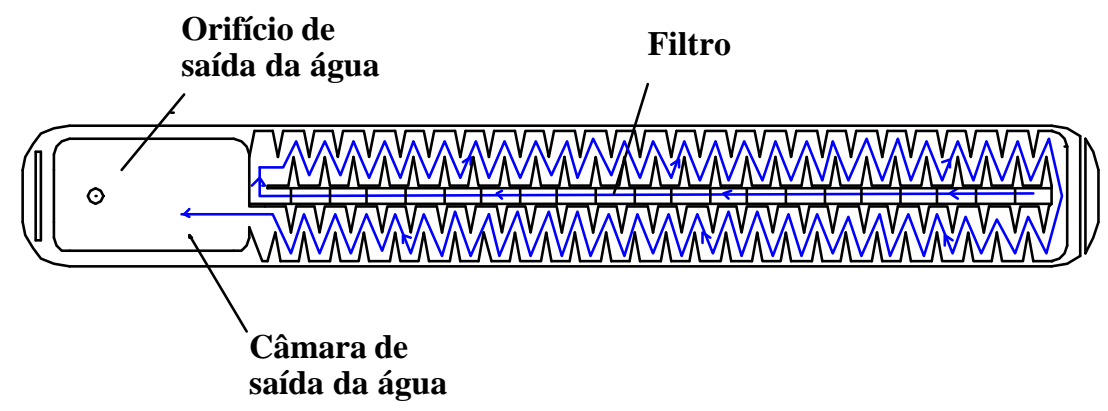

Figura 22 - Desenho esquemático do modelo TR

\subsubsection{Modelo DL}

O modelo DL tem arquitetura e dimensões similares ao HD, e sendo ambos do tipo plano o comentário efetuado para esse último é válido para o DL. O comprimento de labirinto mede $17,8 \mathrm{~mm}$ e o comprimento total do percurso de água mede aproximadamente $21 \mathrm{~mm}$. A área bruta de filtragem mede $14 \mathrm{~mm}^{2}$ e a área líquida 12,3 $\mathrm{mm}^{2}$. A distância entre o ponto de entrada da raiz e a entrada do labirinto (ponto crítico do fluxo) é de 3,2 mm e a área da câmara de saída de água mede $33,3 \mathrm{~mm}^{2}$. A largura do labirinto é de aproximadamente $0,7 \mathrm{~mm}$. A Figura 23 apresenta o desenho do modelo. 


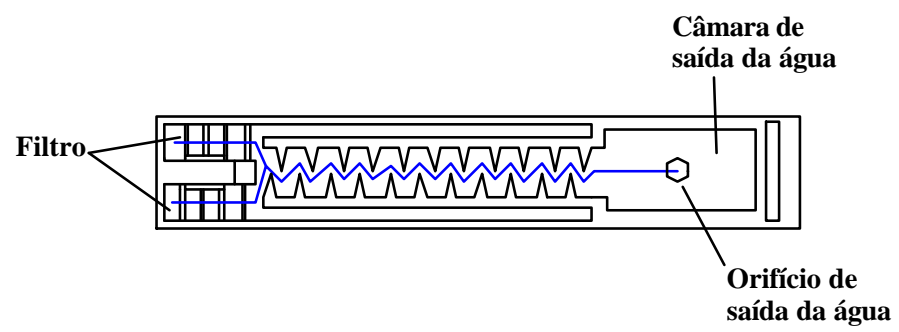

Figura 23. Desenho esquemático do modelo DL

\subsubsection{Gotejadores autocompensantes de pressão}

\subsubsection{Modelo CP}

O modelo apresenta um labirinto com comprimento de 39,8 $\mathrm{mm}$ e uma área de filtragem de $197,7 \mathrm{~mm}^{2}$, sendo a segunda maior de todos o gotejadores avaliados. A distância do orifício de saída de água até a entrada da câmara de compensação, entrada essa considerada o ponto crítico do fluxo de água, é de 71,0 mm; a área da câmara de saída de água é de 550,7 $\mathrm{mm}^{2}$, a maior de todos os modelos avaliados.

Após a intrusão e o desenvolvimento inicial na câmara de saída de água, a raiz seguirá para a câmara morta, através de uma área de passagem, em labirinto largo, que comunica as duas câmaras; uma vez na câmara morta, pode se dar outro ciclo de desenvolvimento de raízes laterais ou penetrar a raiz em um canal largo (2,7 mm), o qual dá acesso à câmara de compensação. O comprimento desse canal é de $8,5 \mathrm{~mm}$ e finaliza em outro, mais estreito, com 0,5 $\mathrm{mm}$ de largura e 5,0 $\mathrm{mm}$ de comprimento, que penetra na câmara de compensação; o início desse canalículo se constitui no ponto crítico do fluxo de água do modelo.

O gotejador CP apresenta a maior distância entre o ponto de intrusão e o ponto crítico ao fluxo de água $(71,0 \mathrm{~mm})$ de todos os gotejadores avaliados, o que não impediu que a raiz alcançasse esse ponto. Uma vez alcançado, duas situações podem ocorrer: a) 
a raiz penetrar na câmara de compensação, podendo ocasionar um aumento de vazão do emissor em um primeiro momento, caso impeça o completo assentamento da membrana de silicone responsável pela característica de compensação de vazão; $b$ ) no decorrer do crescimento da raiz, o seu processo de elongação radial poderá obstruir completamente o canalículo por onde penetrou na câmara de compensação e causar redução de vazão do gotejador.

Uma vez no interior da câmara de compensação a raiz poderá passar para o interior do tubo, através de uma secção retangular (área de comunicação com o interior do tubo, na Figura 24), na qual é atracada uma capa removível(não visualizada ressa Figura), usada para a cobertura da câmara de compensação. A linha de raciocínio apresentada acima para o gotejador CP é válida para todos os modelos do grupo dos autocompensantes de pressão.

Observando-se o caminho a ser percorrido pela raiz, da entrada na câmara de compensação até a área de filtragem, eliminando-se a possibilidade de penetração através dessa secção retangular, percebe-se que a probabilidade de a raiz entrar no interior do tubo seria reduzida significativamente, dado o longo percurso que a raiz teria que percorrer até a área de filtragem.

Nos modelos HP e NP, a área de comunicação entre o interior do tubo e a câmara de compensação (essa área é, na verdade, a área de filtragem) se encontra por baixo da membrana de silicone, formando uma barreira à raiz, diferentemente dos modelos CP, DLP e RM, nos quais a membrana de silicone não se assenta sobre essa área de comunicação e que resulta em uma secção de passagem livre para o interior do tubo.

Na Figura 25 se observa a raiz já tendo passado através da secção retangular e se encontrando no interior do tubo. Nesse caso, a intrusão ocorreu aos 450 dias do início do experimento e, portanto, após o período de coleta seqüencial dos dados (270dias). A intrusão mostrada na Figura 25 resultou em um enovelamento da raiz no interior do tubo, podendo ser visualizado na Figura 13. 


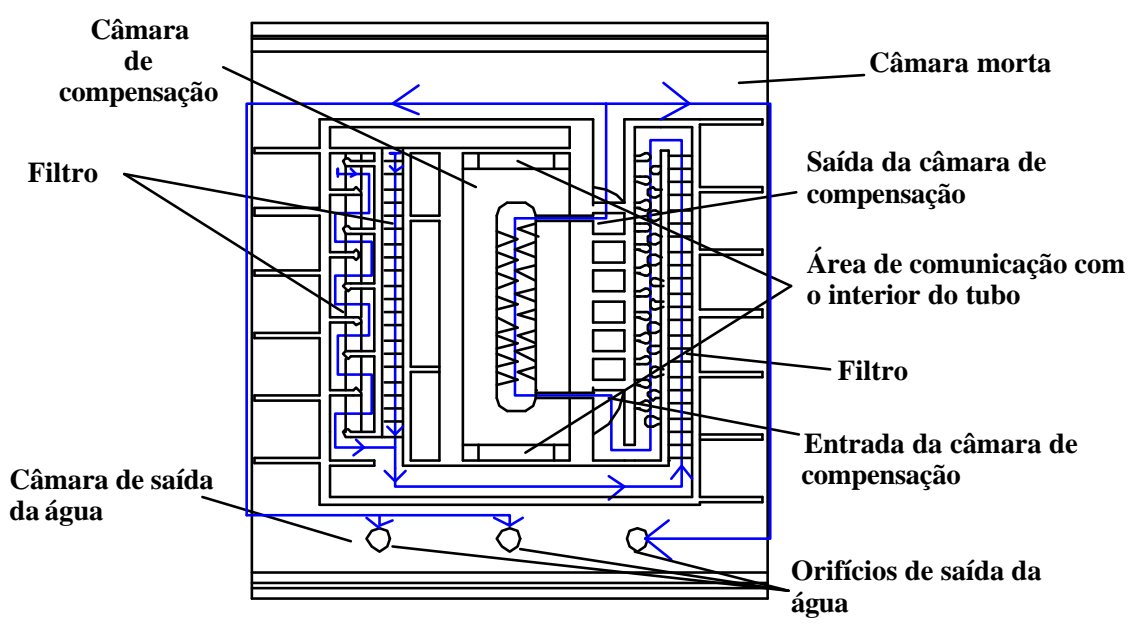

Figura 24 - Desenho esquemático do modelo CP

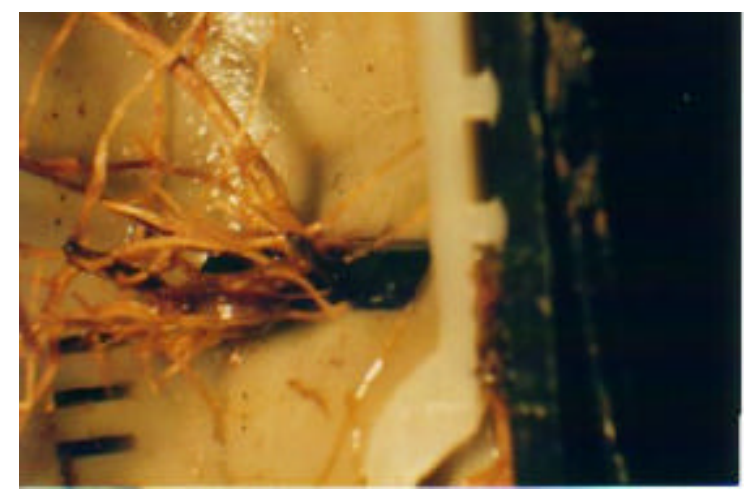

$\mathbf{a}$

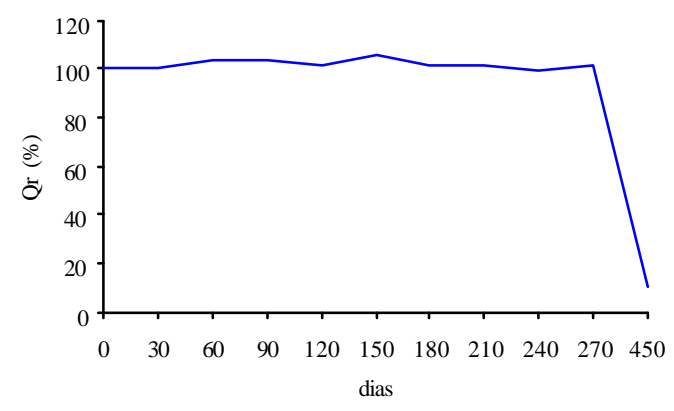

b

Figura 25 - Penetração da raiz no interior do tubo, no modelo $\mathrm{CP}$, através de área da encaixe da tampa da câmara (a) e evolução da vazão em função do tempo (b) 
$\mathrm{Na}$ verdade os processos (a) e (b), de efeitos antagônicos, ocorrem concomitantemente; o efeito de ambos na vazão atual do gotejador dependerá da intensidade com que cada processo ocorra em dado momento.

\subsubsection{Modelo DLP}

A arquitetura do modelo DLP (Figura 26) é idêntica à do modelo CP sendo a diferença entre ambos o tamanho da área de filtragem, que para o modelo DLP é maior, com $214 \mathrm{~mm}^{2}$. Como será discutido à seguir, não é provável que a área de filtragem afete significativamente o nível de suscetibilidade do gotejador à intrusão de raízes, o que se corrobora com a semelhança de comportamento de ambos, frente aos tratamentos aplicados. Assim, a discussão efetuada para o modelo CP é válida para o presente modelo.

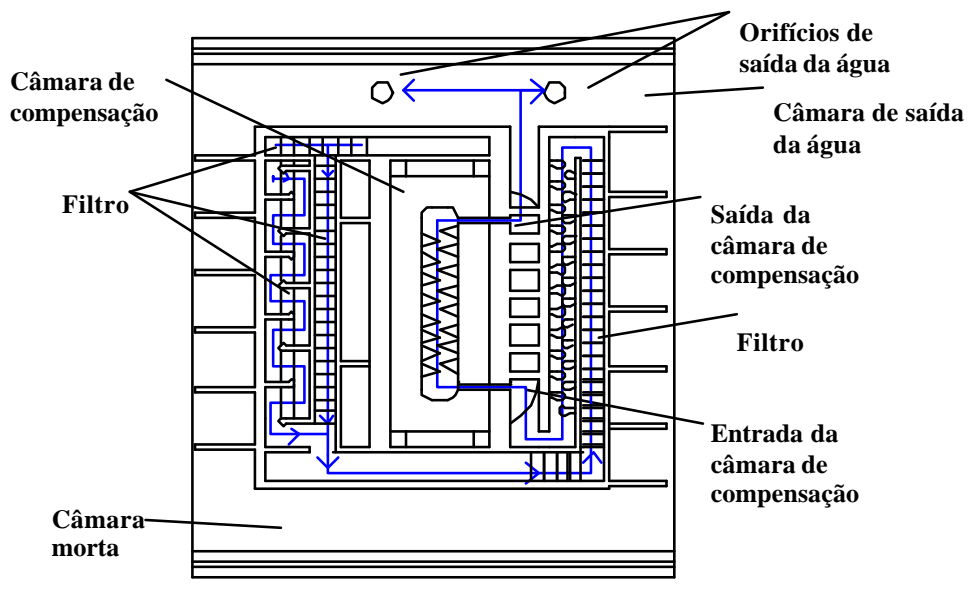

Figura 26 - Desenho esquemático do modelo DLP

Na Figura 27a, obtida antes do final do experimento, a raiz se desenvolve em direção à câmara morta, mas não penetra na câmara de compensação. Como o orifício de saída de água se encontrava no lado oposto ao representado na Figura 26, a redução de 
vazão (Figura 27b) se deu por bloqueio do canal de comunicação da câmara de saída de água com a câmara morta.

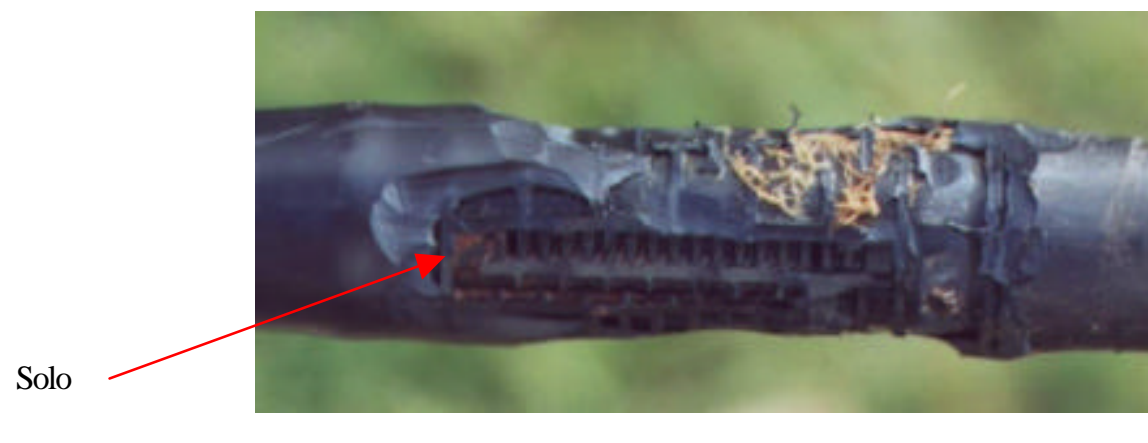

$\mathbf{a}$

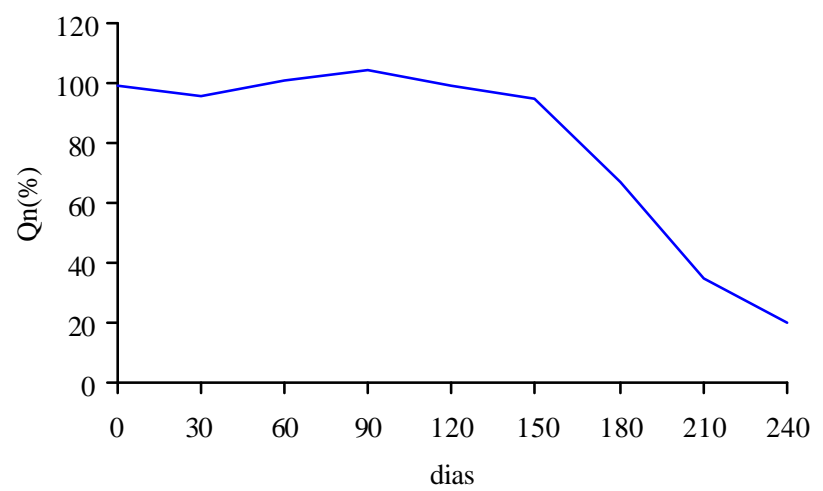

b

Figura 27 - Raiz intrusiva, no modelo DLP, se desenvolvendo em direção à câmara morta (a) e evolução da vazão do gotejador em função do tempo (b). Observar presença de solo (em vermelho) no interior do labirinto

A variabilidade no processo de fabricação do tubo gotejador, da localização do orifício de saída de água em relação às câmaras mortas e de saída de água foi observada em outros modelos avaliados. 


\subsubsection{Modelo DP}

O comprimento do labirinto, nesse modelo (Figura 29) é de 37,7 mm; a área de filtragem mede $12,2 \mathrm{~mm}^{2}$, correspondendo à menor entre os gotejadores avaliados. A distância do orifício de saída de água até o início do canalículo, com largura de $1 \mathrm{~mm}$, que dá acesso ao orifício de saída da câmara de compensação, é de 3,5 mm; o início desse canalículo se constitui no ponto crítico do fluxo de água desse modelo. A área da câmara de saída de água mede $264,0 \mathrm{~mm}^{2}$, com igual valor para a câmara morta. A área vazada apresentada na Figura 29 é completamente vedada pela parede do tubo de polietileno.

O modelo possui dois orifícios de saída de água localizados em uma das câmaras. A raiz, após intrus ão e tendo alcançando a entrada do canalículo de acesso à câmara de compensação, poderá passar direto para a câmara morta ou se dirigir, em ângulo de $90^{\circ}$, para o orifício de saída da câmara de compensação, adentrando nesta. $\mathrm{Na}$ Figura 28 observa-se que, inicialmente a raiz passou direto em direção à câmara morta e, posteriormente, raízes de maior ordem se encontram em processo de desenvolvimento em direção à entrada da câmara de compensação, porém semalcançá- la.

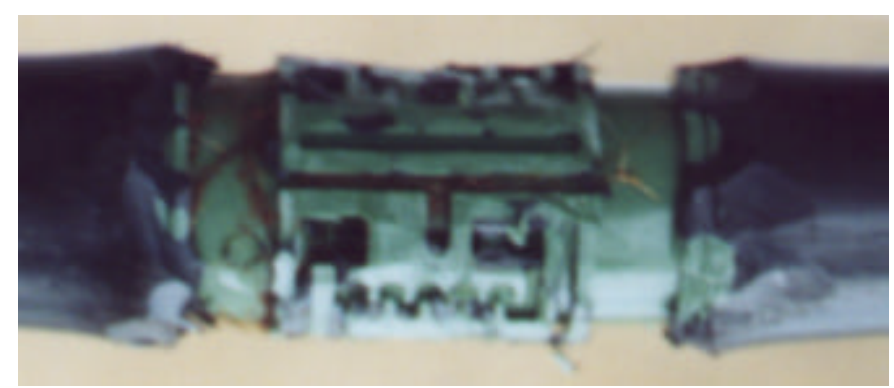

Figura 28 - Desenvolvimento da raiz que alcança a câmara morta através do canalículo de acesso à câmara de compensação 


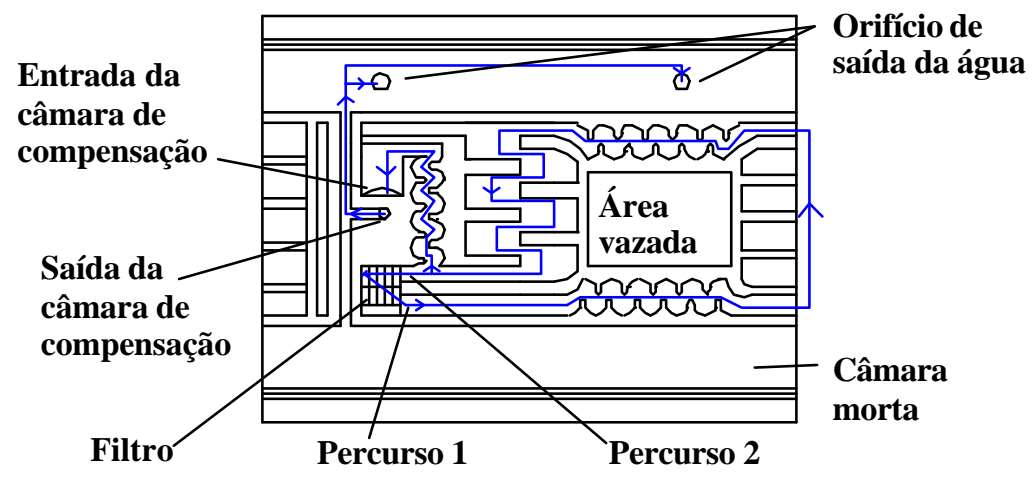

Figura 29 - Desenho esquemático do modelo DP

Uma vez estando a raiz dentro da câmara de compensação, duas formas da raiz penetrar no interior do tubo se fazem mais prováveis : a) a membrana de silicone assentase em uma capa vazada, que separa essa câmara do interior do tubo; através dessas áreas vazadas ou por um pequeno canalículo, situado ao lado e pouco abaixo do nível da membrana de silicone, a raiz poderá passar para o interior do tubo; e $b$ ) a penetração ocorre através de uma pequena fração da área de filtragem, não apresent ada na Figura 29 (somente visualizada em desenho tridimensional), já que, a área de filtragem comunica o interior do tubo com o labirinto que dá acesso ao orifício de entrada da câmara de compensação, como também diretamente com o interior dessa câmara. Do ponto de vista da alternativa $a$ ), essa configuração dificultaria a passagem da raiz para o interior do tubo, embora provavelmente não fosse tão eficiente quanto aquela adotada nos modelos HP e NP. Já do ponto de vista da alternativa $b$ ), a raiz teria acesso direto da câmara de compensação ao interior do tubo, facilitando sua penetração. Na Figura 30a ocorreram essas duas situações: a raiz passou pelas bordas da membrana de silicone, adentrou o interior do tubo, e lá se desenvolveu (Figura 30b). Uma terceira possibilidade, embora mais remota, também foi observada no gotejador apresentado na Figura 30a: uma vez 
dentro da câmara de compensação, a raiz passou pelo orifício de entrada da câmara, acessou o labirinto e se encontrava na metade de um percurso de $21 \mathrm{~mm}$ (percurso 2, na Figura 29) para atingir a área de filtrageme, finalmente, penetrar no interior do tubo.

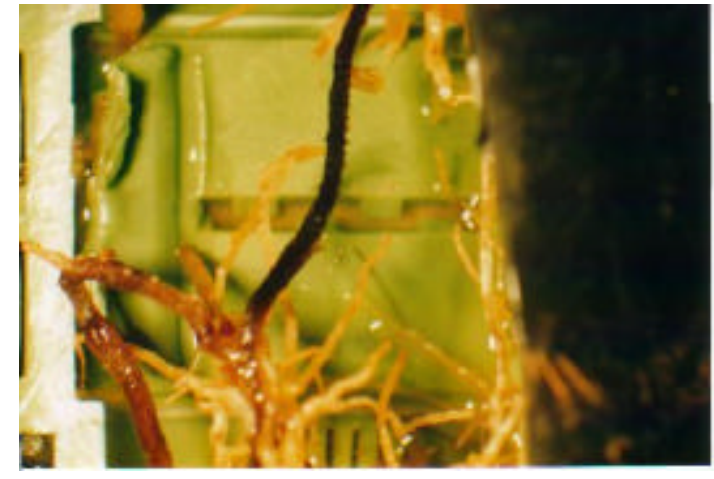

$\mathbf{a}$

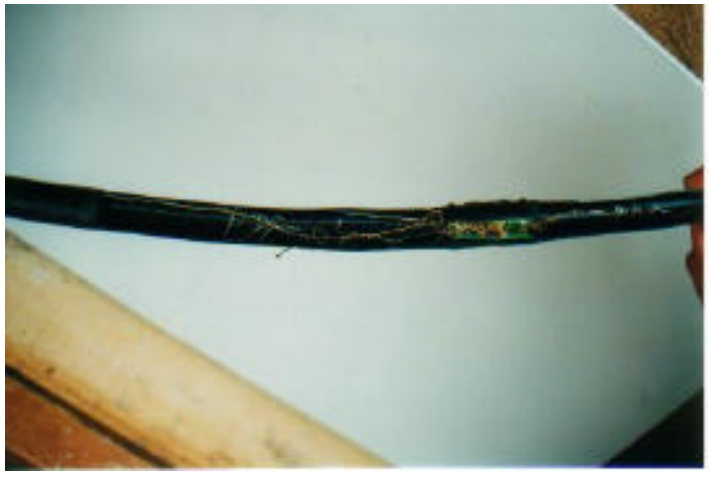

b

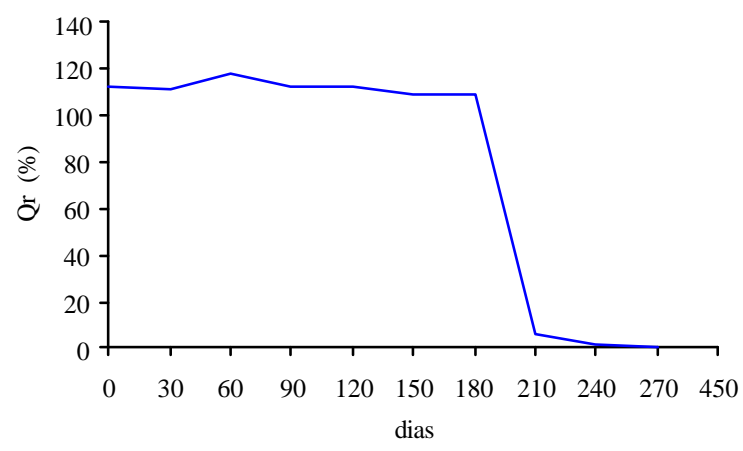

c

Figura 30 - Penetração de raiz no interior do tubo, no modelo DP, através da câmara de compensação e área de filtragem (a), seu desenvolvimento no interior do tubo (b) e evolução da vazão em função do tempo (c)

Uma característica única do modelo DP, entre os demais avaliados, refere-se à existência de dois percursos possíveis da água desde a sua entrada no gotejador, através do filtro, até a entrada na câmara de compensação. O percurso 1 (Figura 29) tem um comprimento de $114,2 \mathrm{~mm}$, passando por dois labirintos horizontais, dois labirintos mais 
largos, verticais, e um labirinto vertical. No percurso 2, com $21 \mathrm{~mm}$, a água passa apenas pelo último labirinto vertical para alcançar a entrada da câmara. Esse se supõe o caminho "preferencial", uma vez que redunda em menor consumo de energia. Tal característica, no entanto, não deve afetar a sensibilidade do modelo ao efeito da intrusão de raízes, porquanto o ponto crítico de fluxo ă se encontraria afetado quando a raiz alcançasse o interior do labirinto.

\subsubsection{Modelo HP}

Da mesma forma que no modelo HG, o gotejador HP conta com duas câmaras funcionais, apresentando cada uma um orifício de saída de água (Figura 31). Um canalículo, com espessura de $1 \mathrm{~mm}$ e entalhado em uma tampa sobre a câmara de compensação, comunica a saída dessa câmara à de saída de água 1 e se constitui no ponto crítico ao fluxo de água no gotejador. Se a intrusão ocorrer através do orifício mais próximo desse canalículo, a raiz poderá tomar dois caminhos: no primeiro, hipoteticamente de maior probabilidade, a raiz se desenvolve dentro da câmara 1, podendo passar para a câmara 2 através de um canal estreito ( $2 \mathrm{~mm}$ no ponto mais largo); no segundo, a raiz penetra no canalículo e se desenvolve em direção à câmara de compensação, podendo resultar em aumento de vazão, no caso de afetar o funcionamento da membrana de silicone, ou redução de vazão, pelo crescimento radial da raiz na secção do canalículo. Essa última alternativa pode ser visualizada na Figura 32, em que a vazão se reduziu a zero (Figura 32c). Nessa Figura observa-se que a raiz principal, quando na câmara de saída de água, efetuou uma curva de $90^{\circ}$, direcionandose para o canalículo da tampa da câmara de compensação e penetrou nesta através do seu orifício de saída de água (Figura 32a). Na Figura 32b, vê-se que a raiz já se encontra junto à parede lateral da câmara de compensação, no entanto sua penetração no interior do tubo é dificultada pelo fato do filtro se encontrar por baixo da membrana de silicone (em verde). 


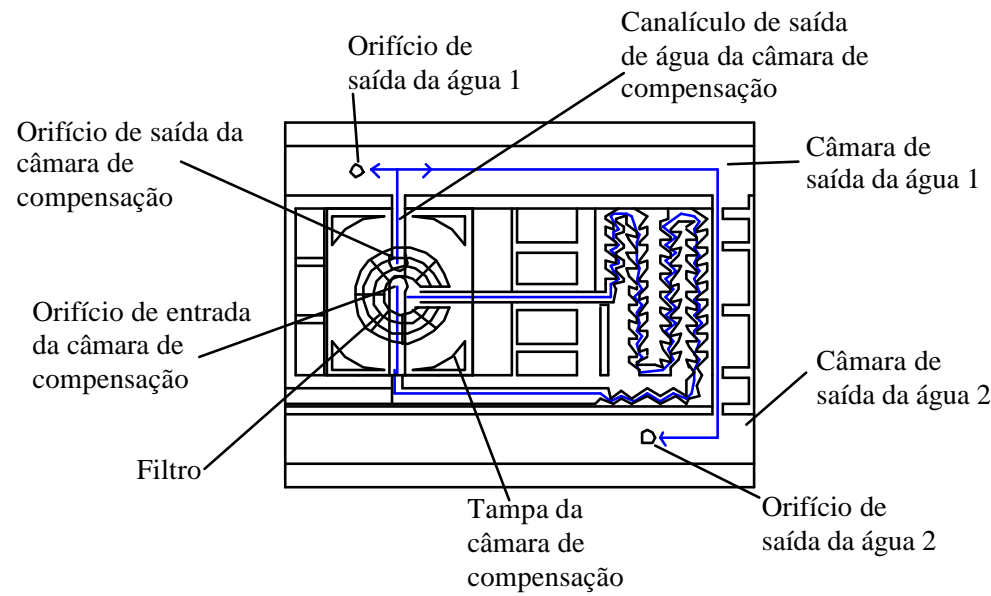

Figura 31 - Desenho esquemático do modelo HP

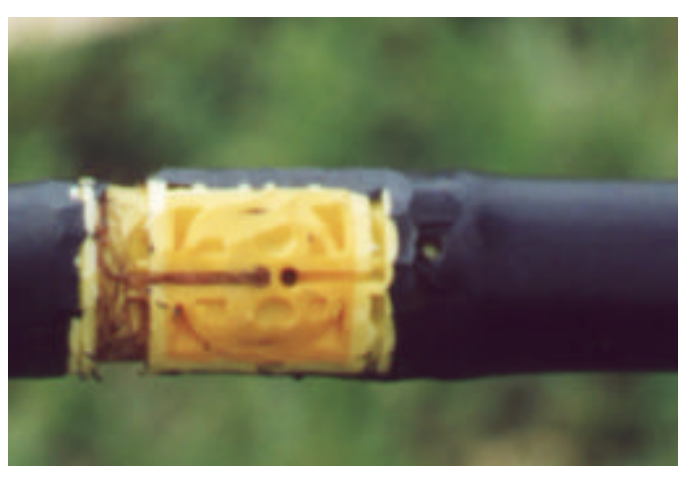

$\mathbf{a}$

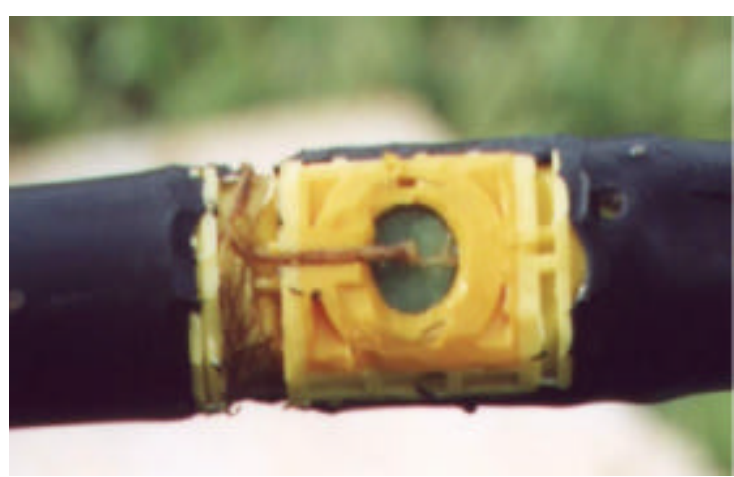

b

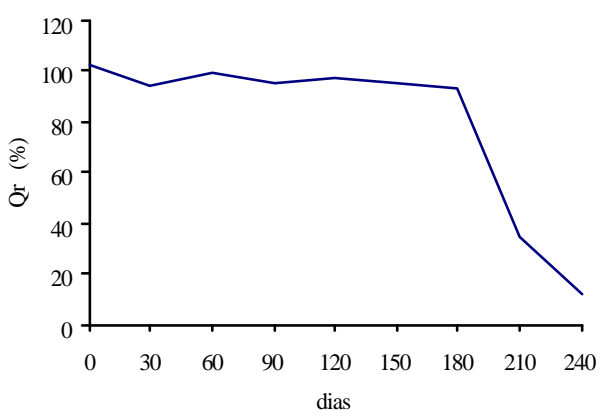

c

Figura 32 - Penetração da raiz na câmara de compensação do modelo HP através do canalículo de passagem de água (a), no interior da câmara, junto àmembrana de silicone, de cor verde (b) e evolução da vazão em função do tempo (c) 


\subsubsection{Modelo NP}

O percurso da água, no modelo NP (Figura 33), mede 154,4 mm; o trecho em labirinto estreito (largura de 0,8 mm) mede $85,0 \mathrm{~mm}$. A área bruta de filtragem é de 37,3 $\mathrm{mm}^{2}$ e a líquida, aproximadamente, $27,7 \mathrm{~mm}^{2}$. O ponto crítico do fluxo de água ocorre na extremidade do canalículo, com largura de $1 \mathrm{~mm}$, que interliga as duas câmaras (de saída de água e a câmara morta, ambas com $247,1 \mathrm{~mm}^{2}$ de área). A distância dessa extremidade até o ponto de intrusão é de $3,5 \mathrm{~mm}$ e até a saída da câmara de compensação, 20,9 mm. O único ponto de comunicação entre as duas câmaras é esse canalículo (em um percurso de $32,7 \mathrm{~mm}$ ), logo, a segunda câmara se configura totalmente não-funcional. A mudança de local do segundo orifício de saída de água, posicionando-o na câmara morta, reduziria a suscetibilidade ao efeito da intrusão, pois esse efeito somente ocorreria quando a raiz alcançasse a entrada da câmara de compensação, distante do ponto de intrusão $20,9 \mathrm{~mm}$. Como no gotejador DP, a área vazada apresentada no desenho do modelo é completamente vedada pela parede do tubo de polietileno.

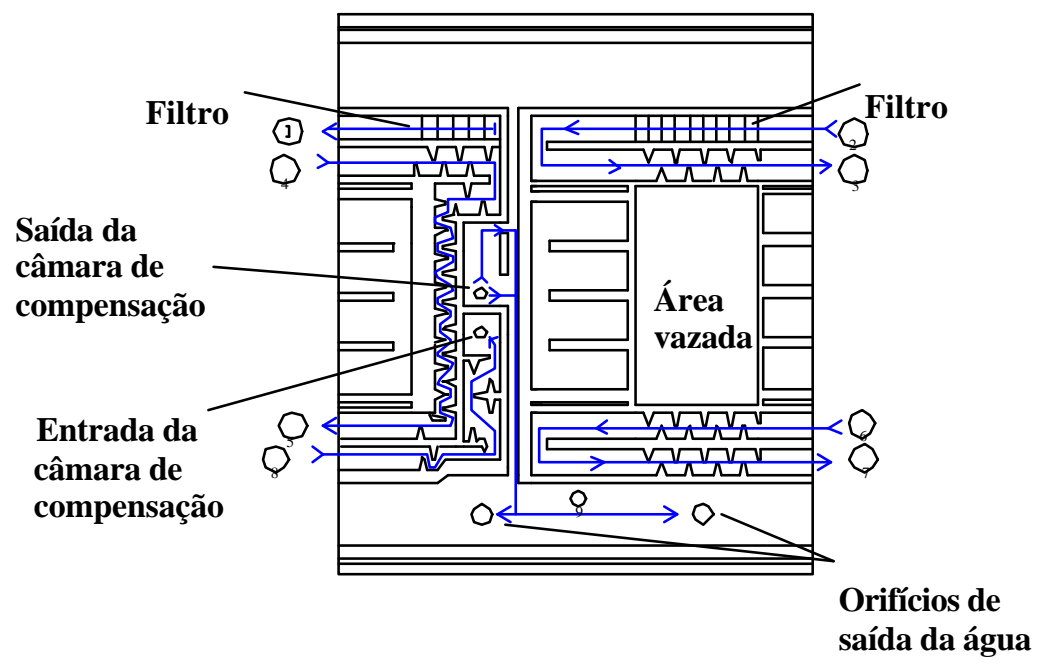

Figura 33 - Desenho esquemático do modelo NP 


\subsubsection{Modelo RM}

Esse modelo tem arquitetura peculiar em relação aos demais gotejadores do tipo plano. Tal peculiaridade se refere ao fato de o caminhamento da água ocorre em dois níveis, com relação à altura do emissor: no primeiro nível ocorre a entrada da água para o interior do gotejador através de uma área de filtragem, de $27 \mathrm{~mm}^{2}$, a qual é seguida de um labirinto de 17,8 $\mathrm{mm}$ de comprimento e largura de 1,0 $\mathrm{mm}$ entre dentes, que deságua em uma câmara com área de 71,0 mm² (câmara de saída de água 1, na Figura 34a). Nessa câmara, um orifício de 1,0 mm de diâmetro faz a comunicação com o segundo nível do gotejador, formado por outra câmara de saída de água (câmara de saída de água 2, na Figura 34c), com 143,2 $\mathrm{mm}^{2}$ de área, no centro da qual se localiza o orifício de saída de água do gotejador, já na parede do tubo de polietileno, com aproximadamente 1,6 mm de diâmetro.

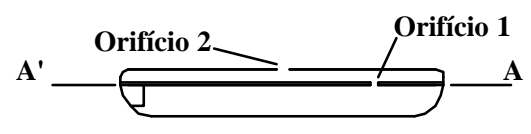

(b)

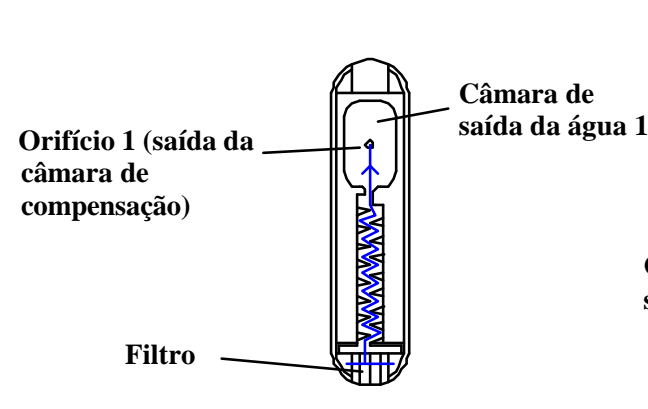

(a)

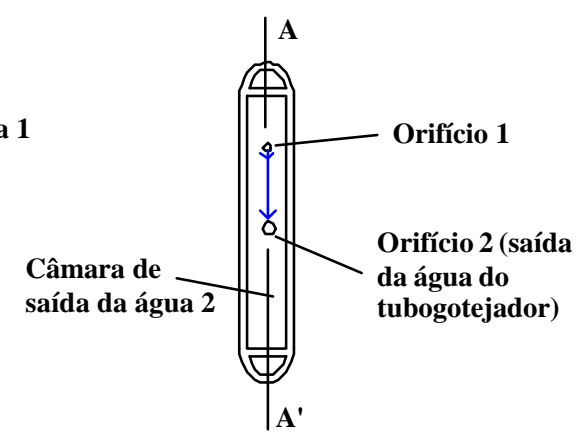

(c)

Figura 34 - Desenho esquemático do modelo RAM, em vistas inferior (a), lateral (b) e superior (c) 
Contrariamente aos gotejadores do tipo cilíndrico, a probabilidade de interceptação da raiz com os dois orifícios não é aditiva, porquanto, em relação ao fluxo da água, os dois orifícios representam uma ligação em série. Hipoteticamente, essa probabilidade se reduz em relação aos gotejadores com apenas um orifício (gotejadores do tipo plano) sendo ainda menor para aqueles com 2 orifícios (gotejadores do tipo cilíndrico).

A raiz, para atingir o interior da câmara de compensação passa por um desenvolvimento inicial na câmara de saída de água 2 , já que seria baixa a probabilidade de a raiz penetrar nos dois orifícios em uma seqüência rápida.

Como nos modelos CP e DLP, a membrana de silicone não se assenta sobre a área de filtragem, o que resulta em maior facilidade de penetração da raiz no interior do tubo. Para o gotejador apresentado na Figura 35a, embora tenha havido passagem de raiz através do filtro (detalhe não visualizado), a passagem ocorreu primeiramente pelo lado oposto da borda onde se assenta a membrana de silicone e a partir daí ocorreu o enovelamento no interior do tubo, conforme apresentado na Figura 13.

Como mencionado na descrição da metodologia de trabalho, foi dada continuidade ao experimento até o segundo corte da cana. Assim, a imagem da Figura 35a foi obtida aos 450 dias após o início do experimento e, portanto, após o final do período de coleta de dados, o qual foi de 270 dias. Dessa forma, não foi possível precisar, no intervalo de 180 dias, o momento de ocorrência da intrusão (Figura 35b). 

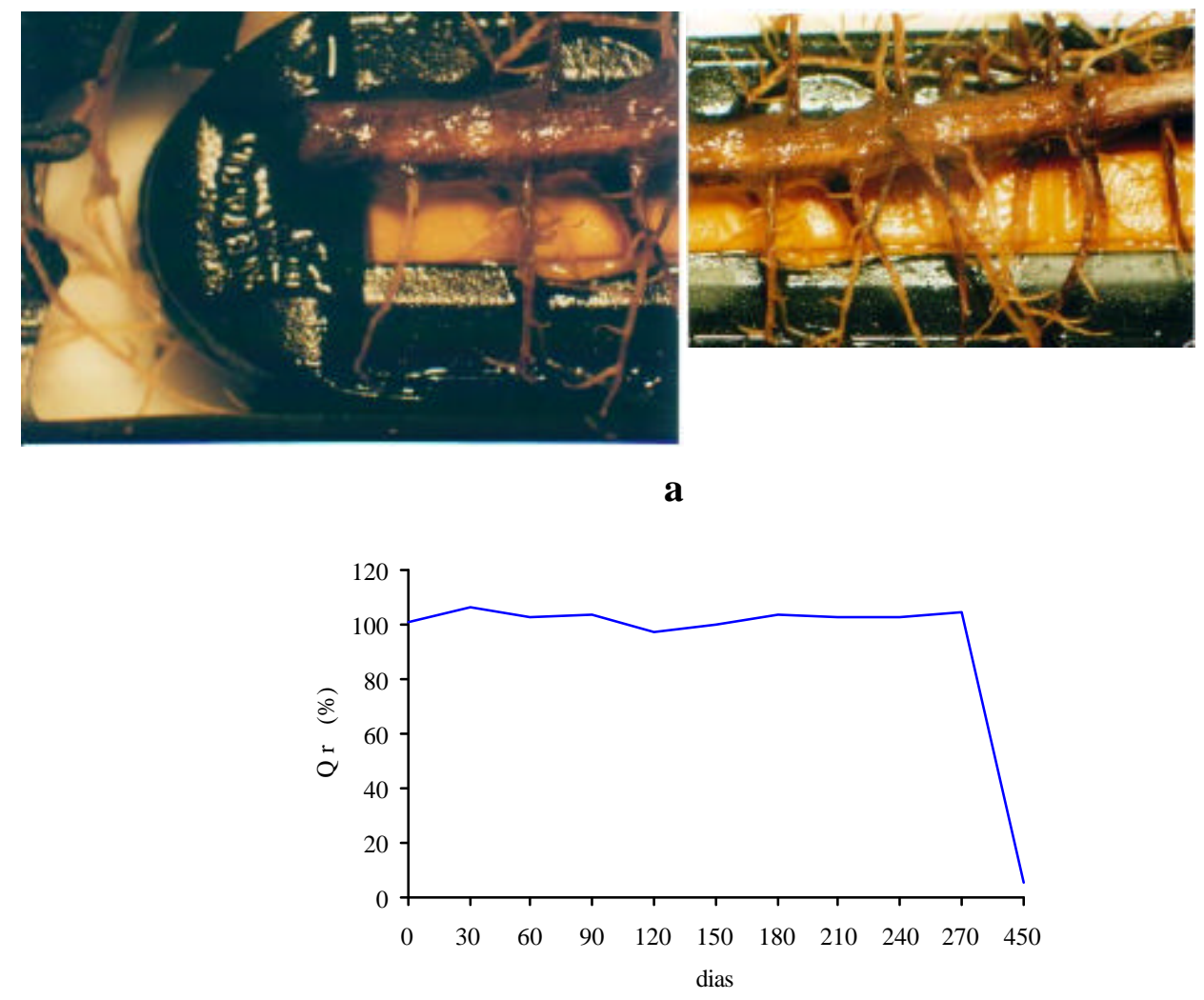

b

Figura 35 - Penetração de raiz no interior do tubo através da borda da membrana de silicone (a) e evolução da vazão do modelo RM em função do tempo (b)

\subsubsection{Modelo VP}

Esse modelo, do tipo botão, apresenta as menores dimensões para todas as variáveis avaliadas: comprimento do labirinto de $6,9 \mathrm{~mm}$; comprimento total do fluxo de água de 19,9 mm; área de filtragem e da câmara de saída de água de 2,6 e 8,1 mm², respectivamente. Uma vez que o modelo tem formato de um cilíndrico sólido $\left(360^{\circ}\right)$, foram tomadas, na Figura 36, duas vistas de $180^{\circ}$, das quais uma de frente (a) a outra de fundo (b), além de uma vista superior (c). 
A arquitetura do modelo conduz a raiz diretamente para a câmara de saída de água e daí para o labirinto. No momento em que alcança a câmara de saída de água a raiz já está em contato com a membrana reguladora de pressão, podendo impedir o seu correto funcionamento e resultar em aumento de vazão. Conforme discutido nos outros modelos autocompensantes, o efeito final na vazão está relacionado ao balanço do efeito combinado tanto do bloqueio da secção do canal que comunica a câmara de saída à área de saída de água do gotejador (redução de vazão) como ao não assentamento da membrana de silicone na secção de fluxo de água (aumento de vazão).

Uma particularidade desse gotejador é que não há orifício de saída de água propriamente dito. Em vez disso, há uma área de saída, na qual se assenta uma esfera de borracha, com diâmetro de 2,8 mm, que pode vedar o canal de comunicação entre a câmara de saída de água e o ambiente externo (a atmosfera ou, no presente caso, o solo).

(a)

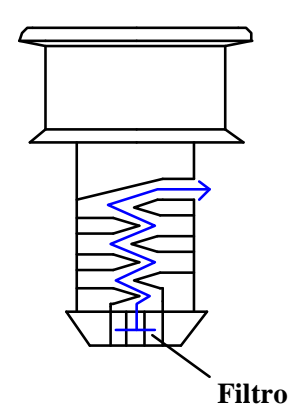

(b)

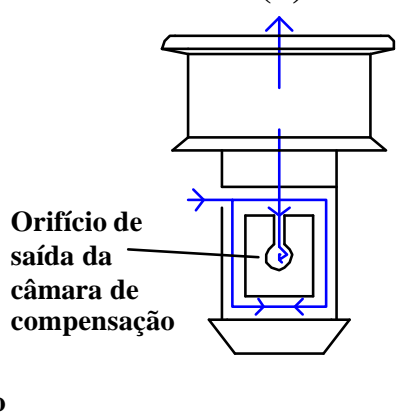

(c)

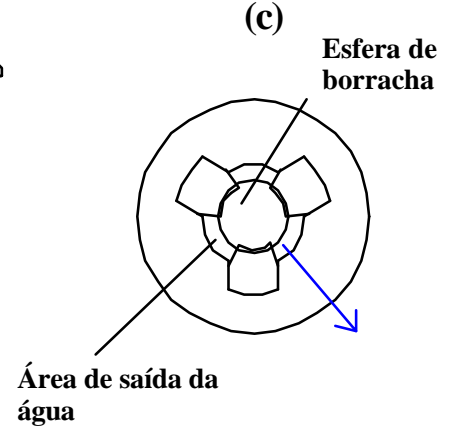

Figura 36 - Desenho esquemático do modelo VP; vistas anterior (a), posterior (b) e superior (c)

O objetivo anunciado dessa esfera é evitar a penetração de partículas de solo no interior do gotejador, prejudicando seu desempenho, quando da ocorrência de vácuo no tubo. Assumiu-se inicialmente na apresentação dos resultados que essa esfera ao ser pressionada pelo solo, na condição de enterrio, explicaria a redução de $10 \%$ na vazão do 
modelo, independentemente da ação das raízes. A ação dessa esfera como barreira física à penetração de raízes não foi consistente, dado a evidência de intrusão registrada (Figuras 37a e 37b) e também pelo nível de redução de vazão observado no decorrer do experimento. (Figura 37c).

Semelhante aos modelos em que a área de filtragem não se localiza sob a membrana de silicone (CP, DLP, RM), nesse modelo a raiz encontra menor dificuldade para alcançar o interior do tubo, com o reflexo na hidráulica da parcela, já discutido.

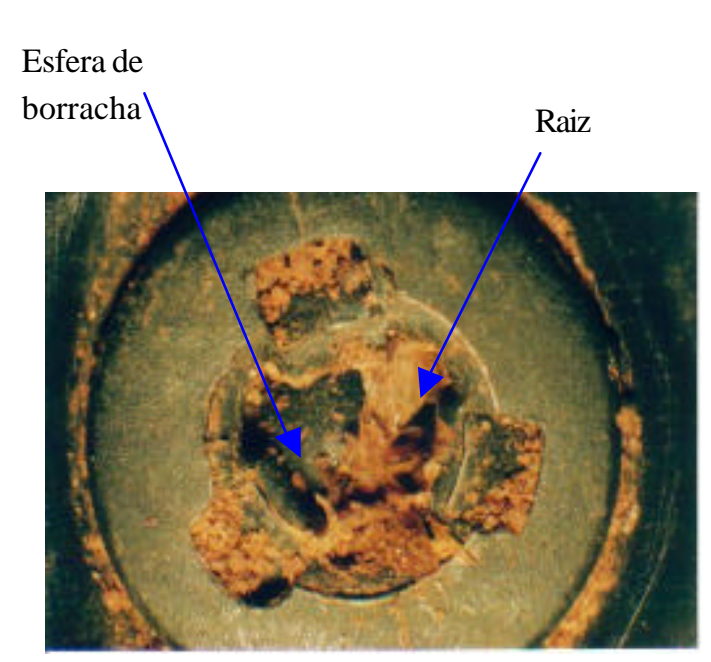

$\mathbf{a}$

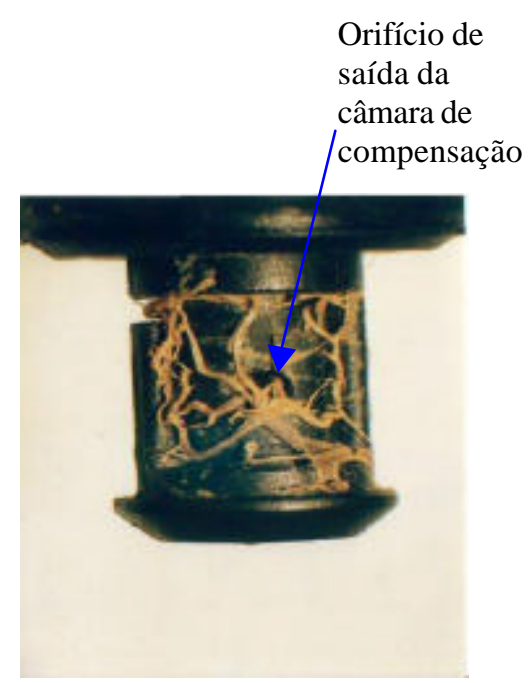

b

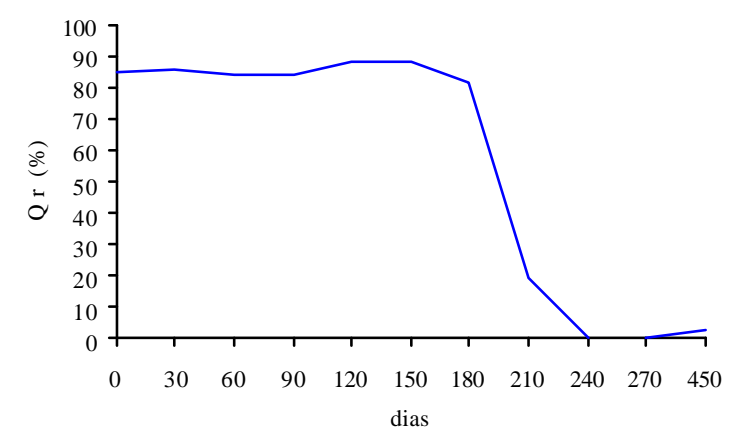

c

Figura 37 - Vista superior (a) e posterior (b) do gotejador VP afetado por raiz intrusa e evolução da vazão em função do tempo (c) 
As Tabelas 21 e 22 apresentam um resumo das medidas das variáveis de arquitetura dos modelos de emissores não-compensantes e autocompensantes de pressão, respectivamente.

Tabela 21. Medidas da arquitetura dos gotejadores não-compensantes

\begin{tabular}{lcccccc}
\hline Mod & $\begin{array}{c}\text { Compri- } \\
\text { mento do } \\
\text { labirinto } \\
(\mathrm{mm})\end{array}$ & $\begin{array}{c}\text { Percurso } \\
\text { da água }\end{array}$ & $\begin{array}{c}\text { Área de } \\
\text { filtragem }\end{array}$ & $\begin{array}{c}\text { Área da } \\
\text { câmara de } \\
\text { saída de água } \\
(\mathrm{mm})^{1}\end{array}$ & $\begin{array}{c}\text { Distância do orifício de } \\
\text { saída de água ao ponto } \\
\text { crítico } \\
\left(\mathrm{mm}^{2}\right)^{3}\end{array}$ & $\begin{array}{c}\text { Largura do } \\
\text { labirinto }\end{array}$ \\
\hline AQ & 187,0 & 229,5 & $\mathrm{~nm}$ & $\mathrm{~nm}$ & $\mathrm{~nm}$ & $(\mathrm{~mm})$ \\
CD & 115,0 & 128,0 & $17,7(3,0)$ & 181,0 & 24,2 & 1,0 \\
DI & 242,0 & 286,0 & 18,7 & 206,5 & 44,0 & 0,9 \\
HD & 22,0 & 26,0 & $11,0(8,4)$ & 28,4 & 4,0 & 0,4 \\
HG & 141,5 & 180,1 & $65,8(55,4)$ & 456,0 & 37,0 & 0,9 \\
TR & 113,4 & 123,6 & $51,4(37,4)$ & 96,1 & 10,2 & 1,0 \\
DL & 17,8 & 21,0 & $14,0(12,3)$ & 33,3 & 3,2 & 0,7 \\
\hline
\end{tabular}

'Da saída do filtro até o orifício de saída de água.

2 Valores entre parênteses se referem à área líquida de filtragem

${ }^{3}$ Não considerando a câmara morta, quando houver.

nm - não medido

Tabela 22. Medidas da arquitetura dos gotejadores autocompensantes

\begin{tabular}{lcccccc}
\hline Modelo & $\begin{array}{c}\text { Compri- } \\
\text { mento do } \\
\text { labirinto } \\
(\mathrm{mm})\end{array}$ & $\begin{array}{c}\text { Percurso } \\
\text { da água }\end{array}$ & $\begin{array}{c}\text { Área de } \\
\text { filtragem }\end{array}$ & $\begin{array}{c}\text { Área da } \\
\text { câmara de } \\
\text { saída de água } \\
(\mathrm{mm})^{2}\end{array}$ & $\begin{array}{c}\text { Distância do orifício de } \\
\text { saída de água ao ponto } \\
\text { crítico } \\
\left(\mathrm{mm}^{2}\right)\end{array}$ & $\begin{array}{c}\text { Largura do } \\
\text { labirinto }\end{array}$ \\
\hline CP & 39,8 & 49,4 & 197,7 & 550,7 & 71,0 & $\mathrm{~nm}$ \\
DLP & 39,8 & 49,4 & 214,0 & 550,7 & $\mathrm{~nm}$ & $\mathrm{~nm}$ \\
DP & 37,7 & 114,2 & 12,2 & 264,0 & 3,5 & 1,0 \\
HP & 62,0 & 107,4 & 51,8 & 477,0 & $\mathrm{~nm}$ & $\mathrm{~nm}$ \\
NP & 85,0 & 154,4 & 37,3 & 247,1 & 3,5 & $\mathrm{~nm}$ \\
RM & 17,8 & 21,0 & 27,0 & 214,2 & $\mathrm{Nm}$ & 1,0 \\
VP & 6,9 & 19,9 & 2,6 & 8,1 & $\mathrm{~nm}$ & $\mathrm{~nm}$ \\
\hline
\end{tabular}

\footnotetext{
Da saída do filtro até o orifício de saída de água.

2 Não considerando a câmara morta, quando houver. nm - não medido
} 


\subsection{Arquitetura do gotejador $x$ intrus ão de raize ocorrência de vácuo}

O caminho percorrido pela raiz no interior do gotejador, durante o processo de intrusão, é semelhante ao efetuado pela água, apenas em sentido contrário. Assim, as estratégias de minimização dos efeitos da entrada de raízes no gotejador poderiam se basear em: a) ampliar o número de caminhos possíveis entre a entrada da água no gotejador, através da área de filtragem e a sua saída para a atmosfera, ou $b$ ) maximizar a distância entre o ponto de entrada da raiz e o ponto crítico do fluxo. $\mathrm{O}$ primeiro caso resultaria no efeito de que mesmo que a raiz viesse a obstruir um dos caminhos o gotejador continuaria funcionando pelo caminho alternativo; essa característica está mais relacionada aos gotejadores do tipo cilíndrico e encontrada, de modo mais efetivo, nos modelos DP e NP (Figuras 29 e 33, respectivamente).

Gotejadores que apresentam dois orifícios de saída de água não necessariamente apresentam essa propriedade, uma vez que o ponto crítico para efeito de fluxo é apenas um, como no caso dos modelos HP, CD, DI e HG. No segundo caso se conseguiria apenas um aumento do tempo para que a raiz atingisse a espessura que resultasse na obstrução da secção de passagem de água, isso com base no fato de que o crescimento longitudinal das raízes predomina sobre o radial.

Além de fatores relacionados às possibilidades de direcionamento do crescimento longitudinal da raiz, em conseqüência das características da arquitetura, a taxa desse crescimento determinará o tempo decorrido entre a intrusão e a chegada ao ponto crítico. De acordo com Klepper, (1990), essa taxa de crescimento é, para uma raiz típica e em condição de solo úmido, friável e não-compactado, da ordem de $1 \mathrm{~mm} \cdot$ hora $^{-1}$, ou, $1 \mathrm{cmdia}^{-1}$, como encontrado em Klepper, (1991). É provável que no interior do gotejador a taxa de crescimento venha a ser maior que a citada por esses autores, uma vez que não haveria as limitações ao crescimento próprias do ambiente existente no solo, como pressão mínima de turgor e resistência imposta pelas partículas do solo.

Nos gotejadores do tipo plano (TR, DL, HD), há, teoricamente, maior probabilidade de a raiz atingir mais rapidamente a área de filtragem, uma vez que existe um caminho único entre o ponto de penetração e essa área, e, a partir daí, penetrar e se 
desenvolver no interior do tubo, ampliando o efeito da intrusão na hidráulica da parcela, como discutido acima. Nesse aspecto, o comprimento do labirinto poderá influenciar na suscetibilidade do modelo à intrusão. Assim, em labirintos mais curtos, como os dos modelos DL e HD, o efeito da intrusão ocorrerá mais rapidamente que em um labirinto mais longo, como o do modelo TR. As Figuras 38a, 38b e 38c mostram o efeito da intrusão e o enovelamento no interior do tubo em gotejadores de comprimento de labirinto mais curto e a Figura 39, a raiz se projetando em um labirinto mais longo, não tendo ainda atingido a área de filtragem do gotejador. A Figura 39a é constituída de uma seqüência de cinco imagens, das quais uma (intermediária), de baixa qualidade, foi descartada.

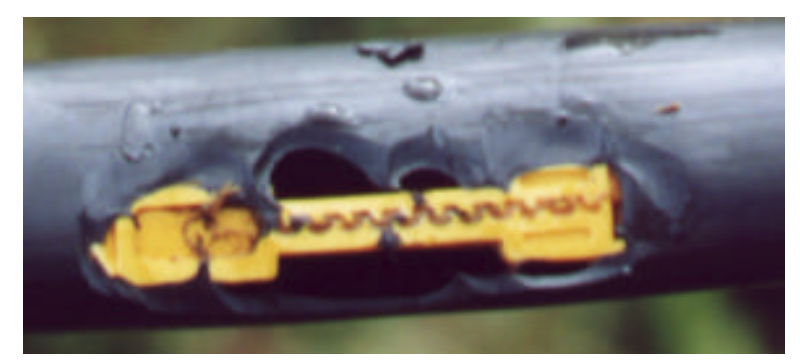

$\mathbf{a}$

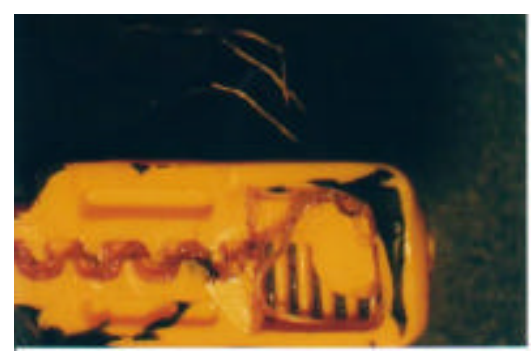

b

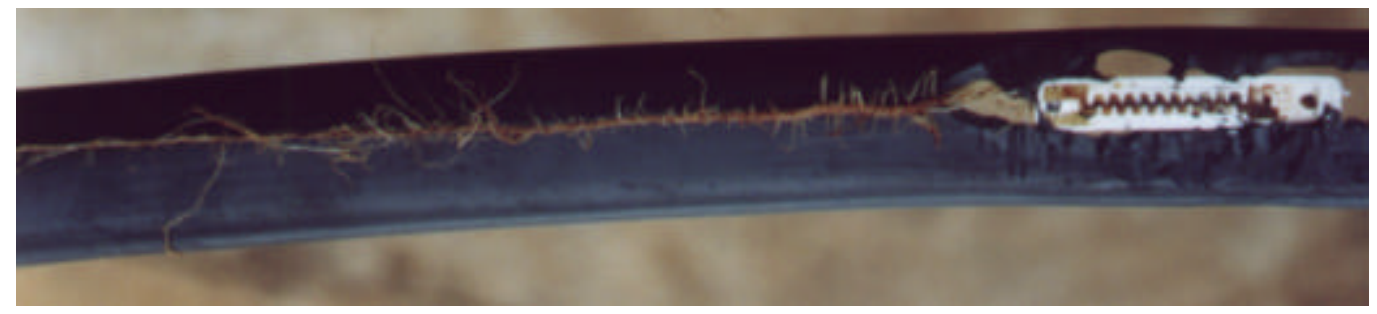

c

Figura 38 - Intrusão de raiz em gotejadores do tipo plano; sem penetração no interior do tubo (a) e com raiz no interior do tubo gotejador (b) e (c)

A raiz pode crescer linearmente, passando entre os dentes que formam o labirinto (Figura 39), ou contornando-os em zig-zag como na Figura 38. Nessa fase o efeito na redução de vazão pode ocorrer de forma parcial. 
Simultaneamente ao crescimento longitudinal, os segmentos anteriores da raiz se encontram em processo de elongação radial (Figura 39a), fechando totalmente a secção de passagem de água justamente no final do labirinto (transição entre a câmara de saída de água e o início do labirinto, onde se configura o chamado ponto crítico ao fluxo).

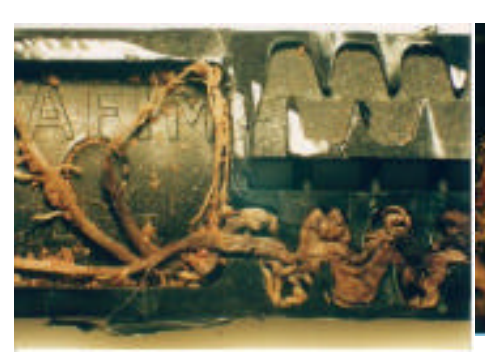

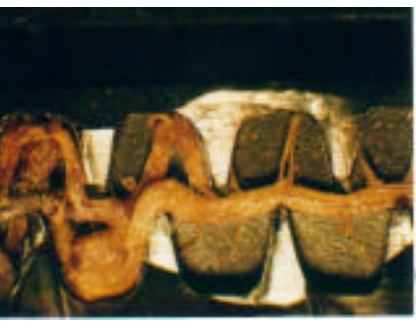

a

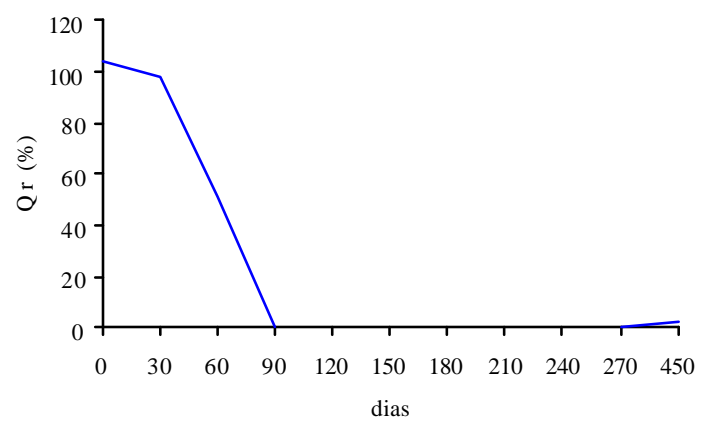

b

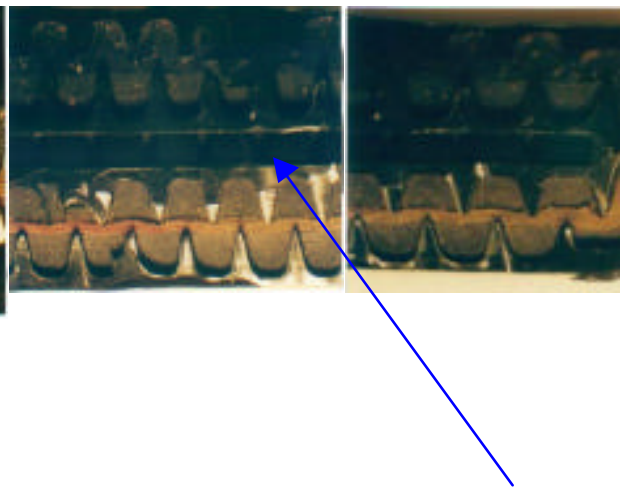

Filtro

Figura 39 - Gotejador plano com raiz em crescimento ao longo do labirinto; sem atingir a área de filtragem (a) e evolução da vazão em função do tempo (b)

Já nos modelos autocompensantes, o comprimento do labirinto tem menor influência no potencial de entrada de raiz no interior do tubo. Tal potencial relaciona-se mais à distância e às alternativas de caminhos entre o orifício de saída de água e a saída da câmara de compensação, nas quais, para a maior parte dos modelos avaliados, se encontra o filtro do gotejador. Para esse grupo de gotejadores, a magnitude das sobrevazões observadas, principalmente nos modelos $\mathrm{CP}$, DLP, HP e NP, estão 
provavelmente mais relacionadas à sucção de partículas de solo no interior dos mesmos, afetando o funcionamento da membrana responsável pela característica de compensação de vazão, que a um estágio inicial de penetração de raiz no interior da câmara. Embora essa última alternativa seja possível, o mais provável é que quando a raiz venha a atingir o interior da câmara de compensação, já tenha comprometido, significativamente, a secção de passagem de água do orifício de saída ou do ponto crítico de fluxo da água.

A área da câmara de saída de água poderá influenciar o tempo que a raiz leva para crescer e ocupar essa área, antes que venha a se direcionar para a saída do labirinto do gotejador ou ponto de acesso à câmara de compensação. Esses locais se configuram, normalmente, como o ponto crítico do fluxo da água; no primeiro caso se encontram os modelos CD, DI, HD, TR e DL e no segundo, os modelos NP, DP, CP, DLP e HP.

Quando ocorre grande desenvolvimento de raiz na câmara de saída de água, o entupimento pode se dar apenas pela massa de raiz formada, obstruindo o ponto crítico do fluxo, sem que a raiz tenha atingido um desenvolvimento tal dentro do labirinto que resultasse em redução significativa de vazão. Esse fato é visualizado na Figura 40, onde se nota que o crescimento radial da raiz não obstruiu a secção do labirinto, enquanto o ponto crítico do modelo já se encontrava obstruído.

Hipoteticamente, a área de filtragem deve apresentar correlação fraca com o potencial de intrusão de raízes do gotejador. Porém a distância da área ou as possibilidades de percurso a partir do ponto de intrusão (orifício de saída de água) pode ser determinante na probabilidade de que a raiz intrusa venha a alcançar o interior do tubo. 


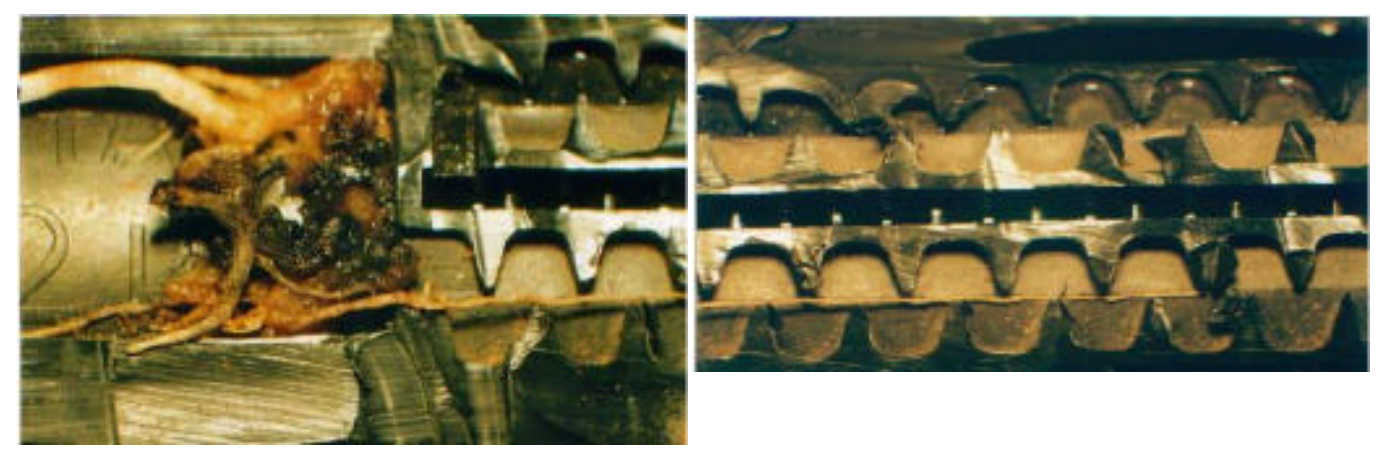

a

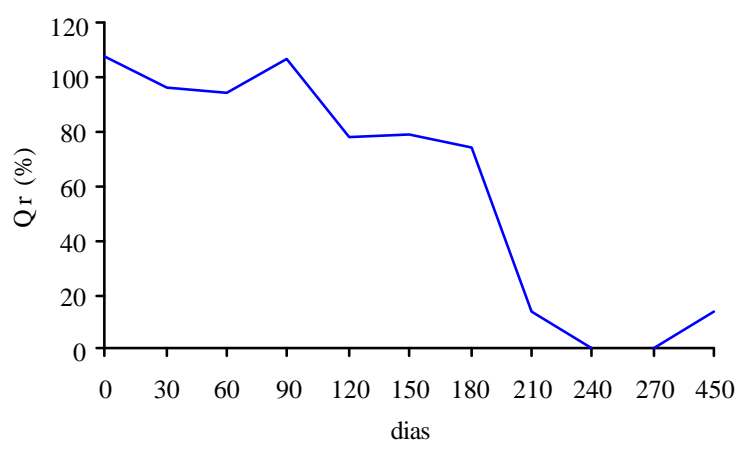

b

Figura 40 - Desenvolvimento de raiz causando obstrução do ponto crítico de um gotejador plano (a) e conseqüente redução da vazão em função do tempo (b)

Para todos os emissores não-compensantes, a penetração de raiz no interior do tubo se deu, necessariamente, pela área de filtragem; nos modelos autocompensantes a penetração ocorreu, predominantemente, através da câmara de compensação, podendo se dar pelo filtro aí localizado (HD, NP, DP, RM, VP) ou por áreas de comunicação com o interior do tubo (DLP, CP).

O número de orifícios de saída de água constitui um fator que pode determinar diferenças na sensibilidade do gotejador ao processo de intrusão. Os modelos avaliados contam com um, dois ou três orifícios. A adoção, por parte da indústria, de mais de um orifício de saída de água se deu com o objetivo principal de reduzir a possibilidade de 
sucção de partículas do solo em gotejamento superficial, por efeito da formação de vácuo no momento da parada do sistema de irrigação. Embora possa ser efetiva na irrigação superficial, essa função deixa de ser exercida na condição de irrigação subsuperficial. Não foi, portanto uma estratégia de redução do efeito da intrusão de raízes em sistemas de gotejamento subsuperficial.

Nos modelos com dois orifícios de saída de água (essa característica está associada aos modelos do tipo cilíndrico), se o desenvolvimento da raiz obstruir somente o orifício onde ocorreu a intrusão, ou seja, se o crescimento se der apenas na câmara de saída da água, a água poderá fluir pelo segundo orifício, minimizando o dano. Essa hipótese se torna mais verdadeira à medida que os orifícios de saída estejam posicionados em lados opostos do gotejador, ou seja, um orifício em cada câmara (não há câmara morta). Dos gotejadores avaliados apenas os modelos HG e HP apresentam essa característica; nos demais, os dois orifícios se encontram em uma das câmaras, formando ângulos de $45^{\circ}$ a $180^{\circ}$ entre si. Os modelos do tipo plano (HD, HG, DL, RM) e o modelo VP, têm apenas um orifício, o que elimina essa estratégia de prevenção do efeito da intrusão.

Mesmo para os emissores que apresentem orifícios em apenas uma das câmaras, a localização do furo no lado oposto ao ponto crítico do fluxo da água se constituiria em atenuante do reflexo da intrusão. Nesse aspecto, observa-se que há variabilidade no processo de fabricação dos tubos gotejadores no que se refere à localização do orifício de saída de água. Um mesmo modelo apresenta o orifício de saída de água ora de um lado, ora de outro do gotejador, além da variabilidade de furação, já discutida, em relação ao perímetro do mesmo.

Apresenta-se como contraponto à vantagem da existência de dois orifícios de saída de água o fato que, em se aceitando a hipótese do caráter probabilístico da intrusão, o segundo orifício representar uma duplicação da área de acesso ao interior do gotejador, ampliando, conseqüentemente, a probabilidade de intrusão de raízes. É de supor, no entanto, que a relação benefício-custo seja positiva.

Os aspectos de arquitetura acima discutidos atuam apenas no sentido de aumentar o tempo em que o gotejador permanece funcional ou permanece com o menor nível de 
alteração de vazão possível após a ocorrência da intrusão. Não constituem, portanto, mecanismos de barreira física à intrusão. No entanto, tais aspectos podem ser efetivos na minimização do potencial de penetração da raiz no interior do tubo gotejador.

Dos gotejadores avaliados, o modelo AQ se constitui no único que apresenta mecanismo de barreira física à intrusão de raízes. Contraditoriamente, esse modelo apresentou, juntamente com os modelos $\mathrm{CD}$ e $\mathrm{HD}$, os maiores níveis de redução de vazão, com diferenças significativas estatisticamente em relação aos demais modelos. A diferença entre a média de vazão dos tratamentos Úmido e Seco em relação ao SC foi significativa (-26,4\% e $-32,8 \%$, respectivamente), evidenciando o efeito das raízes no modelo. Do mesmo modo, a pequena variação, no decorrer do experimento, dos valores do coeficiente de variação dos dados de vazão no tratamento SC em relação aos dos tratamentos úmido e seco, corroboram essa evidência. Alem disso, no experimento sobre o efeito do vácuo na vazão dos gotejadores, o modelo AQ apresentou o menor nível de redução de vazão, evidenciando que o efeito solo não foi determinante para explicar a redução de vazão encontrada. De vinte gotejadores dissecados, oito (40\%) encontravam-se com raízes intrusas; em todos esse, as raízes se mostravam mais finas que as observadas nos demais modelos, com comprimento máximo de $40 \mathrm{~mm}$ e pouco ramificadas. Em nenhum dos gotejadores dissecados a raiz havia penetrado para o interior do tubo: a pequena dimensão da secção de passagem e do orifício de filtragem são determinantes para isso.

A semelhança na arquitetura dos modelos CP e DLP refletiu no comportament o idêntico apresentado por ambos. Tanto no experimento da cana como no do feijão, esses modelos mostraram elevado efeito dos tratamentos em relação aos demais modelos autocompensantes. Também, se destacaram por apresentar significativa variação de Qr no tratamento SC, revelando que o efeito do solo foi, provavelmente, mais preponderante que o das raízes. Concordando com essa hipótese, no experimento de ocorrência de vácuo na malha hidráulica esses modelos se destacaram, juntamente com os modelos HP e NP, por apresentar os maiores níveis de variação de Qr, quando da aplicação de níveis de vácuo a partir de $-26 \mathrm{kPa}$. 
Os gotejadores do grupo dos autocompensantes que apresentaram maior variação de Qr (lembrando que tais variações foram significativas no tratamento SC), foram os mesmos que também mostraram maior resposta ao efeito da simulação de vácuo $(\mathrm{CP}$, DLP, HP e NP). Esse comportamento sugere que a maior parte das sobrevazões encontradas para esses modelos, no tratamento da cana e do feijão, deve ser atribuída ao efeito do solo, mais que à penetração de raízes. Assim, desprende-se que a eficácia da válvula antivácuo, instalada em cada linha de suprimento dos vasos com e sem cultivo (Figura 1), não foi suficientemente efetiva para evitar o succionamento de partículas do solo, pelos gotejadores (Figura 17, 27 e 41). Por sua vez, aqueles modelos que mostraram maior estabilidade da Qr nos experimentos da cana e feijão (DP, RM e VP) também o foram quando submetidos aos níveis de vácuo do experimento respectivo.

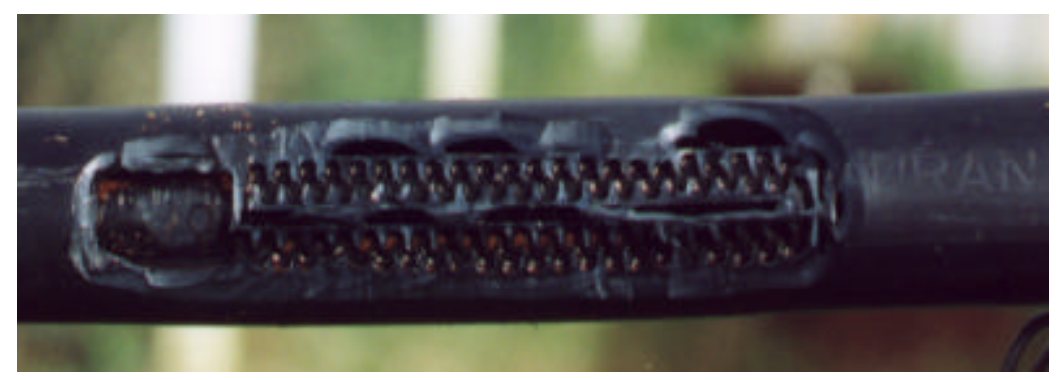

Figura 41 - Depósito de partículas de solo em gotejador, por efeito provável da ocorrência de vácuo

Além da adoção de um número maior de válvulas antivácuo na parcela de irrigação, uma alternativa simples, utilizada por plantadores de cana-de-açúcar nas Ilhas Maurício (Wetherhead, 2000), consiste em deixar um pequeno segmento inicial da lateral exposto na superfície (em "loop"): os gotejadores expostos serviriam como ponto de entrada de ar, quando da ocorrência do vácuo. A desvantagem apontada se refere a uma perda de água pelos gotejadores expostos, além da necessidade de enterrar esse segmento, quando da realização da queima da cana. A instalação de uma válvula anti- 
drenante no início de cada linha de gotejadores pode, também, minimizar a intensidade do vácuo. Essas válvulas são disponíveis no mercado com conexões próprias para tubos de polietileno.

Diferentemente dos gotejadores CP e DLP, nos modelos HD e DL, ambos não compensantes do tipo plano, a semelhança na arquitetura não resultou em semelhança de comportamento. $\mathrm{O}$ primeiro apresentou, para todas as condições ensaiadas, os mais altos níveis de redução de vazão e, na maior parte das vezes, estatisticamente diferente do modelo DL, o qual, juntamente com o modelo HG e TR, apresentou os menores níveis de redução de Qr (Tabelas 9 e 10). Além de semelhantes em arquitetura, os dois modelos apresenta medidas semelhantes para a maior parte das variáveis de arquitetura analisados (Tabela 21), sendo exceção apenas a largura do labirinto, a qual é, aproximadamente, o dobro para o modelo DL.

Para gotejadores do tipo cilíndrico, o comportamento extremo acima referido foi apresentado pelos modelos CD e HG. Nesse caso, mais que as diferenças nos valores das variáveis de arquitetura (principalmente área de filtragem), é provável ter prevalecido a arquitetura em si: o primeiro aspecto se refere funcionalidade de dois orifícios de saída de água alocados em câmaras de saída oposta, o que, como já discutido, reduz a probabilidade de entupimento; um segundo detalhe de arquitetura se refere à saída do labirinto, a qual no modelo $\mathrm{HG}$ se encontra em uma reentrância, em relação ao caminhamento da raiz, no labirinto largo de comunicação das duas câmaras de saída (Figura 21), enquanto no modelo CD essa saída se encontra rente ao caminhamento da raiz, no labirinto largo (Figura 15); um terceiro aspecto e que apresenta relação estreita com o segundo é o fato de que, no processo de montagem do tubo gotejador, há uma variação da câmara onde é realizado a furação do orifício de saída de água. Para o modelo CD, em uma amostra de 20 gotejadores 11 deles (55\%) tinha os orifícios localizados na câmara mais próxima à saída do labirinto, sendo que esse pode ser considerado o ponto crítico ao fluxo de água. Em se efetuando o furo do orifício somente no lado oposto, o percurso da raiz para atingir o ponto crítico se torna ria mais longo. 
As variáveis de arquitetura interna dos gotejadores discutidas no item 5.2 é suposto apresentar baixa correlação com a suscetibilidade dos mesmos aos efeitos da ocorrência de vácuo na malha hidráulica. Mais que isso, faz-se necessário o estabelecimento de mecanismos de ordem construtiva (aqui não considerado relacionado à arquitetura interna, em si). O mecanismo antivácuo apresentado pelo modelo VP se mostrou efetivo, enquanto no modelo AQ seu mecanismo atuou mais eficientemente nos níveis de vácuo mais elevados ( acima de $-26 \mathrm{kPa}$ ).

A utilização de gotejadores autocompensantes em irrigação subsuperficial deve ser mais bem avaliada, uma vez que, além do efeito da raiz, o efeito do solo pode ser preponderante para a ocorrência freqüente de sobrevazões de grande magnitude no gotejador, resultando em grave desequilíbrio no balanço hidráulico do projeto de irrigação. Cabe salientar que há fabricantes que recomendam gotejadores pertencentes a esse grupo, em irrigação subsuperficial.

Assim, os resultados obtidos no experimento de ocorrência de vácuo na malha hidráulica sobre a vazão dos gotejadores se mostraram estreitamente relacionados com aqueles obtidos nos experimentos de intrusionamento de raízes: houve uma tendência clara de redução de vazão para os gotejadores do grupo dos não compensantes de vazão e o oposto para o grupo do autocompensantes. Dentro do grupo dos emissores autocompensantes, os modelos que apresentaram os maiores (HP, CP, DLP e NP) e os menores (DP, VP e RM) níveis de variação de vazão também foram idênticos para os dois grupos de experimentos.

Com base nos resultados obtidos e experiências vivenciadas na condução do presente experimento e com o propósito de contribuir para trabalhos subseqüentes, algumas sugestões são apresentadas:

a) A intrusão radicular nos gotejadores não ocorre na mesma velocidade de aprofundamento radicular das culturas de cana-de-açúcar e de feijão no solo, desta maneira, existe um maior potencial de que culturas perenes venham a serem adotadas como culturas de referência em ensaios de intrusão radicular. 
b) Estudar outras profundidades de enterrio da linha de gotejadores, individualizando os vasos para cada profundidade.

c) Em função da característica de geotropismo positivo da raiz, avaliar o efeito, no potencial de intrusão e em relação a outras causas de entupimento, da instalação do gotejador com o orifício de saída de água voltado para baixo. Esse estudo seria mais específico para gotejadores do tipo plano, que apresentam apenas um orifício de saída de água.

d) No planejamento do experimento, slicitar a numeração do lote do fabricante de cada emissor e discutir previamente detalhes do ensaio com a equipe de Engenharia, para que os produtos analisados sejam entregues certificados pelas empresas fabricantes.

e) Es tudar toda a faixa de vazão de cada modelo, pois à medida que a vazão nominal aumenta, o emissor tende a um comportamento mais estável além de evitar comparações diretas entre emissores de vazões nominais diferenciadas.

f) Avaliar outras culturas de ciclo rápido, ou perenes em estágio inicial de desenvolvimento, que possam ser utilizadas para testes rápidos de suscetibilidade à intrusão de raíz em gotejadores. 


\section{CONCLUSÕES}

Os resultados obtidos permitiram evidenciar as seguintes conclusões:

a. Há diferenças marcantes entre modelos de emissores quanto ao seu desempenho sob condição de enterrio, tanto na suscetibilidade à intrusão de raízes quanto à ocorrência de vácuo nas linhas laterais. Adequações na arquitetura ou no processo de fabricação dos gotejadores avaliados podem minimizar tanto a intrusão de raízes como os efeitos ocasionados por ela;

b. O desempenho dos emissores em irrigação subsuperficial evidencia elevada correlação com a existência, ou não, do mecanismo de compensação de vazão dos mesmos Emissores não-compensantes mostraramse mais estáveis que os autocompensantes na irrigação subsuperficial;

c. O manejo da irrigação visando evitar elevadas alternâncias no nível de umidade do solo não reduz, por si só, o potencial intrusivo de raízes em gotejadores;

d. A profundidade de instalação do gotejador, na faixa avaliada no experimento (0,15 e 0,30 m), não se constitui em fator determinante do potencial de intrusão de raízes em gotejamento subsuperficial;

e. A cultura do feijão não apresenta características favoráveis de crescimento radicular rápido e vigoroso para ser utilizada como cultura de referência em ensaios rápidos de intrusão radicular de gotejadores, na irrigação subsuperficial. 


\section{REFERÊNCIAS BIBLIOGRÁFICAS}

AMALI, S.; ROLSTON, D.E.; FULTON, A.E.; HANSON, B.R. Soil water variability under subsurface drip and furrow irrigation. Irrigation Science, v.17. p.151-155, 1997.

AVILAN ROVIRA, L.; NEPTUNE, A.M.L. Estudio del sistema radicular del frijol (Phaseolus vulgaris L. variedad carioca) por los metodos del monólito, sonda y radioisótopos en un suelo del orden alfisol. Agronomia Tropical, v.26, n.2, p.117142, ene/feb. 1976a.

AVILAN ROVIRA, L.; NEPTUNE, A.M.L. Morfologia inicial del sistema radicular del Phaseolus vulgaris L. 'Carioca' en condiciones controladas. Agronomia Tropical, v.26, n.2, p.109-116, ene/feb. 1976b.

AYARS, J.E.; PHENE, C.J.; HUTMACHER, K.R. et al. Subsurface drip irrigation in row crops: a review of 15 years of research at the Water Management Research Laboratory. Agricultural Water Management, v.42, p.1-27, 1999.

AYARS, J.E.; PHENE, C.J.; SCHONEMAN, R.A.; MESO, B.; DALE, F.; PENLAD, J. Impact of bed location on the operation of subsurface drip irrigation systems. In: INTERNATIONAL MICROIRRIGATION CONGRESS, 5., Orlando, 1995. Proceedings. St. Joseph: ASAE, 1995. p.141-146.

BARTH, H.K. Sustainable and effective irrigation through a new subsoil irrigation system (SIS). Agricultural Water Management. v.40, p.283-290, 1999.

BAR-YOSEF, B.; SAGIV, B.; MARKOVITCH, T. Sweet corn response to surface and subsurface trickle phosphorus fertigation. Agronomy Journal, v.81. p.443-447, 1989. 
BATCHELOR, C.H.; SOOPRAMANIEN, G.C.; BELL, J.P.; NAYAMUTH, R.; HODNETT, M.G. Importance of irrigation regime, dripline placement and row spacing in drip irrigation of sugar cane. Agricultural and Water Management, v.17, p.75-94, 1990.

BELL, A.A.; LIU, L.; REIDY, B.; DAVIS, R.M.; SUBBARAO, K.V. Mechanisms of subsurface drip irrigation-mediated suppression of lettuce drop caused by Sclerotinia minor. Phytopathology, v. 88, n. 3, p. 252-259, 1998.

BRALTS, V.F.; WU, I-PAI; GITLIN,H.M. Emitter plugging and drip irrigation lateral line hydraulics. Transactions of the ASAE, v.25, n.6, p. 1274-1281, 1982.

BOMAN, B.J. Effects of orifice size on microsprinkler clogging rates. Transactions of the ASAE, v.11, n.6, p.839-843, 1995.

BUCKS, D.A.; ERIE, F.J.; FRENCH, O.F.; NAKAYAMA, F.S.; PEW,W.D. Subsurface trickle irrigation management with multiple cropping. Transactions of the ASAE, v.24. n.6. p.1481-1489. 1981.

CAFÉ-FILHO, A.C.; DUNIWAY, J.M. Effect of location of drip irrigation emitters and position of Phytophthora capsici in roots on phytophthora root rot of pepper. Phytopathology, v. 86, n. 12, p.1364-1369, 1996.

CALDWELL, D.S.; SPURGEON, W.E.; MANGES, H.L. Frequency of irrigation for subsurface drip irrigated corn. Transactions of the ASAE, v.37, n.4, p. 1099-1103, 1994.

CALHEIROS, R. O. Sistema radicular de quatro culturas em solo glei pouco húmico da região de Londrina (PR). Revista Brasileira de Ciência do Solo. v.16, p.299-307, 1992.

CAMP C.R. Subsurface drip irrigation: a review. Transactions of the ASAE, v.41 n.5 p.1353-1367, 1998.

CAMP, C.R.; SADLER, E.J.; BUSSCHER, W.J. Subsurface and alternate-middle micro irrigation for the southeastern coastal plain. Transactions of the ASAE, v.32 n.2 p.451-456, 1989. 
CAMP, C.R.; LAMM, F.R.; EVANS, R.G.; PHENE, J. A comparison of uniformity measures for drip irrigation systems. Tansactions of the ASAE, v.40. n.4. p.10131020, 1997.

CAMP, C.R.; LAMM, F.R.; EVANS, R.G.; PHENE, J. Subsurface drip irrigation-past, present and future. In: DECENDIAL NATIONAL IRRIGATION SYMPOSIUM, 4, Phoenix.2000. Proceedings. St. Joseph: ASAE, 2000, p.363-372.

CARMI, A.; PLAUT, Z.; HEUER, B.; GRAVA, A. Establishment of shallow and restricted root systems in cotton and its impact on plant response to irrigation. Irrigation Science, v.13, p.87-91, 1991.

CASAGRANDE, A. A. Tópicos de morfologia e fisiologia da cana-de-açúcar. Jaboticabal: Finep, 1991. 157p.

CASAÑO, C. Informacion general riego por goteo subterrâneo em olivar - Vip Underground. Valencia: Irrimon, 1995, 13p.

CROSBY, D. G. Nonbiological degradation of herbicides in the soil. In: ALDUS, L.S. (Ed). Herbicides - physiology, biochemistry, ecology. London: Academic Press, 1976. v.2, p.65-97.

DALRI, A.B.; GARCIA, C.J.B.; ARAÚJO, M.V.; CRUZ, R.L.; DUENHAS, L.H. Uso da trifluralina para o controle da intrusão de radicelas de cana-de-açúcar em gotejadores enterrados (compact disc). In: CONGRESSO BRASILEIRO DE ENGENHARIA AGRÍCOLA, 31., Salvador, 2002.

DEVINE, M.; DUKE, S.O.; FEDTKE, C. Phisiology of herbicide action New York: Prentice Hall, 1993. 441p.

EVETT, S.R.; HOWELL, T.A.; SCHNEIDER, A.D. Energy and water balances for surface and subsurface drip irrigated corn. In: INTERNATIONAL MICROIRRIGATION CONGRESS, 5., Orlando, 1995. Proceedings. St. Joseph: ASAE, 1995. p.135-140.

FARIA, L.F. Variação de vazão de gotejadores enterrados na irrigação de citros e café. Piracicaba, 2002. 87p. Dissertação (Mestrado) - Escola Superior de Agricultura "Luiz de Queiroz”, Universidade de São Paulo. 
GRAHAM, P.H.; RANALLI, P. Common bean (Phaseolus vulgaris L.). Fields Crops Research. v.53. p.131-146, 1997.

GUAZZELLI, M.A.N.; PAES, L.A.D. Irrigação de cana-de-açúcar comercial. In. SEMINÁRIO COPERSUCAR DE TECNOLOGIA AGRONÔMICA, 7., Piracicaba, 1997. Piracicaba: COPERSUCAR, 1997. 11p.

GUSHIKEN, E.C. Irrigation with reclaimed water trough permanent subsurface drip irrigation systems. In. INTERNATIONAL MICROIRRIGATION CONGRESS, 5., Orlando, 1995. Proceedings. St. Joseph: ASAE, 1995. p.269-274.

HERTWIG, K. von. Manual de herbicidas, desfolhantes, dessecantes, fitoreguladores e bioestimulantes. São Paulo: Ceres, 1983. 633p.

HILLS, D.J.; TAJRISHY, M.A.M.; GU, Y. Hydraulic consideration for compressed subsurface drip tape. Transactions of the ASAE, v.32, n.4. p.1197-1201, 1989.

HOWELL, T.A.; SCHNEIDER, A.D.; EVETT, S.R. Subsurface and surface microirrigation of corn - southern high plains. Transactions of the ASAE, v.40, n.3, p.635-641, 1997.

HUNSIGI, G. Production of sugarcane. New York: Spring-Verlag 1993. 245p.

KLEPPER, B. Root growth and water uptake. In: STEWART, B.A.; NIELSEN, D.R. (Ed). Irrigation of agricultural crops . New York: Academic Press, 1990. p.281322.

KLEPPER, B. Crop root system response to irrigation. Irrigation Science, v.12., n3. p.105-108, 1991

KONDÖRFER, G.H.; PRIMAVESI, O.; DEUBER, R. Crescimento e distribuição do sistema radicular da cana-de-açúcar em solo LVA. Boletim Técnico Copersucar, n.47, p.32-36, 1989.

KOSKINEN, W.C.; HARPER, S.S. Herbicides properties and processes affecting application. In: McWHORTER, C.G.; GEBGHARDT, M.R. (Ed). Methods of applying herbicides. Champaign: WSSA 1987. p.9-18. (Monograph, 4).

LAMM, F. R.; MANGES, H.L.; STONE, L.R.; KHAN, A.H.; ROGERS, D.H. Water requirement of subsurface drip-irrigated corn in northwest Kansas. Transactions of the ASAE, v.38. n.2. p.441-448, 1995. 
MAKASHEVA, R.K. The pea Rotterdam: A.A. Balkema, 1984. 267p.

MATIOLI, C. S. Irrigação suplementar de cana-de-açúcar: modelo de análise de decisão para o Estado de São Paulo. Piracicaba, 1998. 122p. Tese (Doutorado) - Escola Superior de Agricultura “Luiz de Queiroz", Universidade de São Paulo.

MATTHIAS A. D.; SALEHI, R.; WARRICK, W. Bare soil evaporation near a surface point-source emmiter. Agricultural and Water Management. v. 11, p.257-277, 1986.

MESHKAT, M.; WARNER, R.C.; WORKMAN, S.R. Evaporation reduction potential in an undisturbed soil irrigated with surface drip and sand tube irrigation. Transactions of the ASAE, v.43. n.1. p.79-86, 2000.

MITCHELL, W.H. Subsurface irrigation and fertilization of field corn. Agronomy Journal, v.73, p.913-916, Nov./Dec. 1981.

MITCHEL, W.H.; SPARKS, D.L. Influence of subsurface irrigation and organic addition on top and root growth of field corn. Agronomy Journal, v.74 n.6 p.1084 1088, 1992.

MOUSINHO, F.E.P.; D’ALBUQUERQUE JÚNIOR, B.S.; COELHO, R.D. Características de design dos principais gotejadores disponíveis no mercado nacional (compact disc). In: Congresso Brasileiro de Engenharia Agrícola, 32.,Goiânia, 2003.

NAKAYAMA, F. S. Operational principles/water treatement. In: NAKAYAMA, F.S.; BULKS, D.A. Trickle irrigation for crop production. Amsterdam: Elsevier, 1986. cap.3, p. $164-187$.

NAKAYAMA, F.S.; BULKS, D.A. Water quality in drip/trickle irrigation: a review. Irrigation Science, v.12, p.187-192, 1991.

OLIVEIRA, F. A. de; SILVA, J.J.S. Evapotranspiração, índice de área foliar e desenvolvimento radicular do feijão irrigado. Pesquisa Agropecuária Brasileira, v.25, n.3. p.317-322, mar. 1990.

ORON, G.; DeMALACH, J.; ZAFIR, H.; CIBOTARU, R. Subsurface microirrigation with effluent. Journal of Irrigation and Drainage Engineering, v.117, n.1, p.25-36, 1991 
ORON, G.; DeMALACH, Y.; GILLERMAN, L. et al. Improved saline-water use under subsurface drip irrigation. Agricultural and Water Management, v.39, p.19-33, 1999.

PARCHOMCHUCK, P. Temperature effects on emitter discharge rates. Transactions of the ASAE, v.19, n.4, p.690-692, 1976.

PITTS, D.J.; TSAI, Y.J.; MYHRE, D.L. et al. Influence of water table depth on sugarcane grown in sandy soils in Florida. Transaction of the ASAE, v.36, n.3, p.777-782, 1993.

PLAUT, Z.; CARMI, A; GRAVA, A. Cotton root and shoot responses to subsurface drip irrigation and partial wetting of the upper soil profile. Irrigation Science, v.16, p.107-113, 1996.

PHENE, C.J.; RUSKIN, R. Potential of subsurface drip irrigation for management of nitrate in wastewater. In. INTERNATIONAL MICROIRRIGATION CONGRESS 5., Orlando,1995. Proceedings. St. Joseph: ASAE, 1995. p.155-161.

PHENE, C.J. The sustainability and potential of subsurface drip irrigation. In. INTERNATIONAL MICROIRRIGATION CONGRESS 5., Orlando,1995. Proceedings. St. Joseph: ASAE, 1995. p.269-274.

PHENE, C. J.; DAVIS, K.R.; HUTMACHER. R.B. et al. Advantages of subsurface in drip irrigation for processing tomatoes. Acta Horticulturae, n.200 p.101-113, 1987.

PROBST, G.W.; GOLAB, T.; WRIGHT, W.L. Dinitroanilines. In: KEARNEY, P.C.; KAUFMAN, D.D. (Ed.). Herbicides: chemistry, degradation and mode of action. New York: Marcel Dakker, 1975. p.453 - 495.

RAVINA, I.; PAZ, E.; SOFER,Z. et al. Control of emitter clogging in drip irrigation with reclaimed was tewater. Irrigation Science, v.13. p.129-139, 1992.

REICHARDT, K. Dinâmica da matéria e da energia em ecossistemas. Piracicaba: ESALQ. 1996. 505p.

RUSKIN, R. Reclaimed water and subsurface irrigation St. Joseph: ASAE, 1992. 12p. (ASAE. Paper, 922578). 
SADLER, E.J.; CAMP， C.R..; BUSSCHER， W.J. In. INTERNATIONAL MICROIRRIGATION CONGRESS 5., Orlando,1995. Proceedings. St. Joseph: ASAE, 1995. p.763-768.

SHANI, U.; XUE, S.; GORDIN-KATZ, R. et al. Soil-limiting flow from subsurface emitters. I: pressure measurements. Journal of Irrigation and Drainage Engineering, v.122, n.5, p.291-295, 1996.

SILVA, E. F. F.; BLANCO, F. F.; DUARTE, S. N. et al. Distribuição de sais no solo sob fertirrigação de alta freqüência. In: WORKSHOP EM FERTIRRIGAÇÃO: FLORES, FRUTAS E HORTALIÇAS, 2., Piracicaba, Anais. Guaíra:Agropecuária, 2001. p.139-152.

SMAJSTRLA, A.G.; LOCASCIO, S.J.; WEINGARTNER, D.P.; HENSEL, D.R. Subsurface drip irrigation for water table control and potato production. Applied Engineering in Agricultura, v.16, n.3, p.225-229, 2000.

SORENSEN, R.B.; WRIGHT, F.S.; BUTTS, C.L. Subsurface drip irrigation system designed for research in row crop rotation. Applied Engineering in Agriculture, v.17, n.2, p.171-176, 2001

SOUZA, J.A.G.C. Efeito da tensão da água do solo na cultura da cana-de-açúcar (Saccharum spp.). Limeira, 1976. 163p. Tese (Doutorado) - Faculdade de Engenharia de Limeira, Universidade Estadual de Campinas.

STEELE, D.D.; GREENLAND, R.G.; GREGOR, B.L. Subsurface drip irrigation systems for specialty crop production in North Dakota. Applied Engineering in Agriculture, v.12, n.6, p.671-679, 1996.

SUAREZ-REY, E.; CHOI, C.Y.; WALKER, P.M. Feasibility of subsurface drip irrigation on turf in Arizona. St. Joseph: ASAE, 1999. 20p. (ASAE. Paper, 992251).

SUAREZ-REY, E.; CHOI, C.Y.; WALKER, P.M. et al. Comparasion of subsurface drip irrigation and sprinkler irrigation of Bermuda grass turf in Arizona. Transactions of the ASAE, v.43, n.3, p.631-640, 2000. 
TULER,V.V.; NASCIF, A. E.; SOUZA, D. et al. Irrigação por gotejamento de cana-deaçúcar com diferentes níveis de água. In: CONGRESSO NACIONAL DA SOCIEDADE DE TÉCNICOS AÇUCAREIROS DO BRASIL, 2., Rio de Janeiro, 1981. Anais. Rio de Janeiro: STAB, 1981. v.3, p.354-370.

VAN VORIS, P.; CATALDO, D.A.; RUSKIN, R. Protection of buried drip irrigation devices from root intrusion through slow-release herbicides. In: INTERNATIONAL MICROIRRIGATION CONGRESS 4., Albury, 1988. Proceedings. St. Joseph:ASAE, 1988. v.2 p.86-89.

VIEIRA, C. Feijoeiro comum: cultura, doenças e melhoramento. Viçosa:UFV. Imprensa Universitária, 1967. 220p.

VILELA, L.A.A.; RESENDE, R. S.; SOARES, A. J. et al. Entupimento de gotejadores em decorrência de pulsos de partículas sólidas na malha hidráulica. (compact disc) In: CONGRESSO BRASILEIRO DE ENGENHARIA AGRÍCOLA, 30., Foz de Iguaçu, 2001.

WARRICK, W.; SHANI, U. Soil-limiting flow from subsurface emitters. II. Effects on uniformity. Journal of Irrigation and Drainage Engineering, v.122, n.4, p.296300, 1996.

WEATHERHEARD, K. PC drip tube and vacuums.

http://www.microirrigationforum.com/new/archives/pvvac.html (31 maio 2002)

WUTKE, E.B.; ARRUDA, F.B.; FANCELLI, A.L.; PEREIRA, J.C.V.N.A.; SAKAI, E.; FUJIWARA, M.; AMBROSANO, G.M.B. Propriedades do solo e sistema radicular do feijoeiro irrigado em rotação de culturas. Revista Brasileira de Ciência do Solo, v.24, p.621-633, 2000.

ZOLDOSKE, D.F. Root intrusion prevention. Irrigation Journal, v. 49, n.4, p.14-15, 1999. 